\title{
Reframing: A Grounded Theory Study of Postmenopausal Women Following Osteoporotic Fracture
}

Ashley D. Barber

West Virginia University, wilsonash@hsc.wvu.edu

Follow this and additional works at: https://researchrepository.wvu.edu/etd

Part of the Family Practice Nursing Commons, Geriatric Nursing Commons, and the Other Nursing Commons

\section{Recommended Citation}

Barber, Ashley D., "Reframing: A Grounded Theory Study of Postmenopausal Women Following Osteoporotic Fracture" (2021). Graduate Theses, Dissertations, and Problem Reports. 8081. https://researchrepository.wvu.edu/etd/8081

This Dissertation is protected by copyright and/or related rights. It has been brought to you by the The Research Repository @ WVU with permission from the rights-holder(s). You are free to use this Dissertation in any way that is permitted by the copyright and related rights legislation that applies to your use. For other uses you must obtain permission from the rights-holder(s) directly, unless additional rights are indicated by a Creative Commons license in the record and/ or on the work itself. This Dissertation has been accepted for inclusion in WVU Graduate Theses, Dissertations, and Problem Reports collection by an authorized administrator of The Research Repository @ WVU.

For more information, please contact researchrepository@mail.wvu.edu. 
Reframing: A Grounded Theory Study of Postmenopausal Women Following Osteoporotic Fracture

Ashley D. Barber

Follow this and additional works at: https://researchrepository.wvu.edu/etd

Part of the Family Practice Nursing Commons, Geriatric Nursing Commons, and the Other Nursing Commons 
Reframing: A Grounded Theory Study of Postmenopausal Women Following

Osteoporotic Fracture

Ashley Barber, MSN, RN, FNP-BC

\begin{abstract}
Dissertation submitted
to the School of Nursing

at West Virginia University
\end{abstract}

in partial fulfillment of the requirements for the degree of

Doctor of Philosophy in Nursing

\author{
Alvita Nathaniel, PhD, APRN, Chair \\ Ubolrat Piamjariyakul, PhD, RN \\ Mary Jane Smith, PhD, RN \\ Colleen Watkins, MD \\ Department of Nursing
}

\title{
Morgantown, West Virginia \\ 2021
}

Keywords: Osteoporosis; Osteoporotic Fracture; Reframing 


\begin{abstract}
Reframing: A Grounded Theory Study of Postmenopausal Women Following Osteoporotic Fracture

Ashley Wilson
\end{abstract}

BACKGROUND: Osteoporosis is a chronic disease resulting in low bone mass and increased bone fragility. Most often seen in women age 65 and older, osteoporosis is usually diagnosed following osteoporotic fracture. Despite numerous treatment options many women continue to remain untreated for osteoporosis and are at increased risk for subsequent fractures and complications. PURPOSE: The initial purpose of this classic grounded theory study was to explore the decision-making process women aged 65 and older experience when considering osteoporosis treatment following osteoporotic fracture. Following the tenth participant interview the researcher discovered a new main concern that emerged from participant interviews. Participants reported longing to return to a time prior to osteoporosis and fracture during which they reported higher levels of independence and freedom. Based on the emerging information the initial purpose of the study and spill question were altered to reflect the main concern of the participants: to develop a theory of reframing following osteoporotic fracture. METHODS: This classic grounded theory study utilized purposive sampling to recruit 12 women aged 65 and older with a recent osteoporotic fracture. Data from open-ended interviews were collected and analyzed. RESULTS: The grounded theory of reframing: a grounded theory study of postmenopausal women following osteoporotic fracture. The theory consists of three stages and a critical juncture. The first stage of the theory is resting in contentment. This stage occurs prior to osteoporotic fracture during which participants have varying degrees of pre-existing osteoporotic knowledge. The stage includes the properties of unsuspecting danger, 
underestimating risk, and looking the other way. Stage one is followed by the critical juncture, facing the threat, during which osteoporotic fracture occurs. The stage of adjustment follows the critical juncture. During this stage participants are either letting go of a previous life for one with osteoporosis or are blame shifting and diminishing the significance of osteoporosis and its relation to their current fracture. During the final stage, reframing, participants undergo an embodied revelation toward a new life with osteoporosis. Participants unable to view life through a new lens continue to long for a pre-fracture life which may no longer be attainable.

CONCLUSIONS: Reframing: A grounded theory study of postmenopausal women following osteoporotic fracture explains from the participant perspective what is going on following osteoporotic fracture. This new grounded theory has profound implications for research, education, and clinical practice. 


\section{REFRAMING}

\section{ACKNOWLEGEMENTS}

I would like to first thank my dissertation chair, Dr. Alvita Nathaniel, for her constant guidance and support throughout my dissertation journey. Her enthusiasm and immense knowledge for grounded theory served as motivation throughout the writing process. To the members of my dissertation committee: Dr. Ubolrat Piamjariyakul, Dr. Mary Jane Smith, and Dr. Colleen Watkins, I express my sincerest gratitude for your insightful feedback and stimulating advice. Special thanks to Dr. Colleen Watkins for sharing her knowledge in osteoporosis and never ending support!

I would also like to thank my parents, Jim and Debbie Wilson, who have always instilled in me the importance of higher education. Your guidance and support through numerous years of education have helped me achieve my professional dreams. To my loving husband, Curtis, thank you for understanding the craziness that sometimes goes along with being married to a woman in the middle of writing and completing a dissertation. Your never-ending support and encouragement are what kept me going!

Lastly, I want to thank all the women who choose to participate in my study. Your stories serve as my inspiration and are the driving force behind what I do! 


\section{REFRAMING}

\section{DEDICATION}

This dissertation is dedicated to my grandmother the late, Katherine Lou Wilson, whose fracture story and inevitable passing serve as the inspiration for my research and professional career. 


\section{Table of Contents}

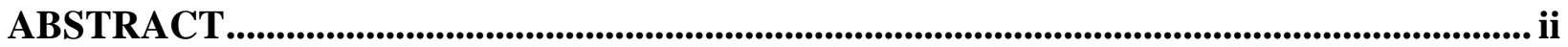

ACKNOWLEGEMENTS ................................................................................................................ iv

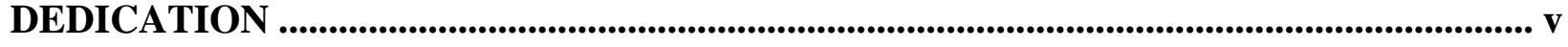

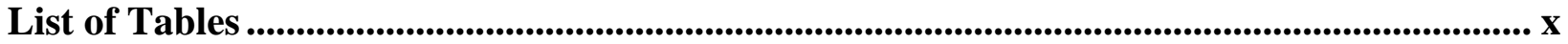

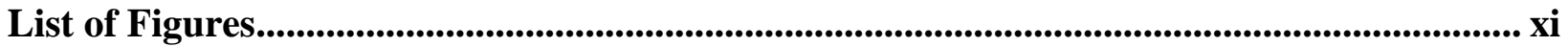

Chapter One: Statement of the Problem ................................................................................ 1

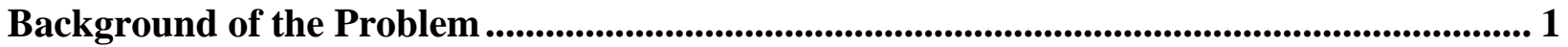

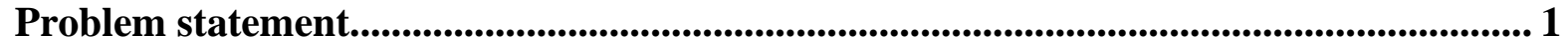

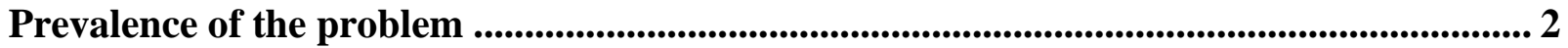

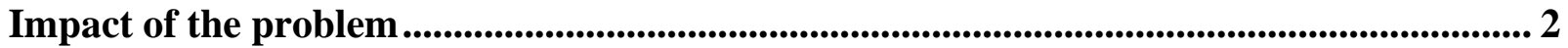

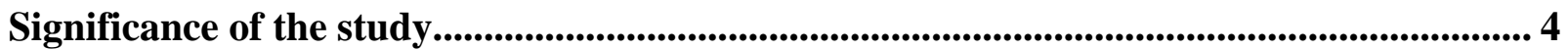

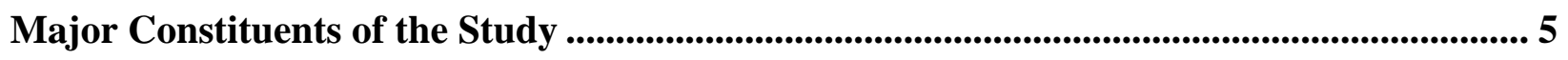

Purpose ...................................................................................................................................5

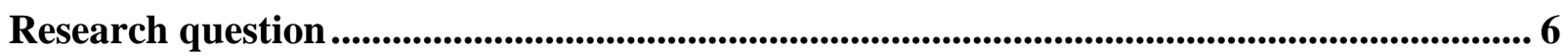

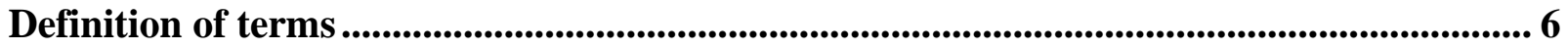

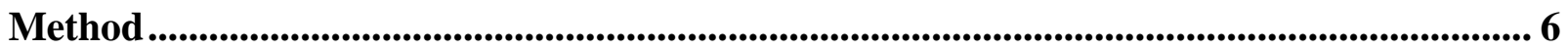

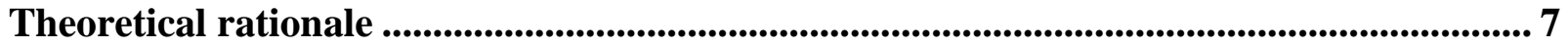

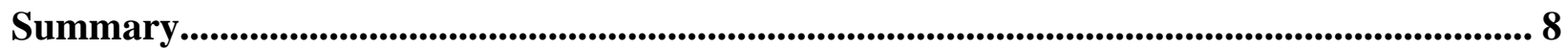

Chapter Two: Review of the Literature .......................................................................................... 9

Literature Search Process ....................................................................................................... 9

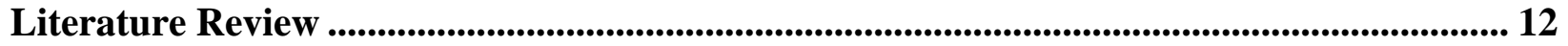

Conceptual and theoretical ....................................................................................................... 12

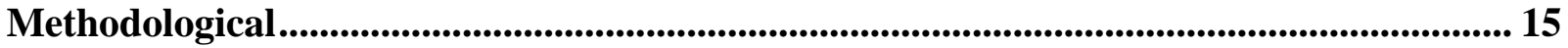

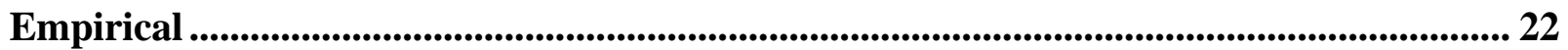

Living with osteoporosis............................................................................................................ 23

Decision-making and chronic illness ........................................................................ 24

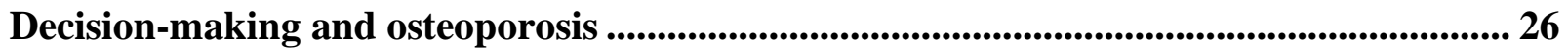

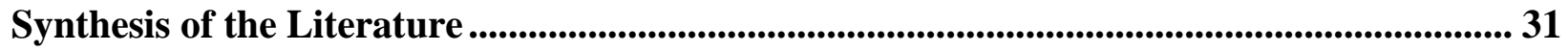




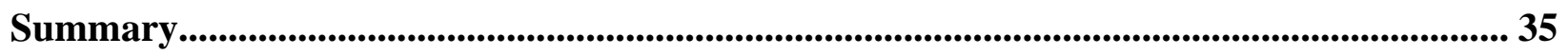

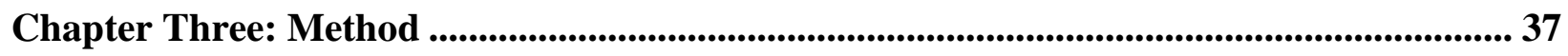

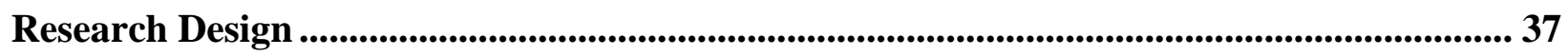

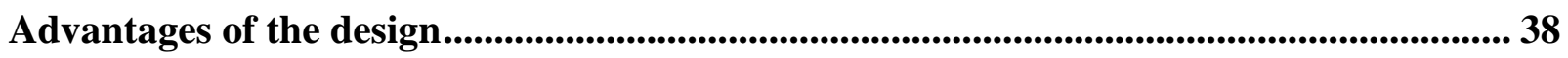

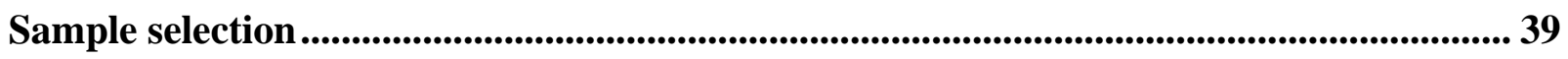

Data collection and analysis................................................................................................................ 42

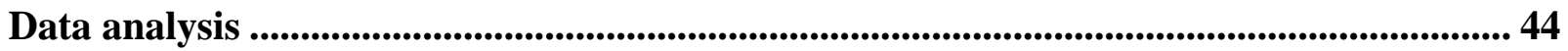

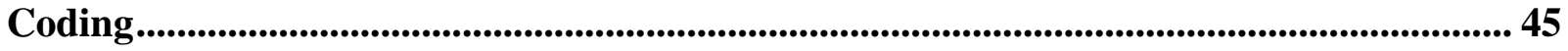

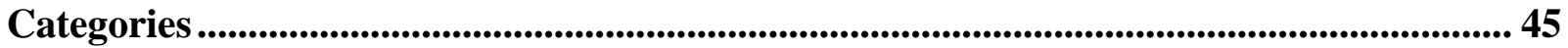

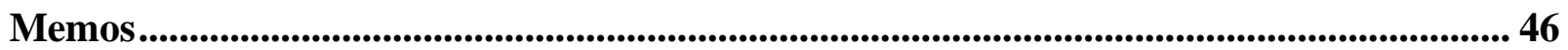

Human rights and ethical considerations ..................................................................... 46

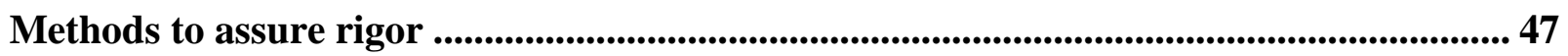

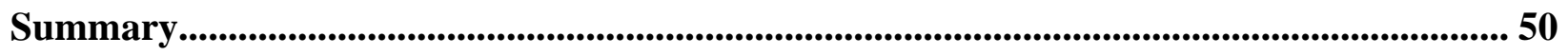

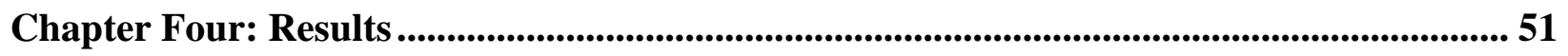

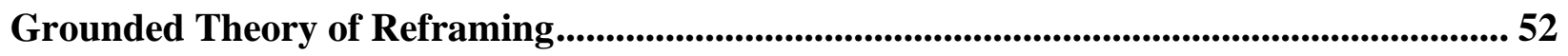

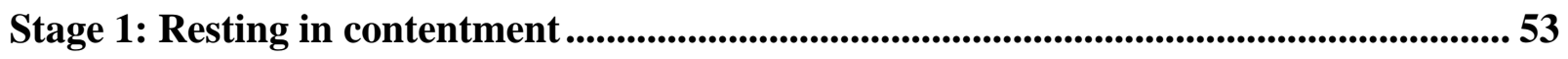

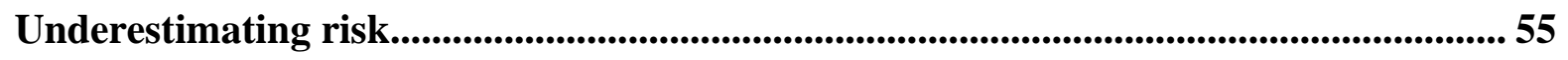

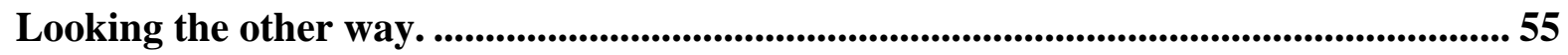

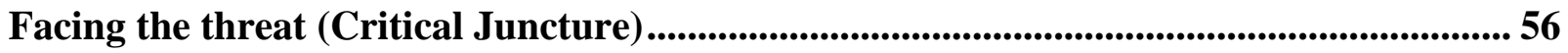

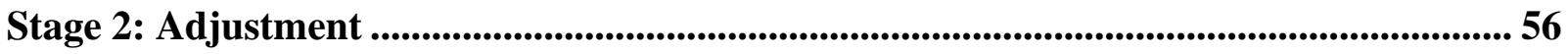

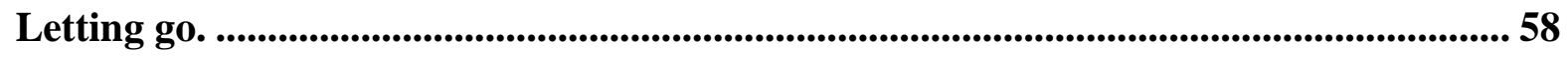

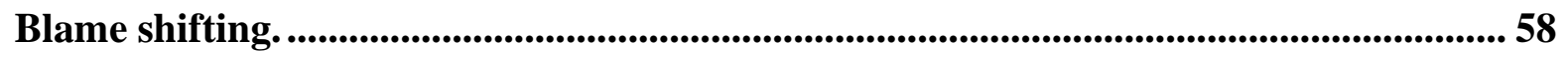

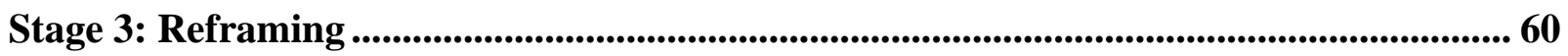

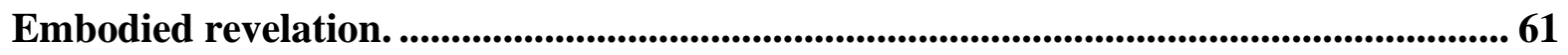

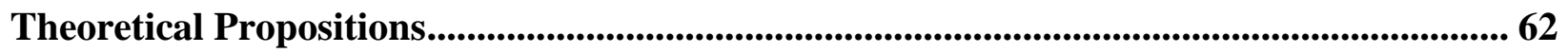

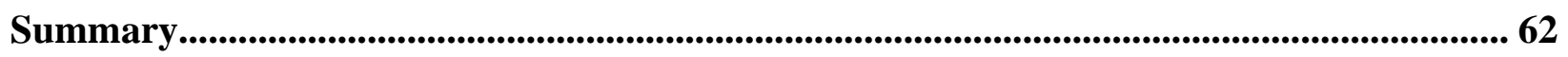

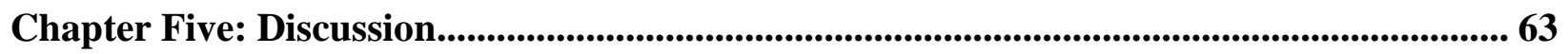


Summary of Reframing: A Grounded Theory Study of Postmenopausal Women Following Osteoporotic Fracture

Comparison of Reframing: A Grounded Theory of Study of Postmenopausal Women Following Osteoporotic Fracture ..................................................................................................... 65

Conceptual and theoretical literature .............................................................................................6 66

Reframing. ……....................................................................................................................................... 66

Writings of Alfred Adler......................................................................................................... 67

Writings of Aaron T. Beck. .................................................................................................................... 68

Writings of Paul Watzlawick. ......................................................................................................... 69

Symbolic interactionism. ................................................................................................................... 71

Health belief model........................................................................................................................................ 73

Writings of Vera Barton-Caro......................................................................................................... 74

Empirical literature .......................................................................................................................................... 75

Reframing by healthcare providers as an aid in patient care................................................. 76

Reframing as an intervention or technique.................................................................................. 79

Reframing as a way for parents to cope or reframe risk.......................................................... 82

Reframing to improve nursing care and/or delivery. ................................................................... 84

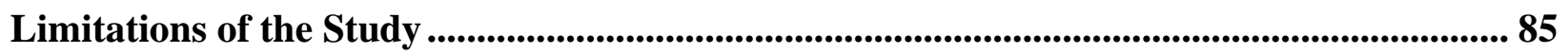

Implications for Research, Nursing Science, and Clinical Practice ........................................... 87

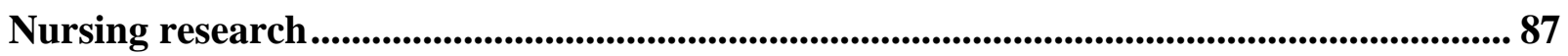

The discipline of nursing ........................................................................................................................... 89

Nursing education........................................................................................................................... 90

Clinical practice ……................................................................................................................................... 91

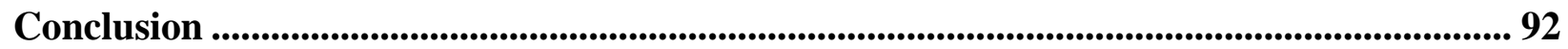

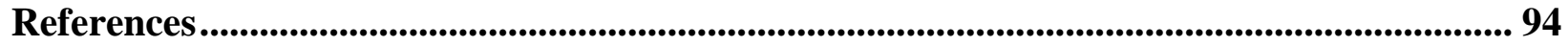

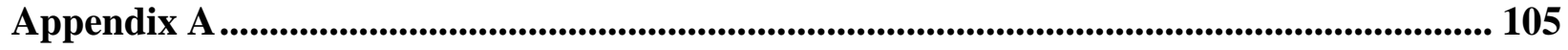

Table 1 ................................................................................................................................................. 105 


\section{REFRAMING}

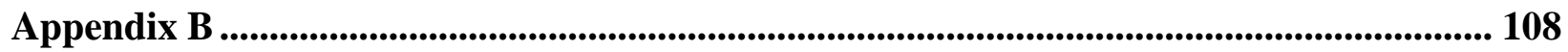

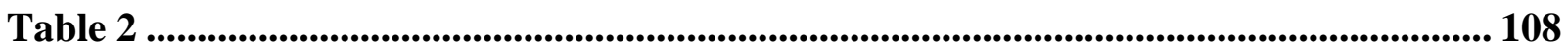

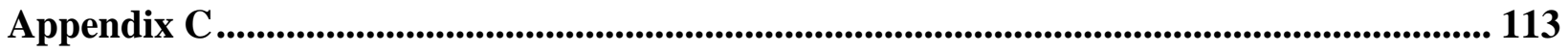

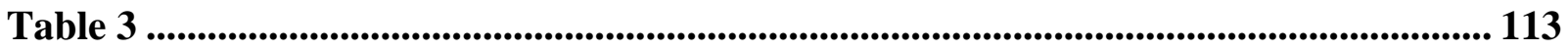

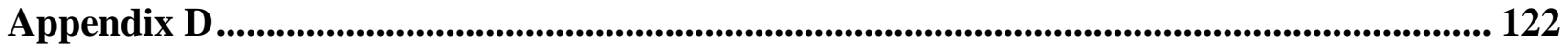

Sample Characteristics.................................................................................................................... 122

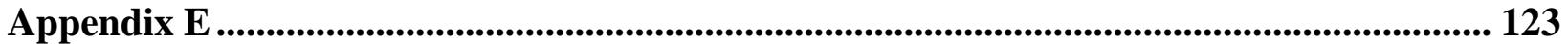

Curriculum Vitae............................................................................................................................. 123 


\section{REFRAMING}

List of Tables

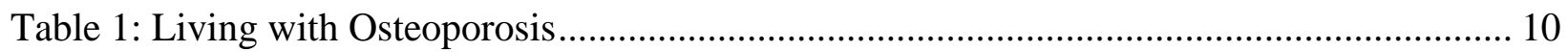

Table 2: Decision Making and Chronic Illness................................................................... 11 


\section{REFRAMING}

\section{List of Figures}

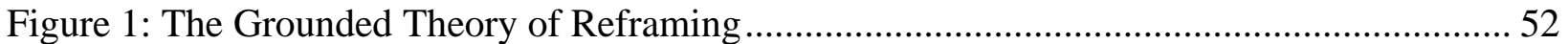

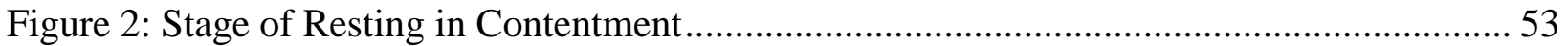

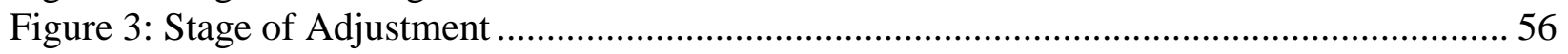

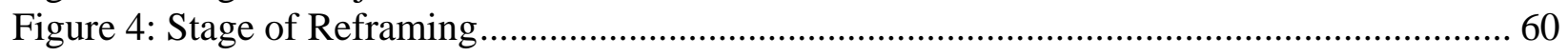




\section{Chapter One: Statement of the Problem}

Osteoporosis is a chronic disease characterized by low bone mass resulting in increased bone fragility. Due to the potential for bone fractures, osteoporosis is a major cause of morbidity in the United States and results in millions of fractures and deaths annually. Osteoporosis is most often seen in women aged 65 and older and is usually diagnosed following osteoporotic fracture. Unfortunately, many women do not obtain treatment even following fracture, resulting in an increased risk for subsequent fracture and complications. Literature explaining the decisionmaking process of women toward treatment following osteoporotic fracture is limited. Therefore, a classic grounded theory study was conducted to learn more about what is going on in the lives of women following osteoporotic fracture. The following chapter will elaborate on the background, prevalence, and impact of the problem. It will also describe and discuss the major constituents of the study and the significance for contributing to the knowledge base of nursing.

\section{Background of the Problem}

\section{Problem statement}

The problem that this study addresses is that osteoporosis is a silent yet chronic condition of bone deterioration, which often leads to bone fractures if left untreated. Further, despite advances in treatment options, many women who have been offered treatment continue to remain untreated for osteoporosis and potentially suffer the physical consequences of subsequent fracture and the chronic disability and pain that follow (Kerr et al., 2017). A better understanding of the decision-making process from the patient perspective is needed to help customize patient education and support aimed at increasing treatment rates and improving quality of life following osteoporotic fracture. However, research on the decision-making process toward treatment in women aged 65 and older who have sustained an osteoporotic fracture is non-existent. 


\section{REFRAMING}

\section{Prevalence of the problem}

Osteoporosis is one of the most prevalent metabolic bone diseases in the United States effecting one in thirty Americans (Salgo, Gill, Singer, \& Olenginski, 2019). It is a major cause of morbidity in the United States and accounts for approximately 2 million fractures and 65,000 deaths annually (Forstein, Bernardini, Cole, Harris \& Singer, 2013). According to the National Osteoporosis Foundation, 10 million Americans over the age of 50 have osteoporosis and an additional 44 million have low bone mass (Salgo et al., 2019). Due to its significant impact on the population, osteoporosis has become a major public health problem. With the world's population of adults aged 65 and older expected to account for $14 \%$ of the total population by the year 2040, osteoporosis is projected to affect 70 million older adults, $80 \%$ of whom will be women (Cauley, 2013; Jeray, 2015; Nuti, Caffarelli, Giuseppe, Gennari, \& Stefano, 2014). In West Virginia alone, $16.5 \%$ of the population is aged 65 or older and $77 \%$ of residents aged 50 and older have osteoporosis or at least diminished bone mineral density (Shuler, Scott, WilsonByrne, Morgan, \& Olajide, 2016). With such a large proportion of West Virginia residents at risk for osteoporosis and subsequent osteoporotic fracture more information regarding the decision-making process surrounding treatment is needed (Shuler \& Conjeski, 2011). Current treatments have been shown to decrease the risk for osteoporotic fracture and offer the opportunity for improved quality and quantity of life (Boudreau et al., 2017).

\section{Impact of the problem}

The incidence of women with osteoporosis and osteoporotic fracture is expected to rise and with that comes increasing physical and economic burdens (Liu, Chao, Want \& Wu, 2018). These burdens will involve both direct and indirect healthcare costs for patients and third-party 


\section{REFRAMING}

payers (Dempster, 2011). According to Dempster (2011) these burdens will also result in physical and psychosocial changes for the patient which may impact quality of life.

With such a high prevalence rate, the economic burden of osteoporosis is substantial. The current cost when considering direct and indirect costs is 50 billion annually (Salgo et al., 2019). This cost is estimated to increase to 95 billion by the year 2040. Direct care costs for inpatient hospital care, emergency room or ambulatory care visits, x-rays, ambulance services, and physician reimbursement are just a few of the required services following osteoporotic fracture (Pfister, Sale, \& Shaukat, 2009). Additional outpatient costs for physical therapy, laboratory fees, and medical assistance devices further increase the burden (Pfister et al., 2009). Assisted living and long-term care may also result and incur indirect costs due to the physical and psychosocial changes that frequently follow osteoporotic fracture (Weycker et al., 2016).

Physical changes such as pain, impaired physical function, and changes in spinal alignment are common following osteoporotic fracture and have a significant impact on quality of life (Kerr et al., 2017). According to the authors these changes vary and may be based on the location of fracture, number of previous fractures, and the degree of bone and muscle loss. Hip fractures are immediately debilitating, resulting in hospitalization and activity restrictions which not only impact participation in life roles but also the capacity to live independently. Fractures of the wrist and vertebra are less debilitating immediately but result in decreased grip strength, changes in spinal alignment, and back pain (Kerr et al., 2017). These changes persist far past fracture healing time and result in an increased risk for subsequent fracture, which may be due to periods of prolonged immobilization resulting in impaired coordination (Johansson et al., 2017). As the number of subsequent fractures increases, further decline in physical functioning and 


\section{REFRAMING}

quality of life increase the likelihood of other medical issues such as pulmonary embolus, pneumonia, infection, and an increased risk of death (Kerr et al., 2017).

Another key factor impacting physical function is the loss of bone and muscle strength, which are often experienced together and result in physical deconditioning and restricted activity levels (Kerr et al., 2017). A fear of falling is also common in people with osteoporosis. This fear can even lead to further restriction of activity, physical frailty, and even an increased risk of falls (Olsen \& Bergland, 2014). Such things as restricted motion and physical pain related to osteoporotic fracture may also lead to physical deformity and limitations (Gold, 1996). These changes not only result in further muscle weakness but also psychosocial changes due to changes in loss of social roles and social isolation (Kumano, 2005).

According to Gold, Lyles, Shipp, and Drezner (2001) three common psychological reactions occurs following osteoporotic fracture: anxiety, depression, and loss of self-esteem. Depressive symptoms according to Gold et al. (2001) can be both physical and psychological and include such things as sleep disorders, uncontrolled appetite, lack of vigor or physical energy, apathy, dejection, and uselessness. Social isolation is common in those experiencing depression (Kerr et al., 2017). Deformity, disablement, and pain related to osteoporotic fracture also rob patients of their self-esteem (Gold, Lyles, Shipp, \& Drezner, 2001). Such changes further enhance the desire to self-isolate and lead to worsening depression.

\section{Significance of the study}

Osteoporosis is a chronic disease, which is potentially preventable with available screening and treatment options, yet many women decline treatment even following osteoporotic fracture. A gap between the knowledge related to osteoporosis and the decision-making process 


\section{REFRAMING}

that occurs when considering treatment following fracture exists. This study aimed to fill that gap.

The study offers a greater understanding of the decision-making process of women who have been offered treatment following osteoporotic fracture. The thought process of these women provides insight into what is going on in the everyday life following osteoporotic fracture from the patient perspective. From this information, it is possible to provide a health-oriented stance aimed at providing patient support in self-management of illness and customizable treatment plans. The knowledge gained also has the potential to improve health outcomes and quality of life following fracture through the reduction of subsequent fracture and other comorbid conditions. The study also adds to nursing knowledge by generating a theory in a substantive area for which very little is known. According to Glaser and Strauss (1967) "generating grounded theory is a way of arriving at a theory suited to its supposed uses" (p. 3). These theories "enable predication and explanation of behavior usable in practicable applications." Theories generated serve as a "strategy for handling data in research and provide modes of conceptualization for describing and explaining” (Glaser \& Strauss, 1967, p. 3). From this theory nurses will have a better understanding of what is going on from the patient perspective and can improve the nursing care they provide as caretakers and advocates.

\section{Major Constituents of the Study}

\section{Purpose}

The purpose of this classic grounded theory study was to explore the decision-making process women aged 65 and older experience when considering osteoporosis treatment following osteoporotic fracture. The researcher entered the substantive field without knowing the problem and all previous knowledge was suspended from the researcher's mind (Glaser, 1998). Using this 


\section{REFRAMING}

approach, the researcher was open to discovery and emergence of a different main concern resulted in a change in the purpose of the study. It became apparent following the tenth participant interview while reviewing notes and memos that the decision-making process was not a main concern, rather it was a longing to return to a time prior to osteoporosis and fracture during which participants reported higher levels of independence and freedom. Thus, the initial purpose of the study and spill question were altered to reflect the main concern of the participants: to develop a theory of reframing following osteoporotic fracture.

\section{Research question}

The initial research question for the investigation is: "What is going on during the decision-making process of women aged 65 and older when considering treatment for osteoporosis following osteoporotic fracture?" Emergence of a new main concern resulted in the use of a new research question for the final two interviews. The new research question was: "What is going in the lives of women aged 65 and older following osteoporotic fracture?"

\section{Definition of terms}

The author defines decision-making process as a logical selection from a list of possible options. Osteoporotic fracture is a fracture that results from minimal trauma, such as a fall from a "standing height or less" (Weycker, Li, Bornheimer, \& Chandler, 2016, p. 186).

\section{Method}

Based upon the research question, classic grounded theory was chosen as the most appropriate method. Classic grounded theory is a complex and multivariate method that involves the systematic generation of theory from data (Glaser, 1998). The method aims at explaining a social process and emphasizes the emergence of theory through a revolving-step method of constant comparisons, theoretical sampling, and theoretical coding (Glaser, 1998). Through the 


\section{REFRAMING}

discovery of latent patterns of behavior, classic grounded theory can explain what is going on in a substantive area, rather than just describing what happened (Glaser, 1998). Classic grounded theory is beneficial when the complex social process holds great meaning to the individuals involved (Barton-Caro, 2015). Original selection of this method was also based on grounded theory's ability to offer a greater understanding of a complex decision-making process. Although a decision-making process was not identified, the emergence of a new main concern serves to provide support for the use of grounded theory since emergence is a pillar of classic grounded theory (Nathaniel, 2019).

\section{Theoretical rationale}

Classic grounded theory examines social processes. These processes and the human interactions involved can be directly linked to the theoretical underpinnings of symbolic interactionism. Although Glaser does not credit symbolic interactionism as the basis of grounded theory, Strauss the co-author of The Discovery of Grounded Theory has that background and studied among two notable symbolic interactionists at the University of Chicago, Everett Hughs and Herbert Blumer (Simmons, 2020). The ideas of George Herbert Mead, a strong influencer of Blumer, played a large role in the development of the symbolic interactionist paradigm (Simmons, 2020). In symbolic interactionism, human beings act toward things based on the meanings they assign to them (Blumer, 1969). According to Blumer (1969) things can include "physical objects such as trees or chairs; other human beings, such as a mother; categories of human beings, such as friends or enemies; institutions, as a school or a government; guiding ideals, such as individual independence or honesty; activities of others, such as their commands or requests; and such situations as an individual encounters in daily life" (p. 2). These meanings are obtained through social interaction, and knowledge comes to be known through an 


\section{REFRAMING}

interpretative process from within the individual. Social interaction and reality are based on those interactions from which meaning is derived. What is true and real is what the individual perceives to be real, and that reality is constantly shaped through further interactions. Through this process, the ontological and epistemological roots of the methodology are grounded and further explain the meaning of human behavior and its relation to social interaction.

\section{Summary}

Osteoporosis is a chronic condition of low bone mass that affects older women and often results in osteoporotic fractures. With the world's population of older adults expected to account for $14 \%$ of the total population by the year 2040 , osteoporosis has become a major public health problem (Cauley, 2013; Jeray, 2015; Nuti et al., 2014). Despite the availability of several treatment options, many women decline treatment and suffer subsequent osteoporotic fracture further increasing their risk for other co-morbid conditions or even death. The use of a classic grounded theory method offers a better understanding of what is going on during the decisionmaking process when considering treatment for osteoporosis following osteoporotic fracture. This information will not only fill the gap in the current literature on osteoporosis, but it will also add to the body of knowledge of nursing by developing a substantive theory that can explain and predict basic social processes occurring with women with osteoporosis. It will also provide a better understanding of the physical, psychosocial, and economic burden of osteoporosis and osteoporotic fracture. 


\section{REFRAMING}

\section{Chapter Two: Review of the Literature}

In accordance with classic grounded theory, a general review of the qualitive literature surrounding the area of interest was conducted prior to embarking on the study. A more extensive secondary literature review took place throughout the process of constant comparative analysis and prompted the addition of a third literature review including quantitative literature. The purpose of this chapter is to present a discussion of the current qualitative research related to living with osteoporosis and decision-making in chronic illness. It will also include a description and analysis of the existing qualitative conceptual/theoretical, methodological, and empirical literature.

\section{Literature Search Process}

The traditional approach to conducting a study involves performing a literature review in a substantive area prior to beginning research (Glaser, 1998). According to Glaser (1998) this approach is not taken in classic grounded theory and should be avoided unless deemed necessary. If a review must be completed Glaser (1998) recommends looking at the review as data collection and selecting literature that will not pre-conceptually contaminate the emerging theory. He also recommends avoiding areas of abundant or overloaded literature (Glaser, 1998). For this study, an initial review of the qualitative literature was completed and resulted in five qualitative studies on the topic of living with osteoporosis. A second review on the topic of decision-making and osteoporosis resulted in an additional five qualitative studies. To gain a more comprehensive review of the literature a third review was completed on the topic of decision-making and osteoporosis and resulted in a total of eleven new studies which included both quantitative and qualitative literature. In total, twenty-one studies were reviewed during the 


\section{REFRAMING}

pre-search literature search. According to Glaser (1998) if this search must be completed the researcher should turn the review into "data collection, not reverence for authenticity" (p.72).

Literature searches were conducted on three separate occasions to gain a better understanding of the phenomenon of interest. The first search used the search terms, living with osteoporosis and included the following databases: CINAHL with full text, Academic Search Complete, ERIC, HealthSource: Consumer edition, HealthSource: Nursing \& Academic edition, Medline, PsycArticles, and Psych INFO. A filter for qualitative studies was placed and a total of ten articles resulted. Of those ten, six were excluded because they did not focus on the phenomenon of interest. An additional article was found during a review of the references and was included in the review. A condensed table of those five articles is listed below in Table 1. For the full Table 1 please refer to the attached Appendix A.

Table 1: Living with Osteoporosis

\begin{tabular}{|c|c|c|c|}
\hline Year & Author ('s) & Title & Method \\
\hline 2001 & $\begin{array}{l}\text { Roberto K.A. \& } \\
\text { Reynolds, S.G. }\end{array}$ & $\begin{array}{l}\text { The meaning of osteoporosis } \\
\text { in the lives of rural older } \\
\text { women }\end{array}$ & $\begin{array}{l}\text { Qualitative } \\
\text { Descriptive }\end{array}$ \\
\hline 2006 & $\begin{array}{l}\text { Baheiraei, A. et } \\
\text { al. }\end{array}$ & $\begin{array}{l}\text { Exploring factors influencing } \\
\text { osteoporosis prevention and } \\
\text { control: A qualitative study of } \\
\text { Iranian men and women in } \\
\text { Australia }\end{array}$ & $\begin{array}{l}\text { Qualitative } \\
\text { Descriptive }\end{array}$ \\
\hline 2011 & $\begin{array}{l}\text { Nielsen, D.S. et } \\
\text { al. }\end{array}$ & $\begin{array}{l}\text { Men's experiences of living } \\
\text { with osteoporosis: Focus } \\
\text { groups interviews }\end{array}$ & $\begin{array}{l}\text { Qualitative } \\
\text { Phenomenologic } \\
\text { al }\end{array}$ \\
\hline 2013 & $\begin{array}{l}\text { Nielson, D. et } \\
\text { al. }\end{array}$ & $\begin{array}{l}\text { Handling knowledge on } \\
\text { osteoporosis: A qualitative } \\
\text { study }\end{array}$ & $\begin{array}{l}\text { Qualitative } \\
\text { Phenomenologic } \\
\text { al }\end{array}$ \\
\hline 2014 & $\begin{array}{l}\text { Hansen, C. et } \\
\text { al. }\end{array}$ & $\begin{array}{l}\text { Women's experiences of } \\
\text { their osteoporosis diagnosis } \\
\text { at the time of diagnosis and } 6 \\
\text { months later: A } \\
\text { Phenomenological } \\
\text { hermeneutic study }\end{array}$ & $\begin{array}{l}\text { Qualitative } \\
\text { Phenomenologic } \\
\text { al }\end{array}$ \\
\hline
\end{tabular}




\section{REFRAMING}

The second literature search used the search terms, decision-making and chronic illness.

Similar databases were used, but during the second search the following databases were

excluded: HealthSource: Consumer edition, HealthSource: Nursing \& Academic edition,

Medline, PsycArticles, and Psych INFO. Filters for peer reviewed articles between 2012 to 2018

were placed and additional filters for females aged 65 and older were set and resulted in a total of

53 articles. Despite the filter for female gender all 53 articles included both male and female

perspectives. Some also included the additional perspective of the provider, caregiver, or family.

Further review of those articles showed that they offered valuable information regarding

decision-making and chronic illness and a decision was made to include them in the review. A

total of 48 articles were excluded since they failed to focus on the phenomenon of interest. An

abbreviated table of the five articles is listed below and the full Table 2 is attached as Appendix

B.

Table 2: Decision Making and Chronic Illness

\begin{tabular}{|c|c|c|c|}
\hline Year & Author ('s) & Title & Method \\
\hline 2012 & Chang, H.A. et al. & $\begin{array}{l}\text { Decision-making related to } \\
\text { complementary and alternative } \\
\text { medicine use by people with } \\
\text { Type } 2 \text { diabetes: A qualitative } \\
\text { study }\end{array}$ & $\begin{array}{l}\text { Exploratory } \\
\text { study using a } \\
\text { naturalistic } \\
\text { design }\end{array}$ \\
\hline 2012 & Morton, R.L. et al. & $\begin{array}{l}\text { Factors influencing patient } \\
\text { choice of dialysis versus } \\
\text { conservative care to treat end- } \\
\text { stage kidney disease }\end{array}$ & $\begin{array}{l}\text { Discrete choice } \\
\text { experiment }\end{array}$ \\
\hline 2013 & Lowey, S.E. et al. & $\begin{array}{l}\text { Living with advanced heart } \\
\text { failure or COPD: Experiences } \\
\text { and goals of individuals nearing } \\
\text { the end of life }\end{array}$ & $\begin{array}{l}\text { Qualitative } \\
\text { Descriptive }\end{array}$ \\
\hline 2014 & $\begin{array}{l}\text { Harwood, L. \& } \\
\text { Clark, A.M. }\end{array}$ & $\begin{array}{l}\text { Dialysis modality decision- } \\
\text { making for older adults with } \\
\text { chronic kidney disease }\end{array}$ & $\begin{array}{l}\text { Qualitative } \\
\text { Ethnography }\end{array}$ \\
\hline 2015 & Allen, D. et al. & $\begin{array}{l}\text { Fragmented care and whole- } \\
\text { person illness: Decision-making } \\
\text { for people with chronic end- } \\
\text { stage kidney disease }\end{array}$ & $\begin{array}{l}\text { Qualitative } \\
\text { Ethnography }\end{array}$ \\
\hline
\end{tabular}




\section{REFRAMING}

To more specifically understand the decision-making process that occurs following diagnosis with osteoporosis a third literature review was conducted using the search terms, decision-making and osteoporosis. Databases for the review included: ABI/INFORM Collection, JSTOR Arts \& Sciences collections I-XIII, JSTOR Business IV Collection, JSTOR Current Scholarship Journals, JSTOR Life Sciences Collection, Medline, Science Direct, and WorldCat.org. Filters for full text, peer reviewed articles, within the last 5 years, in English were applied and resulted in a list of 272 potentially relevant citations. A review of the titles and abstracts of the 272 articles resulted in the elimination of 247 articles due to a lack of relevance. Following more extensive review by the researcher an additional 14 articles were eliminated due to not focusing on the phenomenon of interest and duplicate results. A total of 11 studies were included. Those studies are listed in Table 3 which is Appendix C.

\section{Literature Review}

\section{Conceptual and theoretical}

A conceptual or theoretical framework provides the structural support for a research study, so identifying the framework is important when assessing and interpreting a study's findings. The twenty-one articles meeting the search criteria for inclusion for this review utilized five theoretical frameworks including critical psychology, life course perspective, Antonovsky's theory of sense of coherence, and the theory of stratified ontology. Fifthteen studies did not specify a formal theoretical framework, one provided information on the literature that guided the study, and another was guided by the Information, Motivation, and Behavioral skills model.

Two studies utilized critical psychology as the theoretical framework. Critical psychology aims at "understanding the conduct of everyday life and how it is subjectively reasoned from the perspective of the patient" (Nielsen, Brixen, \& Huniche, 2011, p. 517). The 


\section{REFRAMING}

framework includes two main categories, conduct of everyday life and personal abilities (Nielsen et al., 2011; Nielsen, Hunich, Brixen, Sahota, \& Masud, 2013). These categories explore how older adults engage in everyday life while living with osteoporosis. The focus is on the meaning of objective conditions and how individuals' reason through their actions (Nielson et al., 2013).

Another theoretical framework used in one of the studies, is the life course perspective (Roberto \& Reynolds, 2001). The use of life course perspective allows for the examination of osteoporosis within the context of everyday life. This perspective examines the role social interactions throughout life play in shaping past, present, and future experiences toward healthcare and illness (Roberto \& Reynolds, 2001). The perspective also allows aging to reflect an accumulation of lifetime social, behavior, and biomedical processes which are key in shaping personal responses to illness (Roberto \& Reynolds, 2001).

Hansen, Konradsen, Abrahamsen, and Pedersen (2014) used Antonovsky's, theory of Sense of Coherence (SOC) to discuss their findings. "SOC is a salutogenic orientation concerning how humans interpret and relate to life circumstances" (Hansen et al., 2014). According to Antonovsky a salutogenic orientation is one which resonates from the origins of health and is shaped by life experiences (Mittelmark \& Bauer, 2017). From this viewpoint a cognitive process of comprehension and meaning creation occurs which affects an individual's SOC (Hansen et al., 2014). When confronted with stress, such as a new diagnosis of osteoporosis, individuals must grasp the impact on everyday life and the adaptations that may need to be made.

The second literature review resulted in the addition of the theory of stratified ontology, which is the basis for critical realist ethnography. According to this theory reality exists beyond personal perceptions and actions are patterned and structured (Harwood \& Clark, 2014). The use 


\section{REFRAMING}

of this framework allows for not only the emic perspective, but also perspectives from a wider social structure (Harwood \& Clark, 2014). This is useful when examining both personal and structural factors influencing home-dialysis modality selection.

Although not a theoretical framework, the work by Hansen et al. (2014) was guided by Paul Ricoeur's theory of interpretation of text which involves "three levels: a naïve reading, a structural analysis, and a critical analysis and discussion" (p.3). Ricoeur proposes that through this process one can see something new in what is usually taken for granted (Ricoeur, 1973, as cited in Hansen, et al., 2014). Its use in this study provided for a greater understanding of women's experiences of their osteoporosis diagnosis.

A thorough review of the literature on decision-making and osteoporosis revealed an intervention grounded in the "principles of narrative communication and guided by the constructs of the Information, Motivation, and Behavioral skills model” (Danila et al., 2018, p.3). The Information, Motivation, and Behavioral skills model was originally used by Fisher (1992) to change AIDS-risk behavior. According to Fisher (1992) the model was grounded in the theory of reasoned action which "asserts that to increase motivation to perform AIDS-preventative behaviors, one should influence attitudes toward the performance of AIDS-preventative acts or perceptions of social normative support for such behavior, or both” (p.467).

The study by Danila et al. (2018) used video vignettes developed from actual osteoporosis patients' experiences and portrayed by actresses of similar race/ethnicity. Use of the intervention was aimed at influencing participant motivation toward osteoporosis treatment by addressing lack of awareness to action (Danila et al., 2018). By tailoring the intervention to participant race/ethnicity, perceived barriers, readiness for behavior change, and history of 


\section{REFRAMING}

osteoporosis treatment the authors aimed at influencing the attitudes of participants in hopes to trigger transition from a pre-contemplative stage to a decision-making stage (Danila et al., 2018).

\section{Methodological}

A general requirement of a research study is the identification of a research methodology. It is from this methodology that readers can base judgements on the quality, rigor, and trustworthiness of the study. A review of the methodological approaches identified the use of ten different approaches. The studies by Lowey et al. (2013), Roberto and Reynolds, (2001), and Baheiraei et al. (2006) utilized a qualitative descriptive approach and a grounded theory study was completed by Wozniak et al. (2017). While the studies by Nielsen et al. (2011), Nielsen et al. (2013) and Hansen et al. (2014) took a qualitative phenomenological approach. Hawood \& Clark (2014), Allen et al. (2015), and Jensin, Lomborg, Langdahl, and Wind (2016) used an ethnographic qualitative approach. An exploratory study by Chang et al. (2012) used a naturalistic design and a discrete choice experiment was done by Morton et al. (2012), Hilingsmann et al. (2017), and Cornelissen et al. (2020).

The third literature review identified four new approaches that were not previously discussed. The studies by Boudreau et al. (2017) and Billington et al. (2019) took an observational approach by using cross-sectional and prospective cohort study designs. Smallwood et al. (2017), Jones et al. (2017), and Danila et al. (2018) performed randomized controlled trials. A piloted prevention program design was used by Anderson-Wurf et al. (2018) and an edutainment model incorporating patient story lines was used by Lopez-Olivo et al. (2018).

The studies by Baheiraei, Richie, Eisman, and Nguuyen (2006) and Roberto and Reynolds (2001) utilized the qualitative descriptive approach used focus groups as the main 


\section{REFRAMING}

method for data collection. These groups focused on participant experiences to gain a better understanding of the phenomenon. They used either guiding questions or topics related to osteoporosis to guide the tape-recorded discussion which was later transcribed. Baheiraei et al. (2006) also included the additional steps of translation and a consistency check. Roberto and Roberts (2001) performed data analysis in three phases to "generate a comprehensive understanding of themes" (p. 602). Whereas Baheriraei, et al. (2006) used both an iterative approach and thematic analysis.

Lowey, Norton, Quinn, and Quill (2013) used a qualitative descriptive approach took a different method of data analysis. The authors conducted 40 semi-structured interviews with 20 participants to explore first-hand experiences. These audiotaped interviews were conducted in the participants' homes on two separate occasions using a semi-structured interview guide. The second interview explored the themes identified from the first interview, insight that arose over the 4-week period, and any changes in health status. Data were analyzed using qualitative content analysis, which is an iterative process, to identify themes that described the phenomenon of interest.

The use of a grounded theory method was only seen in one study. The study by Hiligsmann et al. (2017) conducted 21 interviews with 12 patients aged 50 and older with an upper extremity fracture who had been started bisphosphonates. Interviews were the primary source of data collection and theoretical sampling was used to inform emerging concepts until saturation was reached. Data analysis occurred through constant comparative analysis throughout the data collection process.

The two studies that utilized the phenomenological approach collected data through interviews, while one used focus groups. Nielsen et al. (2013) performed semi-structured 


\section{REFRAMING}

individual interviews with an open and active approach. They additionally performed three days of participant observation in England to gain insight into the way educational information was dispersed. The analysis involved identifying relevant themes using meaning condensation. The study by Hansen et al. (2014) obtained data through individual interviews which were conducted on two separate occasions. Analysis was guided by Paul Ricoeur's theory of interpretation of text to gain insight on women's experiences of osteoporosis at time of diagnosis and six months later.

Another study by Nielsen et al. (2011), although not specifically stated as phenomenological, analyzed data using meaning condensation - a type of analysis attributed to Giorgi's phenomenological method. Data were collected using focus group interviews that were guided by a thematic interview guide. It was then analyzed using meaning condensation, a threestep process used to identify themes related to the phenomenon.

The studies by Harwood and Clark (2014) and Allen et al. (2015) utilized ethnography to gain a better understanding of human behavior in the context in which it is embedded. The study by Harwood and Clark (2014) used critical realism ethnography, a distinct form of the methodology, and performed realistic interviewing which is a theory driven method of data collection. The priority of this type of data collection is "what is to know, who might know, and how to ask" (Pawson \& Tilley, 1997 as cited in Harwood \& Clark, 2014, p. 3380). Interviews were audio-recorded and conducted by healthcare professionals using a semi-structured interview guide. Conventional content analysis was used for patient interviews and data were examined for common themes. Analysis of the interviews also focused on barriers and facilitators influencing home-dialysis modality selection due to the specific form of ethnography selected. Data management was performed by the data analysis program, NVIVO version 10. 


\section{REFRAMING}

Allen et al. (2015) also utilized ethnography and collected biweekly observations over 12 months and examined patient experiences about in-hospital care and decision-making (Allen et al., 2015). Information was obtained through observations of care interactions, data from family members or close friends, and two focus group discussions with collaborating health professionals. Data collection and analysis occurred concurrently, and thematic analysis occurred within and across cases. Analysis also focused on the interviews with health professionals and field logs.

Another study by Jensin et al. (2016) used ethnographic field work while using an interpretive description strategy. The authors aimed to find out if and how patients implemented knowledge gained from a multifaceted group education. The study included 14 women and 3 men diagnosed with osteoporosis. Data collection and analysis occurred concurrently with collection strategies involving participant observation and interviews.

The use of a discrete choice experiment was used to look at the decision-making process during chronic illness and patient preferences toward osteoporosis treatment options. The study by Morton et al. (2012) collected data between October 2010 and February 2011 using surveys that were completed in either a renal clinic or home. The survey was an unlabeled choice survey with "12 questions comprising two dialysis alternatives and one fixed "no dialysis: alternative" (Morton et al., 2012, p. E278). Selection of characteristics and levels for the survey were based on previous literature reviews, policy initiatives from government dialysis plans and a ranking exercise. "Levels for life expectancy time spent undergoing dialysis were retrieved from international registry data" (Morton et al., 2012, p. E278). A mixed logit model was used to perform all analyses. 


\section{REFRAMING}

Studies by Hiligsmann et al. (2017) and Cornelissen et al. (2020) explored patient preferences toward osteoporosis treatment. Hilignsmann et al. (2017) conducted an experiment with 1124 patients who were repeatedly asked to choose between two hypothetical unlabeled drug treatments which varied in efficacy in reducing fracture risk, potential common side effects, drug mode, and frequency of administration. The study by Cornelissen et al. (2020) also used hypothetical treatment options varying by treatment efficacy, side effects, and mode/frequency of administration. In that study 188 participants were asked to answer questions on a paper-based questionnaire regarding treatment preference.

Chang, Wallis, Tiralongo, and Wang (2012) performed an exploratory study with a naturalistic approach to examine decision-making related to complementary and alternative medicine (CAM) in people with type 2 diabetes. Data collection occurred through note taking that occurred during and after in-depth semi-structured interviews that were also audio-recorded. Following transcription open coding, axial coding, and selective coding of the field notes took place. Data analysis ended when saturation about a category was reached. The study also used an expert in Taiwanese and qualitative research along with two experts from Australia to crosscheck data analysis.

The two studies that used an observational design aimed at gathering a better understanding of women's beliefs regarding treatment following osteoporotic fracture and adherence with patient choices with recommended guidelines. The study by Boudreau et al. (2017) enrolled women aged 55 and older from a Female Group Health Cooperative and had a final sample size of 985. Participants were mailed a survey to gain information on health behaviors, osteoporosis related history, concern about and knowledge of perceived risk of 


\section{REFRAMING}

osteoporotic fracture, beliefs about osteoporosis treatment, sources of information on osteoporosis, and post-fracture discussions with provider and subsequent recommendations.

Billington et al. (2019) aimed to determine if patient decisions to initiate treatment adhered to recommended guidelines. There was a total of 85 participants aged 45 and older referred for age-associated osteoporosis to a group osteoporosis self-management consultation. During sessions participants received education on osteoporosis and had their risk for major and hip fractures estimated. Following the intervention participants made a decision regarding treatment initiation.

The third literature review added a quantitative approach to the phenomenon of interest with studies by Smallwood et al. (2017), Jones et al. (2017), and Danila et al. (2018). All three studies used a randomized controlled trial. The study by Smallwood et al. (2017) did a pilot randomized controlled trial looking at the use of a patient portal-based osteoporosis decision aid. The study was conducted on primary care patients aged 55 and older who were enrolled in a patient portal and had a T-score of less than -1. A total of 50 patients participated in the study and were blinded to allocation to either the experimental group which received the decision aid or the control group which was directed to a national website on aging. According to the authors the decision aid contained a "10-year fracture risk calculator, summary of medication risks and benefits (prescription and nonprescription), and an elicitation of values" (Smallwood et al., 2017, p. 567). Participants completed questionnaires and patient charts were reviewed to determine medication intake and discussion between the provider and participant about osteoporosis.

A randomized clinical trial was also used by Jones et al. (2017) to determine the impact of 3-D models versus animations to change participant perceptions of osteoporosis and motivation toward treatment. Participants were recruited from e-mail advertisements and flyers 


\section{REFRAMING}

placed around the University of Auckland Research Clinic and women's gyms. A total of 128 women aged 50 and older participated in the study and were randomly assigned to either view a 3-D printed bone model or electronic tablet animation (Jones et al., 2017). "Illness perceptions, medication beliefs and motivations were measured at baseline and post-presentation" and a “mixed ANOVA's was used to identify significant changes over time and between groups" (Jones et al., 2017, p.899).

Like the interventions by Smallwood et al. (2017) and Jones et al. (2017) the intervention by Danila et al. (2018) also aimed to improve osteoporosis treatment rates in a high-risk population. Danila et al. (2018) performed a parallel controlled randomized clinical trial to determine if a multimodal patient-centered behavioral intervention increases the rates of osteoporosis treatment among a high-risk population with a previous osteoporosis fracture. The study included 2684 women with self-reported fracture history after age 45 who were not on osteoporosis treatment. Participants were recruited from the US Global Longitudinal Study of Osteoporosis in Women (GLOW) sites and randomized 1:1 to receive video intervention versus

usual care. "The primary outcome of the study was self-report of osteoporosis medication use at 6 months" following the intervention (p. 763). Other outcomes included supplementation intake, screening for osteoporosis, reported readiness for behavioral change, and barriers to treatment (Danila et al., 2018). An intent-to-treat analysis was performed.

The final two articles in the review were also identified during the third literature review and neither stated a defined methodology. The study by Anderson-Wurf et al. (2018) piloted and evaluated a two-phased osteoporosis prevention program and the study by Lopez-Olivo et al. (2018) followed an edutainment model with educational patient story lines. Both studies aimed at increasing participant knowledge on osteoporosis. Anderson-Wurf et al. (2018) also focused on 


\section{REFRAMING}

goal setting and its role in a retirement village to improve bone health and prevent osteoporosis. The study included 60 retirement village residents who underwent a group education session. Of those 60, 30 participants volunteered to undergo the second phase of the project to develop an individualized bone plan. Participants completed an osteoporosis knowledge assessment questionnaire during their individualized session and given a copy of their goals which included their calculated fracture risk. A midpoint educational session was provided in the community center and six months following goal development participants underwent an individual interview. Data from the questionnaires were analyzed using computer software and a paired ttest was used.

Lopez-Olivo et al. (2018) developed and pilot tested an education model for patients with knee osteoarthritis, osteoporosis, and rheumatoid arthritis. The multimedia intervention, which was described by the authors as a video tool, follows an "edutainment" model approach and incorporates educational patient story lines (p. 213). For the study 60 participants, 20 per disease process mentioned above, were shown the tool, and interviewed. Questionnaires were completed by participants' pre- and post-intervention.

\section{Empirical}

A description and analysis of the empirical dimensions of the literature focuses on the findings of the phenomenon of interest in the current literature. More specifically it looks at the data obtained, the analyses used, and the cohesiveness of the results with other studies. The results of the review provided a deeper understanding of the phenomenon, living with osteoporosis, and several similar themes were identified. The second review also offered insight into decision-making in chronic illness. 


\section{REFRAMING}

\section{Living with osteoporosis}

The results from each of the five studies provided a deeper understanding of the phenomenon. Roberto and Reynolds (2001) studied 21 women, ages 53 to 89, with a diagnosis of osteoporosis from southwest Virginia. "Five major categories of responses emerged: identifying and diagnosing osteoporosis, changes the women made in their daily activities, concerns and challenges facing the women, interventions used by the women to manage their osteoporosis, and advice from other women with osteoporosis" (p. 602-603).

In the study by Baheiraei et al. (2006), two groups and methods were used for data collection. The first method involved the use of a focus group and included twenty-two Iranian women and five Iranian men. The second method used semi-structured interviews and included a group of ten Iranian women between the ages of 35 and 56. Textual analysis of the two methods identified four major themes: "understanding of disease, perception of causes, preventive behaviors, and obstacles to preventive actions" (p.129). It was also found that participants thought that emotional pain could lead to diminished bone density.

Nielsen et al. (2011) looked at the experiences of sixteen men living with osteoporosis. Interviews were conducted in four focus groups, consisting each of three to five participants. The authors found patterns that resonated with hegemonic masculinity and four main themes emerged: "the importance of being active, acting on a need for help, social context of osteoporosis, and relations with other patients and professionals" (p.168). They also found that men have a broader range of strategies for handling osteoporosis than previously thought.

In a subsequent study by Nielsen et al. (2013), participants were recruited from two English university hospitals and one Danish university hospital. There was a total of 14 participants, 10 women and 4 men, with osteoporosis from the two English university hospitals 


\section{REFRAMING}

and twelve participants, ten women and two men, with confirmed osteoporosis from a Danish university hospital. Three themes emerged from the condensed meaning analysis: life conditions influence the way in which risk, pain and osteoporosis are handled, everyday life is influenced by the way in which treatment is handled, and patients' experiences and relationships are related to how information on osteoporosis is handled.

Hansen et al. (2014) studied 15 women with confirmed osteoporosis defined as a T-score below -2.5 (low back or hip). Inclusion also required no previous osteoporotic fracture, at least one osteoporosis risk factor, and a prescription of an anti-osteoporotic treatment. Three key themes emerged from the structural analysis: "being diagnosed, being prescribed medical treatment, and being on the path of learning to live with osteoporosis" (p.3).

\section{Decision-making and chronic illness}

Results from the additional five studies that looked at decision-making provided a wealth of information on the process that occurs within an individual when faced with choices regarding care during chronic illness. Chang et al. (2012) examined decision-making related to complementary and alternative medicine use in people with type 2 diabetes. Sixteen participants (6 men and 10 women) ranging in age from 38 to 71 were purposively selected from patients attending diabetes clinics at three hospitals in Taiwan. Four major categories emerged during constant comparative analysis: "recognizing the need for using complementary and alternative medicine, assessing potential complementary and alternative medicine before use, matching complementary and alternative medicine use to personal philosophy, and ongoing evaluation of complementary and alternative medicine" (p. 3208). The recognition of the need included the need to be in control, the need to improve well-being, and the need for spiritual comfort. Participants required multiple sources of data to make decisions and were influenced by the 


\section{REFRAMING}

opinion of others and assessment of products. Complementary and alternative medicine use was found to be closely related to personal beliefs, values, and attitudes of the participant. Three subcategories emerged: belief or skepticism, proactive involvement in self-management and critical assessment of information. Ongoing evaluation of complementary and alternative medicine use was found to be a highly individualized process based on subjective perceptions rather than objective outcomes.

Morton et al. (2012) looked at factors influencing patient choice of dialysis versus conservative care in end-stage kidney disease. It included 105 patients with chronic kidney disease (stages 3-5) aged 18 and older from eight Australian metropolitan and rural renal clinics. Three factors were found to be strongly associated with patient preference for dialysis over conservative care. These include "increased life expectancy, the opportunity to undergo dialysis during the day or evening, and the availability of subsidized transport" (p. E282). The authors also found that patients wanted a life free from the restrictions of dialysis and were willing to accept shorter life spans to maintain or obtain a level of independence.

Lowey et al. (2013) looked at the experiences and goals of individuals with chronic obstructive pulmonary disease (COPD) and advanced heart failure nearing the end of life. The study included 20 participants (9 male and 11 female) from two large Medicare-certified home health agencies in western New York. Despite having life-threatening conditions many participants believed they still had time. They based this hope on previous experiences of bouncing back despite signs of a worsening state. Participants "described daily life as a tradeoff between dependence on assistive devices for independence with activities" (Lowey, et al., 2013, p. 356). 


\section{REFRAMING}

Harwood \& Clark (2014) also looked at decision making in older adults with chronic kidney disease. The authors aimed to examine facilitators and barriers for home dialysis. Included in the study were 13 participants ( 7 men and 6 women) aged 65 to 83 who received care in a team chronic kidney disease clinic in Canada. Four themes emerged and "represented homedialysis decision-making for older adults: precariousness with limited choices and uncertainty, personal factors, gender differences, and the necessity of support” (p. 3381). Age imposed limitations on modality and transplantation. "Modality decisions were influenced by health status, gender, knowledge, values, beliefs, past experiences, preferences, lifestyle and resources" (p. 3378). Home-dialysis selection was found to be linked to family and provider support. Functional status and resources also enabled home-dialysis selection.

Allen et al. (2015) included 6 hemodialysis patients and 11 health professionals involved in their care at an urban Canadian teaching hospital. The study looked at decision making for people with chronic end-stage kidney disease and found that decision-making is fluid and cumulative. The authors also found that the "distribution of care according to disease specialty works well for short-term, acute-care needs; but when faced with long-term, multi-morbid chronic illness this carefully distributed care becomes fragmented and inefficient” (p. 53).

\section{Decision-making and osteoporosis}

An additional review of the literature surrounding the decision-making process more specifically related to osteoporosis was conducted. This review resulted in both qualitative and quantitative literature. The study by Jensin et al. (2016) investigated if and how patients implemented knowledge from a multifaceted osteoporosis group education provided at a Danish hospital. It included 14 women and 3 men diagnosed with osteoporosis. The authors found that group education can potentially support and influence transfer of preventive actions by patients' 


\section{REFRAMING}

(Jensin et al., 2016). Participants displayed more reflection and confidence toward prevention. Jensin et al. (2016) also found that participants who could make the preventative activity into a social even were more likely to implement the preventative activity. This finding shows the value participants place on maintaining social roles even during osteoporosis screening and prevention.

Beliefs surrounding osteoporosis treatment preferences prior to and following fracture were also examined by several studies. Boudreau et al. (2017) identified women's beliefs and other factors associated with lack of osteoporosis treatment during the 6 months following osteoporotic fracture. Participants included 634 enrollees from the Female Group Health Cooperative that were aged 55 and older. The authors found that women were at greatest risk for not undergoing osteoporosis treatment when they did not think osteoporosis caused their fracture, were not concerned about osteoporosis or future fracture, were uncertain of treatment effectiveness to prevent fracture, had not been recommended by a provider to take treatment or discussed osteoporosis treatment, screening, or prevention (Boudreau et al., 2017). Knowledge regarding osteoporosis and the benefits of treatment were highest in those who pursued treatment following osteoporotic fracture, but awareness remained low (Boudreau et al., 2017).

The study by Hiligsmann et al. (2017) examined patient preferences for anti-osteoporosis drug treatment. The sample included 1124 patients from across Europe. Participants were presented with two hypothetical unlabeled drugs treatments which varied according to "efficacy in reducing the risk of fracture, type of potential common side effects, and mode and frequency of administration" (p.1167). Participants were found to prefer a highly effective treatment and 6month subcutaneous injections over oral tablets (Hiligsmann et al., 2017). They also found that participants even preferred a monthly oral tablet and yearly intravenous infusions over a weekly 


\section{REFRAMING}

tablet (Hiligsmann et al., 2017). Lower cost treatments were also found to be preferred in countries where there was an out-of-pocket cost.

Treatment preference was also the focus of the study by Cornelissen et al. (2020). The authors sought to identify single patient characteristics that influence preferences for osteoporosis drug therapy and to investigate how patient characteristics influence treatment profiles (Cornelissen et al., 2020). Participants were presented with two hypothetical treatment options with the following "attributes: treatment efficacy, side effects, and mode/frequency of administration" (p.85). The sample included 188 patients, $78 \%$ females, with an average age of 66 years old. Of the 188 participants $70 \%$ of participants had osteoporosis, $49 \%$ took an osteoporosis medication, $38 \%$ suffered from a previous osteoporotic fracture, and $79 \%$ suffered from gastrointestinal problems (p. 87). The authors found that all treatment options were important to participants when deciding about treatment. They also found that participants with a "previous fracture valued efficacy most, those participants aged 65 and older or with a fear of needles preferred tablets", and "elderly patients disliked intravenous medications "(p.85). No statistically significant associations between socio-demographic or clinical characteristics could be found.

There was only one study in the entire review that used a grounded theory approach like the current study. The study by Wozniak et al. (2017) aimed to understand how older patients with new fractures decided to persist with or stop osteoporosis treatment over a one-year period. A total of 21 interviews were conducted with 12 patients. Three major themes emerged: " 1 ) patients perceived osteoporosis was not a serious health condition and considered its impact negligible, 2) persisters and stoppers differed in weighing the risks versus benefits of treatments, with persisters perceiving less risk and more benefit. Persisters considered treatment as 


\section{REFRAMING}

"required" while soppers deemed treatment as "optional, 3) patients could change treatment status even 1-year post-fracture because they re-evaluated severity and impact of osteoporosis versus risks and benefits of treatments over time" (Wozniak et al., 2017, p.219). These findings suggest that future research focus on the severity and risk related harm related to untreated osteoporosis to better approach treatment start and adherence.

Billington et al. (2019) looked at women's choices to accept osteoporosis and how closely it relates to the current treatment guidelines. It included women aged 45 and older with a diagnosis of osteoporosis who attended an osteoporosis self-management consultation at a tertiary osteoporosis center (Billington et al., 2019). Participants were given education on osteoporosis during a group session, then had their individual fracture risk score calculated. Based on those results participants then decided whether to initiate osteoporosis treatment. Those choices were then evaluated based on a physician-set intervention threshold which focused on the fracture risk score.

The three studies which used a randomized controlled trial focused on interventions to help with decision-making toward treatment initiation and osteoporosis perception motivation. Smallwood et al. (2017) looked at 50 patients aged 55 and older with a T-scores of -1 or less to determine the feasibility and potential efficacy of a patient portal-based osteoporosis decision aid. The authors found that participants found the decision aid acceptable, but that $17 \%$ in the decision aid arm entered their T-scores incorrectly into the fracture risk calculator (Smallwood et al., 2017). Decisional conflict was lower post-intervention for those in the decision aid arm with a significant difference in the percentage of patients making treatment decisions postintervention seen. Despite the decrease in decisional conflict no significant differences were observed in medication uptake. 


\section{REFRAMING}

The use of a 3-D model versus electronic animations were also evaluated for their effectiveness to impact osteoporosis perceptions and treatment motivation. Jones et al. (2017) found "no significant interaction effects, revealing that neither medium had a greater impact on beliefs over time" (Jones et al., 2017, p.899). According to the authors both mediums increased "consequence beliefs, personal and treatment control, understanding of osteoporosis, motivations to take treatment if needed and medication necessity beliefs" (p. 899). Over time the authors also found that timeline beliefs and medications concerns decreased for participants using both mediums.

Danila et al. (2018) evaluated a patient-centered video based behavioral intervention to improve treatment rates among a high-risk population with a previously reported osteoporotic fracture. Participants were randomized to the intervention or usual care. No significant difference between groups were identified in osteoporosis medication use, supplement intake, and bone density screening (Danila et al., 2018). Those participants in the intervention group had fewer women in the pre-contemplative stage of behavior change and more of those women reported seeing their primary care provider, had concerns about common medication side-effects such as osteonecrosis of the jaw, and reported difficulty remembering to take osteoporosis medications (Danila et al., 2018). Although the intervention wasn't effective at increasing the use of osteoporosis uptake 6 months post-intervention, it increased non-bisphosphonate medication use and bone density screening in select subgroups, it shifted participants' readiness toward behavior change, and helped alter perceptions of barriers to treatment (Danila et al., 2018).

The piloted prevention program by Anderson-Wurf et al. (2018) explored if individual goal setting in a retirement village could improve prevention strategies aimed at reducing the risk of osteoporosis. Education was provided in a group setting at a retirement village and 


\section{REFRAMING}

participants were offered the opportunity to set individualized osteoporosis prevention goals. According to the authors there was a significant improvement in osteoporosis knowledge and the strategies available to prevent and manage the disease. These improvements were seen even 6 months following the intervention.

The final study in the review by Lopez-Olivo used an edutainment model with educational patient story lines to improve disease knowledge and decrease decisional conflict toward treatment. This study not only included participants with osteoporosis, but also those with osteoarthritis of the knee, and rheumatoid arthritis. Statistically significant differences in pre to post-intervention scores were seen in knowledge for all disease processes (Lopez-Olivo et al., 2018). Participants reported "clarity on disease duration, symptoms, and the mechanism of onset of medications" (Lopez-Olivo et al., 2018, p.213). They also reported being more aware of taking medications and seeking care from healthcare providers.

\section{Synthesis of the Literature}

Much was learned from the first literature review about how older adults live with and adapt to a new diagnosis. A common theme which emerged was the importance of maintaining one's independence and physical activity while living with osteoporosis. Many older adults found the ability to perform daily tasks and activities crucial to maintaining a quality of life. Quality of life was also key to participants when discussing independence and autonomy. Participants stressed the importance of maintaining roles within the family and social context. Roberto and Reynolds (2001) found that rural women although resilient were especially vulnerable due to their need to maintain their own environment and the increasing demands such a lifestyle imposes. Being actively engaged in one's preferred activities and priorities was also described as an expression of a sense of self by Nielsen and colleagues (2011) during their 


\section{REFRAMING}

examination of men's experiences of living with osteoporosis. Despite differences in geographic location, age, and sex all participants facing a new diagnosis of osteoporosis voiced concern about maintaining a sense of self, despite a new chronic illness.

The literature also revealed that the severity of osteoporosis was not a determining factor on how patients experienced and handled osteoporosis. Instead, it was the burdens in a person's life which influenced how they handled osteoporosis. Burdens such as other pre-existing medical conditions hindered participants from adapting to a new diagnosis. Nielsen, D.S. et al. (2011) found that those patients with available resources and a positive outlook were better able to accommodate the uncertainty of a new diagnosis of osteoporosis. Pre-existing misconceptions were also found to adversely influence osteoporosis prevention and control. Baheiraei et al. (2006) found that misconceptions about osteoporosis and its risk factors are likely contributory factors to lack of action regarding osteoporosis prevention.

Barriers to preventive actions were also identified as obstacles to dealing with a life with osteoporosis. One barrier discussed by Baheiraei et al. (2006) was communication. The authors found that participants had difficulty communicating their problems and suggested that healthcare providers pay special attention to how they articulate the seriousness of the disease. This is particularly important when communicating with non-English speaking patients with limited English skills. Another barrier identified by Nielsen, D.S. et al. (2011) was the insufficient translation of osteoporosis knowledge and prevention strategies for men. The authors suggest a better understanding of the participants everyday life outside of the healthcare system to better identify the needed communication and educational activities. Lack of trust in the patient-provider relationship was another barrier discussed and participants placed emphasis on 


\section{REFRAMING}

trust and related lower levels of trust to an inability to effectively manage a life with osteoporosis.

Although common themes were identified in the literature, few unexpected findings were identified. The study by Baheiraei et al. (2006) brought about the aspect of emotional pain. Participants thought that emotional pain may contribute to diminished bone density. This unexpected finding was not seen in the other studies but may be due to the cultural practices and religious beliefs of Iranian men and women. In the study by Nielsen et al. (2011) men were found to have a broader range of strategies for handling a diagnosis of osteoporosis than previously thought. They also identified maintaining physical activity following diagnosis as a priority, but the theme of acting on a need for help was identified. This theme was unique and could be due to gender differences since the study focused specifically on men's experiences.

The second literature review offered a greater understanding of the decision-making process during chronic illness. Most of the studies (three out of five) focused on participants with chronic kidney disease and two of the five used a qualitative ethnographic method. A common theme which emerged was an unawareness of the seriousness of illness. In three out of the five studies participants held on to hope and past experiences during which their health improved. They relied on the opinions and information gathered from others suggesting that decision-making is a cumulative process. In one study participants with chronic kidney disease were even willing to give up years of life expectancy for a life free from the burden and restrictions of assistive devices.

The importance of the patient-provider relationship on decision making was another finding from the review. This finding is like the one seen during the first review. Lack of trust in the patient-provider relationship was identified as a barrier when learning to live with 


\section{REFRAMING}

osteoporosis. A holistic approach to care with collaborating providers aided in decision-making especially in patients with multi-morbid chronic illnesses. Participants in two of the studies required information from their provider regarding the seriousness of their illness to make appropriate decisions and to have a better awareness of their current health status. Allen et al. (2015) suggested that decision-making should occur as a longitudinal conversation between health professions and patients to better recognize the values and goals of everyone. Support from family and healthcare professionals was also identified as important in the decision-making process.

The decision-making process was also found to be influenced by the availability of financial resources and treatment accessibility. The study by Morton et al. (2012) found that two factors associated with patient preference for dialysis over conservative care included the availability of subsidized transport and the opportunity to schedule throughout the day or evening. Harwood \& Clark (2014) also found that access to available resources may influence the type of treatment one may choose.

In the study by Chang et al. (2012) the need for spiritual comfort and control was found. These participants placed more emphasis on their personal philosophy and critical assessment of CAM information. Personal perceptions of the outcomes were preferred to those of healthcare professionals and social support networks. These findings were specific to this study and may be related to the use of complementary and alternative medicine.

The third review offered a greater understanding of the available decision aids and interventions and their ability to aid in decision-making, improve osteoporosis screening, and osteoporosis medication intake. The review also offered additional information about beliefs and perceptions regarding osteoporosis in at risk populations and current preferences for treatment 


\section{REFRAMING}

options. Although interventions were effective at increasing awareness of osteoporosis and the need for treatment, awareness remained low and had limited lasting effects. Interventions provided in a social setting or as a group had promising results and participants reported an increased willingness to attend a preventative activity that was completed as a social event. Results were also favorable for those interventions that used real life patient situations portrayed by actors. These portrayals offered participants a real-life view of life with osteoporosis and the consequences of the unmanaged disease process. Also, the setting of individualized prevention goals along with group education also proved to be successful for participants at a retirement village (Billington et al., 2019).

Beliefs regarding treatment showed that patients prefer treatments that are highly effective at preventing fracture. Surprisingly patients also preferred 6-month injections over oral weekly tablets or annual intravenous infusions. Participants only preferred oral tablets when cost was factored in. This finding can help providers focus on the treatment options preferred by participants.

\section{Summary}

A general review of the literature surrounding the area of interest was conducted prior to embarking on the proposed study. The review offered information on the existing conceptual/theoretical, methodological, and empirical literature related to living with osteoporosis and decision-making in chronic illness. In accordance with the classic grounded theory method, a more extensive literature review focusing on concepts which emerged from the data is included in chapter 5.

Only one study used a grounded theory methodology but focused on the decision to continue osteoporosis treatment following fracture. Most of the studies in the two initial reviews 


\section{REFRAMING}

focused on the decision-making process involved in patients with chronic kidney disease. Although osteoporosis and chronic kidney disease are both chronic illnesses, the decisionmaking process regarding treatment may differ. Investigation into the decision-making process following osteoporotic fracture is needed to gain a better understanding of what is going on in this specific population. The third review offered a quantitative approach to the decision-making process and included literature specific to osteoporosis and decision-making toward treatment or treatment preferences. Several interventions were offered as aids to improve osteoporosis knowledge and treatment motivation. Although most were successful in improving knowledge on osteoporosis, knowledge remained low and motivation toward treatment limited. Chapter three will delve into this area and will fill the gap that currently exists in the literature. 


\section{REFRAMING}

\section{Chapter Three: Method}

The research question used for the study is "What is going on during the decision-making process of women aged 65 and older when considering treatment for osteoporosis following osteoporotic fracture?" Based on this question, the classic grounded theory method was chosen. Classic grounded theory was discovered by Barney Glaser and Anselm Strauss during their research on dying in hospitals (Glaser, 1998). The method aims at generating theory in a substantive area based on the words and behavioral actions of those living it, instead of just verifying preconceived theories (Glaser, 1998). It is a useful method when looking at social processes, such as the decision-making process following osteoporotic fracture, which holds great meaning to those involved. The purpose of this chapter is to discuss the background and origin of classic grounded theory and its use in the study. It will also provide information on the study population, sample selection processes, data collection and analysis, and human rights and ethical considerations. The advantages and limitations of the method along with study feasibility will also be examined.

\section{Research Design}

Classic grounded theory is a complex and multivariate methodology that involves the systematic generation of theory from data (Glaser, 1998). It aims at explaining a social process and emphasizes the emergence of theory through a revolving-step method of constant comparisons, theoretical sampling, and theoretical coding. According to Glaser (1998) through the discovery of latent patterns of behavior, classic grounded theory can explain what is going on in a substantive area, rather than just describing what happened. The goal of grounded theory development is to uncover the main concern of individuals in a substantive area and to understand how that concern is continually resolved. 


\section{REFRAMING}

\section{Advantages of the design}

Classic grounded theory, as a research methodology, holds several advantages for researchers. Its design is exciting, empowering, and motivational due to its emphasis on emergence. It also provides for researcher autonomy, unlike other more forcing methodologies

(Glaser, 1998). Classic ground theory does not constrain or take over the researcher, it frees him or her toward ongoing discoveries (Glaser, 1998). Glaser (1998) states that "grounded theory can be taken in the researcher's direction and made his or hers own within the parameters of the grounded theory package" (p. 19).

Another advantage of the method is the "ability to put it down and pick it up later" (Glaser, 1998, p. 15). There is no need for researchers to sacrifice obligations to family and friends since the research is always waiting to move forward (Glaser, 1998). This not only frees the researcher up physically, but also mentally to allow time for reflection. Many research methodologies do not have this advantage and sequester the researcher away from other obligations for days, months, and even years.

Because of this freedom and its ability to be used in a wide range of disciples, classic grounded theory offers an intuitive appeal and fosters researcher creativity (Glaser, 1992). It affords researchers the ability to be immersed within the data where themes and concepts can naturally emerge (Hussein, Hirst, Salyers, \& Osuji, 2014). Immersion allows researchers the ability to derive meaning from data using an inductive process (Hussein, et al., 2014). In addition, classic grounded theory offers researchers the opportunity to conceptualize through a systematic approach and to obtain data rich in depth (Hussein, et al., 2014). 


\section{REFRAMING}

\section{Sample selection}

The sample of the study included English-speaking women aged 65 and older who had sustained a previous osteoporotic fracture requiring hospitalization and who had not previously received treatment for osteoporosis. Those women with a formal diagnosis of dementia or previous treatment for osteoporosis prior to fracture were excluded. The age of 65 or older was chosen based on the current literature review and is based on the paper, Treatment of Low Bone Density or Osteoporosis to Prevent Fractures in Men and Women: A Clinical Practice Guideline Update from the American College of Physicians, that was released in the Annals of Internal Medicine in May 2017. In this report Qaseem, Forciea, McLean, and Denberg (2017) do not recommend screening for osteoporosis with a dual-energy x-ray absorptiometry (DXA) scan until after the age of 65. A DXA scan is the current gold standard test for diagnosing osteoporosis in people without osteoporotic fracture and is used to help predict fracture risk. The literature review focused on women who have sustained a previous osteoporotic fracture due to their higher risk for further complications related to osteoporosis.

Initial sampling was guided by the purpose of the study due to the narrow population interest, older women recently sustaining an osteoporotic fracture. Purposive sampling is a form of nonprobability sampling used when a sample is selected based on characteristics of the group (Polit \& Beck, 2008). Older women recently sustaining an osteoporotic fracture live a unique experience. Sampling for this study was purposive in that participants were referred for participation once they were identified as meeting inclusion criteria.

The sample came from West Virginia University Hospital and appropriate participants were identified by an osteoporosis specialist, Dr. Colleen Watkins, and the researcher, a colleague of Dr. Watkins. Through a consultation process, which involves the gathering of 


\section{REFRAMING}

information on the current fracture, previous fractures, and treatments received all eligible participants meeting inclusion criteria were identified. Further sampling was conducted once the subsequent substantive theory began to emerge. This type of sampling is known as theoretical sampling. "Theoretical sampling is the conscious, grounded deductive aspect of inductive coding, collecting, and analyzing" that directs the emerging theory toward further emergence (Glaser, 1998, p. 157). This process of sampling allows for constant focus while preventing data pile up and repetition. It also yields the "collection of data to the saturation of categories and their properties" to provide theoretical completeness (Glaser, 1998, p. 157). According to Glaser (1998) "it is the "where next" in collecting data, the "for what" according to the codes, and the "why" from the analysis in memos" (p.157). The researcher enrolled ten participants during initial sampling and as the theory began to develop two additional participants were identified using theoretical sampling. Sampling was complete and saturation reached following interviews with the last two participants as no new concepts emerged.

The researcher discussed details regarding the study with all eligible participants during their hospitalization in a private hospital room. Potential participants also received a handout from the researcher that described the study in lay terms as well as gave contact information for the researcher and the dissertation faculty member. Participants were given the opportunity to read the information and told to contact the researcher if interested in participating or if any additional information was needed. Review of the consent was completed with each participant by the researcher and involved the review of the purpose of the study, a description of procedures, confidentiality, and the use and disclosure of information. Participants were given the opportunity to ask questions and a signature was required prior to participating in the interview process. Some participants choose to set up an interview during the initial encounter 


\section{REFRAMING}

with the researcher while some scheduled for a later time following discharge from the hospital. Each patient that chose to participate selected a date and time for the interview. All interviews took place in a private, convenient, and comfortable location where confidentiality could be maintained. Interviews took place in the following settings: five were completed in inpatient rooms at West Virginia University Hospitals, four completed in outpatient clinic rooms in the Department of Orthopaedics located in the Physician's Office Center at West Virginia University Hospitals and three over the phone while the researcher was in a private office in the Department of Orthopaedics at the Physician's Office Center. Participant enrollment was slow and even required an amendment to the protocol submitted to the institutional review board at West Virginia University to allow additional time for recruitment. A statement was also included to allow for enrollment of participants of both the researcher and Dr. Colleen Watkins. Slow enrollment was due to a temporary reduction in the number of osteoporotic fractures admitted and referred. The delay was also due to a scarcity of patients meeting inclusion criteria.

The final sample included 12 female participants. Based on the demographic survey that each participant completed all women identified as white. This finding correlates with the United States Census from 2019 which found that $93.5 \%$ of West Virginia residents identified as white (United States Census Bureau, 2019). Each age category was represented equally with four participants falling in each age range (65-70, 71-80, and 81 or older). Half of the participants reported their highest level of education as a high school diploma or equivalent. Of the remaining participants one did not complete high school, three reported having some college education without a degree, one with a bachelor's degree and one with a master's degree. 


\section{REFRAMING}

\section{Data collection and analysis}

Interviews were the primary source of data collection and the researcher suspended all preconceptions prior to the interviewing process to ensure that she did not force the data. Glaser (1998) recommends keeping the researcher as free and open to discovery and emergence. To do this the researcher followed Glaser's (1998) recommendation to suspend, as much as possible, what she knows about osteoporosis and study the data. She also avoided performing a literature review in the substantive area and related areas (Glaser, 1998). The investigation began with a loosely structured, in-depth interview of each participant in a private and comfortable setting. The researcher's goal was to create an environment that would instill the spill (Glaser, 1998). According to Glaser (1998) instilling the spill is when a participant shares about what matters the most to him or her. The conversation began with a broad open-ended "spill" question: "I know that you have osteoporosis and have had a recent fracture. I am interested in finding out more about women's experience with osteoporosis. Can you tell me your experience with osteoporosis and its treatment?” The use of a spill question provides the participants the opportunity to tell their stories openly and freely without influence from the researcher. The researcher used bracketing to mitigate any unacknowledged preconceptions (Tufford \& Newman, 2010). According to Tufford and Newman (2010) one method of bracketing involves reflecting and examining memos for researcher engagement with the data. Once the interview began it continued as a conversation between equal participants, led by the subject (Glaser 1998).

The words and phrases of participants served as direct sources for category development and substantive theory formulation. During all interviews, the researcher obtained field notes while maintaining undivided attention. Interviews were conducted in a quiet room with just the participant and researcher to help minimize distractions. Field notes should capture the context in 


\section{REFRAMING}

which the participants relay their experiences. For this study, field notes were recorded immediately following the interviews and included statements, observations, and reactions to the shared experience of both the researcher and participants. Minimal notes were taken during the interview process as not to distract from the conversational process and to provide attentiveness to the participant. No audiotaping was used since Glaser (1978) advises against audiotaping. He suggests that it creates a lack of attentiveness to the richness of participant description and is time consuming due to the need for transcription (Glaser, 1978). Glaser (1998) also states that taping "neutralizes and undermines the power of grounded theory methodology to delimit the research" and that it "forestalls and delays theoretical sampling" (p.108). Taping may also limit the comfortability of participants to share openly about their experiences.

Participants were advised that additional interviews may be needed depending on emerging categories. For this study only one interview was needed from each participant. All interviews were conducted by the researcher to assure consistency. During initial sampling interviews began with the same spill question and subsequent questions were determined by the need for theoretical sampling. A different spill question emerged from the interviews of the first ten participants and was used during theoretical sampling. The spill question used during theoretical sampling was "Can you tell me about your experience following fracture?" The use of constant comparative analysis allows for the simultaneous collection and analysis of new data with pre-existing data to further explore variations and similarities in responses. Theoretical sampling continued and using constant comparative analysis the researcher continued to select participants until the point of saturation.

The researcher avoided premature closure, a common methodological mistake, by continuing to interview until saturation was reached. Saturation is present when no new data on 


\section{REFRAMING}

an emergent category can be obtained (Glaser, 1998). With grounded theory there is no "N" or set number of participants, instead Glaser recommends that researchers should collect and analyze data until saturation and completeness yields a substantive theory. He states "the researcher cannot know by preconception the problem and the core category and other categories that will later emerge and where theoretical sampling will lead" which makes setting a number of interviews or participants impossible when using grounded theory. The author recognized that saturation was met in the current study when participants began reporting the same thing when asked. Also, during the process of memoing the researcher identified no new concepts.

\section{Data analysis}

Data analysis involves the coding of data and occurs simultaneously with data collection using constant comparative analysis. Throughout data collection and analysis, documentation of “ideas and hypotheses as theoretical memos" will occur and can be used later to help "facilitate the identification of conditions, action/interactions, and consequences of the social process" being studied (Petty et al., 2012, p.379). To better understand a social process, one must understand the process from the perspective of the one experiencing it. Classic grounded theory allows for the "discovery of what is there and emerges, it is not invented" (Glaser, 1998, p. 4). The use of constant comparative analysis also provides the opportunity to modify, check, and verify concepts and patterns that emerge (Glaser, 1998). To facilitate constant comparison, the researcher compared each interview to the previous one and integrated categories with the addition of new information (Glaser \& Strauss, 1967). The use of this process continued until all sources were compared and all commonalities identified. 


\section{REFRAMING}

\section{Coding}

Coding is the first step in concept formation and is an important aspect in the generation of grounded theory. According to Glaser (2002) concepts are the meaningful names that best capture an emergent social pattern grounded in the data. Coding, specifically open coding, is the first step in concept formation and begins with the careful examination of field notes. It involves the fracturing of data and then conceptually grouping it into codes that later become the theory which explains what is going on (Glaser, 1978). Open coding is "aimed at generating a set of categories and their properties that fit, work, and are relevant for integration into theory" (Glaser, 1978, p. 56). It involves the coding of data in every way possible according to Glaser, 1978). It allows the researcher the opportunity to see the direction in which theoretical sampling should occur (Glaser, 1978). Many codes can be generated during open coding therefore memos are written throughout the coding process which leads to the addition of theoretical codes.

\section{Categories}

The next step in concept formation is the building of categories. These categories form themes which give a sense of what the participants are saying and expressing (Glaser, 1978). They form from the clustering of codes, from which concepts begin to develop, and a core category emerges. According to Glaser (1978) the emergence of a core category assumes a common process among participants that resolves a common concern. Simply stated the core category is how participants resolve/solve their main concern. The core category is continually modified through the process of constant comparative analysis and results in more selective substantive and theoretical coding. Substantive codes build the conceptual theory. They are the categories and properties of the theory. "Theoretical coding conceptualizes how the substantive

codes relate to each other as interrelated, multivariate hypotheses and resolve the main concern 


\section{REFRAMING}

(Glaser, 1978, p.55).” Glaser's (1978) phrase multivariate hypotheses relates to hypothetical statements with two or more concepts and their theoretical relationship. Through the process of constant comparative analysis and memoing the researcher identified the main concern of participants. The main concern expressed by participants in the current study was a longing to return to a time prior to osteoporosis and fracture during which participants reported higher levels of independence and freedom. This main concern was found to be resolved through the process of reframing.

\section{Memos}

Memoing is completed throughout the coding process and is documentation of the thought processes used to deal with information received from multiple participants. Memos were written during data collection and analysis and included any ideas and possible hypotheses about connections between codes and categories. They were completed as separate word documents following interviews and any time a new thought came to mind. As suggested by Glaser (1978), the process of memoing raised codes to a conceptual level. The researcher wrote numbered memos in OneNote following each interview session to help capture her thoughts or to document any similarities or differences with previous interviews. The researcher also added additional memos when sparked with a new thought or connections. Memos were later printed and sorted according to codes and theoretical fit.

\section{Human rights and ethical considerations}

To help ensure confidentiality and appropriateness of the research study and setting the researcher obtained IRB approval under expedited board review. Approval was granted on January 7, 2019 for protocol number 18806173547. Participant consent was obtained prior to any data collection and participants were given the opportunity to withdraw from the study at any 


\section{REFRAMING}

time. All data was de-identified by placing specific codes on each data form, field notes, memo's, and interview transcripts. The consent and data forms were kept in separate locked cabinets in the researcher's office. Respect for participants was maintained by assuring that the location of interviews was comfortable and private. The researcher also showed respect for participants by listening attentively and maintaining an unbiased attitude.

\section{Methods to assure rigor}

Rigor plays an important role in qualitative research and is key to enhancing the trustworthiness of a study (Lincoln \& Guba, 1985). Glaser and Strauss (1967) stressed the importance of basing trustworthiness on the strategies used for collecting, coding, analyzing, and presenting data. To assure rigor in this study Lincoln and Guba's (1985) criteria to assure qualitative research rigor, internal and external validity, reliability, and objectivity was addressed in terms of credibility, transferability, dependability, and confirmability as they apply to Glaser's (1978) criteria of fit, work, relevance, and modifiability. Lincoln and Guba's criteria for trustworthiness are compatible with the unique measures of rigor in grounded theory. As stated by Glaser, (1992) a well-constructed grounded theory fits, works, is relevant, and is modifiable.

According to Glaser (1978) fit means that the categories of a theory fit the data and are not forced or selected to fit pre-conceived or pre-existent categories. Work means that a theory should be able to "explain what happened, predict what will happen, and interpret what is happening in an area of substantive or formal inquiry (p.4)." The criteria of modifiability involves the understanding that generation is an ever-modifying process (Glaser, 1978). Lincoln and Guba's criteria were used since they are well known measures of rigor in qualitative research. 


\section{REFRAMING}

Credibility is the first criterion and involves demonstrating that a true picture of the phenomenon of interest is being presented (Lincoln \& Guba, 1985). It was achieved in this study using the constant comparative method during which all new data was compared to previous data. The use of this method ensures fit and demonstrates the connection between Lincoln and Guba’s (1985) criteria with Glaser's. Additionally, Glaser's (1978) criteria of work and relevance demand that a theory accurately represents the thoughts and concerns of participants. The findings and theory from this study emerged from the thoughts and words of participants and truthfully represented the process being studied. The researcher closely worked Dr. Alvita Nathaniel, an expert on grounded theory, to help assure credibility of the findings. She also took a one-hour independent study offered by Dr. Nathaniel on the classic grounded theory method.

Transferability involves providing sufficient detail of the fieldwork to enable consumers to generalize and make comparisons to other like populations in similar circumstances (Lincoln \& Guba, 1985). "Yvonne Lincoln and Ergon Guba (1985) maintain that generalization is unrealizable, but, in a manner like Stake (1995), they claim that extrapolation or transferability of findings from one specific case to another is possible. In their view, case-to-case transfer, an activity that is the responsibility of the reader of research, can be accomplished if the inquirer provides sufficient detail about the circumstances of the situation or case that was studied so that readers can engage in reasonable but modest speculation about whether findings are applicable to other cases with similar circumstances" (Schwandt, 2007). Comparisons may even lead to additional studies which may provide a more vivid depiction of the phenomenon and further support the trustworthiness of the initial researcher's findings (Lincoln \& Guba, 1985). Glaser (1978) proposed that the findings of classic grounded theory were meant to serve future investigators as groundwork for transferable judgements. Due to the conceptual nature of the 


\section{REFRAMING}

finding's transferability of the theory to other human processes is possible. The addition of embodied revelation, a process discovered by Barton-Caro (2013), was easily transferred due to the thorough explanation offered by Barton-Caro.

Dependability, the third criterion used to increase trustworthiness addresses the issue of reliability (Lincoln \& Guba, 1985). Researchers must be able to include documentation in the form of an audit trail to support the dependability of their study. By providing sufficient information regarding the processes used, implementation strategies, and the operational detail of data collection, replication may be achieved, and reliability confirmed (Lincoln \& Guba, 1985). Findings of a grounded theory investigation are grounded in the data ensuring dependability. Also, the use of the constant comparative method ensures a good fit between the labeled concepts and stages allowing for deconstruction back to the original data (Martin \& Gynnild, 2011). In the current study interviews and memos were numbered to help keep track of data and to provide proof of the emerging concepts.

Confirmability provides evidence that findings emerge from the data and are based on the experiences and information provided by the participants (Lincoln \& Guba, 1985). This criterion can be achieved by including such things as an audit trail and member checking. These methods allow the researcher the ability to demonstrate rigor and to provide readers with the data used to make sound scientific interpretations. For this study, an audit trail could be completed by reviewing field notes and memos and how they relate to the identified codes and categories. A separate word document of all participant data was maintained and available to review to help cross check emerging concepts and categories. Interviews and memos were labeled for easy identification and consistent record taking was maintained. The emergence of a grounded theory 


\section{REFRAMING}

that fits and explains the data is a prime example of confirmability. Although member checking is included by Lincoln and Guba as a method for assuring credibility, it is not done in grounded theory due to the conceptual nature of the methodology. Participants may not recognize their specific experiences in the higher-level language.

\section{Summary}

Since its discovery in the late 1960's, classic grounded theory has provided researchers from various fields and disciplines with a qualitative research method rich in emerging concepts and theories. It was a need to generate theory from data that first led Barney Glaser and Anselm Strauss to discover the method known today as classic grounded theory. Using this method, the researcher can explain a social process, such as the decision-making process following osteoporotic fracture based on the views of those who have experienced it. Treatments have been shown to be effective in reducing the risk of subsequent fracture, but many women continue to decline treatment even after fracture. With a greater understanding of what is going on in this population this study can not only decrease the economic burden of osteoporotic fracture, but also the physical and psychosocial consequences that follow. 


\section{REFRAMING}

\section{Chapter Four: Results}

This chapter presents the grounded theory of reframing. The theory emerged from interview data collected and analyzed from women aged 65 and older who had recently experienced an osteoporotic fracture. An in-depth analysis of interview data was conducted using a classic grounded theory method as described in Chapter 3. The final sample included 12 female participants. Based on the demographic survey that each participant completed all women identified as white. This finding correlates with the United States Census from 2019 which found that $93.5 \%$ of West Virginia residents identified as white (United States Census Bureau, 2019). Each age category was represented equally with four participants falling in each age range (65$70,71-80$, and 81 or older). Half of the participants reported their highest level of education as a high school diploma or equivalent. Of the remaining participants one did not complete high school, three reported having some college education without a degree, one with a bachelor's degree and one with a master's degree.

This original grounded theory set out to describe the decision-making process women experience when considering osteoporosis treatment following osteoporotic fracture. After speaking with ten participants, a different and new process emerged resulting in the discovery of the theory reframing. The study sample included 2 women who refused to accept the new diagnosis and its relation to their current fracture. The sample began as one homogenous group that later diverged into two distinct groups following osteoporotic fracture. The ten participants who accepted the new diagnosis, necessary lifestyle modifications and eventual treatment underwent a reframing. This reframing allowed participants a new way of looking at life as it exists in its present state and was achieved through an embodied revelation, a process discovered by Barton-Caro in 2013 while looking at the threat of sudden cardiac death for ICD candidates. 


\section{REFRAMING}

The revelation participants experienced was two-fold and involved an internal realization of the impact of osteoporosis and the decision to accept treatment, which Barton-Caro describes as a "tangible expression of personal risk" (p.41). Those participants who refuse to accept the existence of the new diagnosis, its relation to the current fracture, and the necessary lifestyle modifications begin to shift blame and diminish the significance of osteoporosis. Two participants in the current study were unable to move forward toward a new reality and due to their current fracture were also unable to return to their pre-fracture state.

\section{Grounded Theory of Reframing}

Figure 1: The Grounded Theory of Reframing

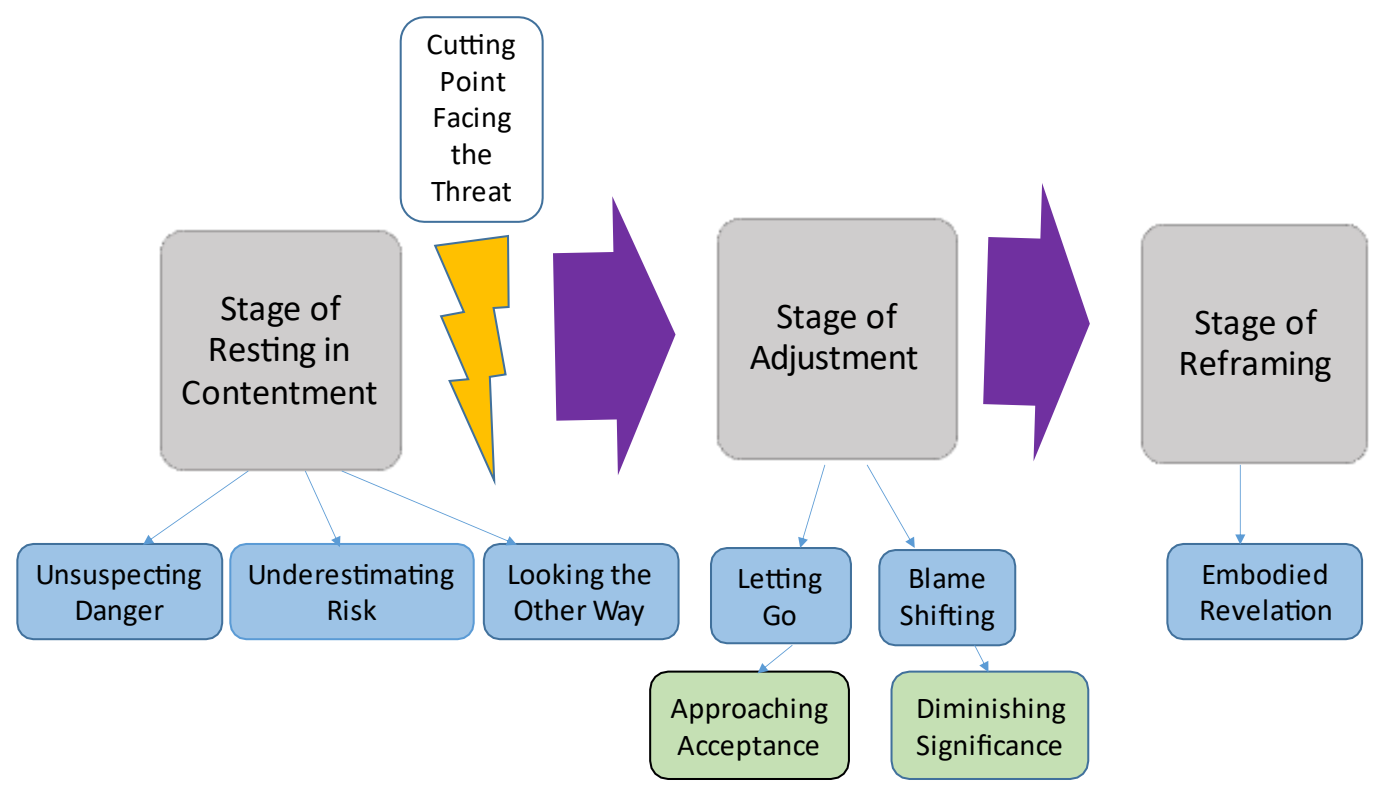

The grounded theory of reframing includes the three stages of resting in contentment, adjustment, and reframing and also includes one critical juncture, facing the threat. Figure 1 depicts a model representing the new grounded theory. The first stage of the theory is resting in contentment. This stage occurs at a time prior to osteoporotic fracture during which pre-existing 


\section{REFRAMING}

knowledge of osteoporosis varies. The properties of unsuspecting danger, underestimating risk and safeguarding everyday help to describe the varying levels of osteoporosis comprehension in stage one. Stage one ends abruptly when osteoporotic fracture occurs and results in the critical juncture of facing the threat. The critical juncture is brief and is immediately followed by the stage of adjustment. During the stage of adjustment, participants are either letting go of a previous life for one with osteoporosis or continue to employ blame shifting and diminishing the significance of osteoporosis and its relation to their current fracture. Transition from the stage of adjustment to the stage of reframing is gradual and does not occur until a formal decision to accept or reject treatment for osteoporosis is made. During the stage of reframing, those participants who decide to accept treatment undergo an embodied revelation toward a new reality with osteoporosis. In the current study all but two participants underwent an embodied revelation toward reframing. The two participants unable to accept their new diagnosis and its relation to their current fracture continued to long for a pre-fracture life.

Throughout the interview process all participants stated a desire to return to a pre-fracture state. They reminisced about a time of independence prior to osteoporosis and longed for the ability to complete tasks that they previously performed daily. This desire emerged as the main concern of participants. The core concept is the way participants continually resolve their main concern. Through further review of interview data, the core concept, reframing emerged.

\section{Stage 1: Resting in contentment}

Figure 2: Stage of Resting in Contentment 


\section{REFRAMING}

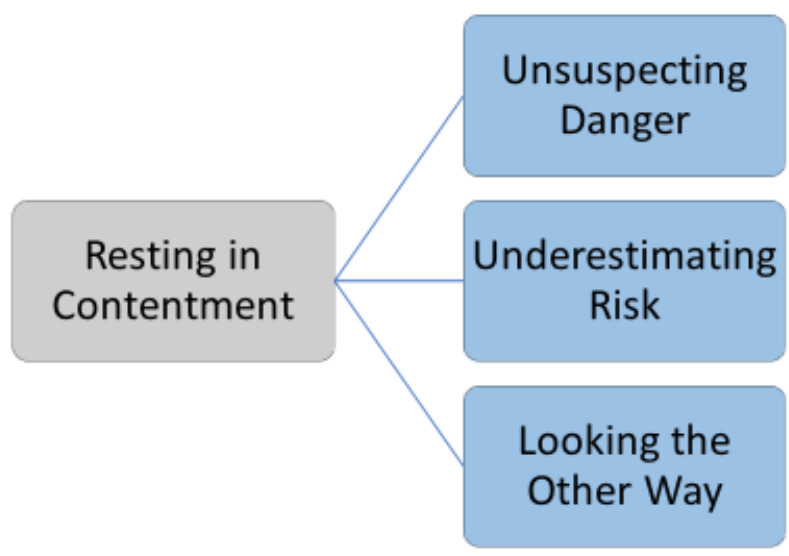

The first stage of resting in contentment, depicted in Figure 2, is also referred to as "normal life" by many participants. It is the period prior to fracture during which participants report high levels of independence and satisfaction. Participants report completing such tasks as cleaning, mowing grass, and working during this stage. Stage one includes the three properties of unsuspecting danger, underestimating risk and looking the other way. These properties describe the continuum of osteoporosis comprehension prior to fracture. Participant comprehension of osteoporosis and fracture risk vary and are not prioritized until forced by osteoporotic fracture. Resting in contentment lasts for years and only ends after fracture occurs with the critical juncture of facing the threat. Following the critical juncture all participants proceed into stage two, becoming accustomed.

Unsuspecting danger. Some participants in the stage of resting in contentment approach unsuspecting danger as they have no knowledge of osteoporosis or their current risk for osteoporotic fracture. They do not recall ever being told about osteoporosis or receiving 


\section{REFRAMING}

screening or treatment. One participant stated "I was never told until this broken bone that I had osteoporosis. Over the past couple of years, I have been seeing a chiropractor and it was never mentioned." Another participant explained that her lack of knowledge on osteoporosis may have been due to her non-compliance with seeing her primary care provider. A participant who identified as a retired nurse even stated "I should have known since I was a nurse, but I didn't. I just thought I had arthritis." This statement offers support that osteoporosis knowledge, even in those in previously employed in a healthcare is limited.

Underestimating risk. The property of underestimating risk explains how participants with prior knowledge of osteoporosis de-prioritize the risk for future fracture. Several participants reported a diagnosis of osteoporosis prior to fracture but had not received treatment due to a personal unwillingness or due to the inability of a provider to obtain or recommend a medication. One participant stated, "my family doctor tried to get me shots for my bones before, but Medicare wouldn’t approve them." While several other participants reported being told that they had osteoporosis, osteopenia, or the "beginnings" of osteoporosis without any recommendation of treatment.

Looking the other way. Looking the other way represents another property of resting in contentment. Despite an awareness of osteoporosis, osteopenia and in some cases an actual diagnosis of osteoporosis, participants continue to deny the existence of a problem. Looking the other way is aimed at preventing harm to the participant and their current life. Many participants reported looking the other way by providing information to refute the existence of osteoporosis. One participant stated "this was due to a bad fall, nothing else" while others reported a false sense of security based on previous knowledge that was either false or inaccurate and used it to provide proof for denying the existence of a problem. "They told me I was big boned, and I 


\section{REFRAMING}

drank milk, so I thought my bones were good." Another participant even stated, "I thought my bones were strong since they hadn't broken."

\section{Facing the threat (Critical Juncture)}

The first stage, resting in contentment, is brought to an abrupt end when osteoporotic fracture occurs. This fracture serves as a critical event leading to the end of stage one. According to Strauss (1969) the time between stages following the occurrence of a critical event is a critical juncture. Facing the threat is the critical juncture in reframing. It is from this point participants begin to experience changes in their daily lives. From physical pain and deformity to the need for surgical fixation. This is also the point during which participants begin to lose some of their independence. All participants, even those with little to no prior osteoporosis knowledge, are faced with the diagnosis of osteoporosis and the physical and psychosocial changes that follow. Most participants described the fracture and new diagnosis as a surprise, while others reported it as a "horrible experience" or a "big whammy." One participant surprised by the diagnosis stated, "I don't believe it." Other participants that were surprised reported "not being aware until now" and "never being told until the broken bone." Even those participants with previous knowledge of osteoporosis or bone thinning stated that they "didn't' know" their bones were "that bad" or that they needed treatment. Following fracture, participants are unable to hide from the diagnosis or underestimate the risk for future complications. They are forced to decide how to proceed with life post fracture.

\section{Stage 2: Adjustment}

Figure 3: Stage of Adjustment 


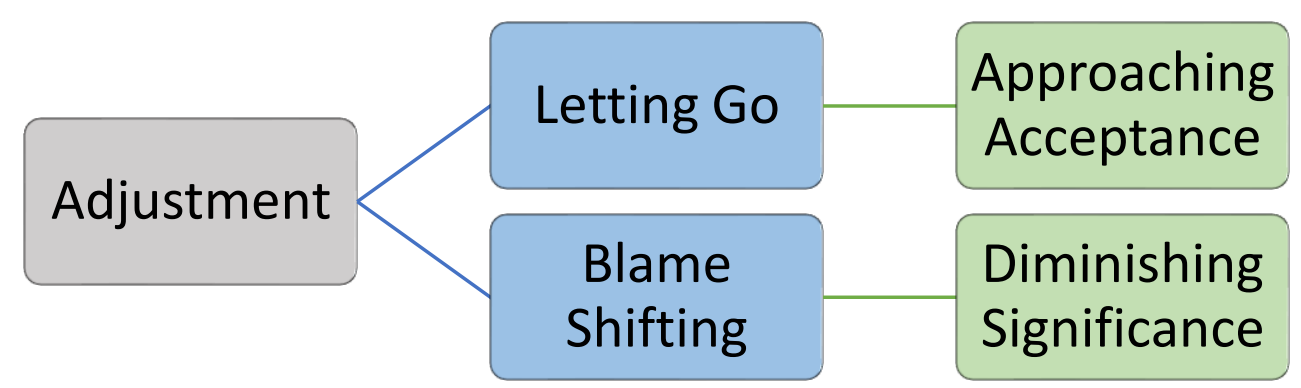

The second stage, adjustment, is a time of adaptation. Participants in this stage are starting to contemplate how they are going to handle life after a fracture. It includes the two properties of letting go and blame shifting. Letting go has the sub-property of approaching acceptance and blame shifting has the sub-property of diminishing significance. Stage two begins after the critical juncture of facing the threat, which is signified by osteoporotic fracture. All participants proceed from stage one and in stage two begin to contemplate the effects that osteoporosis and osteoporotic fracture will have on their daily lives. Participants are faced with a loss of independence and control, have pain due to their recent fracture, and are experiencing fear about future fracture and post fracture life. They are still processing what has occurred and deciding how to handle it. A participant asked what osteoporosis has meant in her life stated, "I really can't answer because I just found out." Those participants who accept the loss of independence, temporary or permanent, following fracture and move toward a new reality are letting go of a pervious life which existed pre-fracture. Participants who, despite medical advice, continue to place blame of their recent fracture on external causes are blame shifting and diminishing the significance of osteoporosis and osteoporotic fracture. 


\section{REFRAMING}

Letting go. Letting go is relinquishing control and leaving behind a previous life which existed pre-fracture. Approaching acceptance is the sub-property of letting go. Participants who proceed along this path recognize that they are no longer in complete control over the events that are happening to them. From this realization they are better able to adapt and make the necessary changes to live with osteoporosis and prevent future fracture. One participant stated "therapy helped me realize that I don't have complete control over the things that are happening to me. Coming to that realization has helped me learn to adapt to living with osteoporosis." Another two participants discussed how osteoporotic fracture led them to a realization of aging and the physical changes they were experiencing. One stated "you think you can do the same things you did at a younger age, but you can't. I have never thought of myself as old, but this second broken bone has made me realize that I cannot and that I should probably consider treatment to prevent broken bones. I think it made me realize my age. I don't feel like I am getting old, but I am.” The other reported 'I feel like I am 65 but I'm in my 80's. This broken bone and osteoporosis mean I am getting old and it changes how I must do and think about things. I must be more cautious and make the changes that are best for my health." By letting go participants are moving toward acceptance and the needed modifications to prevent future fracture.

Blame shifting. Although most participants were able to let go and move toward accepting a new normal some resorted to blame shifting. Blame shifting is the act of placing blame on anything other than the actual cause. Despite being told that their fracture was related to osteoporosis, several participants continued to believe that something/anything other than osteoporosis was the cause. One participant even stated that her fracture was just the result of a bad fall and/or medication. It was "just due to a bad fall, nothing else. I fell because I think my blood pressure medication is making me dizzy." Another participant said, "I fall all of the time 


\section{REFRAMING}

and this is the first time that I have ever broken a bone so I can't have osteoporosis." Blame shifting was even seen regarding the actual fracture. One participant blamed her increase in dependency and fatigue on her age, not her recent fracture. "I feel like I am more dependent than usual and little things wear me out. I guess I feel this way due to my old age." Diminishing significance is a sub-property of blame shifting.

Approaching acceptance. Participants who are approaching acceptance are letting go and are open to modifications which may include such things as household adjustments, treatment, or even the use of assistive devices. They are aimed at improving their health and believe that through acceptance and modifications that they can return to a new normal. One participant explained that she was willing to do anything to get back to what was important to her, her puppy and roommate. "All I know is that I want to get back to my roommate of 15 years and my puppy. Even if I have to go to an assisted living facility, I am ok with that as long as I can have my roommate and puppy with me. They are the most important things to me." The same participant reported being used to making unexpected changes due to her history of endometrial cancer. She stated, "I just do what I have to do." Another participant reported being slower and more cautious due to her new diagnosis and recent fracture but was "pushing to get back" to where she was. Several other participants acknowledged the importance of the diagnosis and the impact it would have on their life going forward.

Diminishing significance. Diminishing significance was also seen in participants unable to accept the role osteoporosis played in their fracture. Participant responses varied from complete disbelief “I just don't believe it and I don't like it. I just don't believe I have osteoporosis." All the way to deprioritizing osteoporosis "I'm not sure that I even want treatment. My main focus is getting my broken bones cared for." One participant even went as 


\section{REFRAMING}

far as to say "I haven't given it a lot of thought. I never let it bother me until this broken bone." Diminishing significance is the downplaying or reduction of a problem aimed at decreasing the importance. By reducing the importance of osteoporosis participants are hopeful that they can ignore osteoporosis and go back to a life prior to diagnosis and fracture. They are unable to discuss treatment or modifications because they do not believe that they have osteoporosis and that it led to their current state.

\section{Stage 3: Reframing}

Figure 4: Stage of Reframing

\section{Reframing}

\section{Embodied} Revelation

The third stage of reframing includes the property of embodied revelation. The stage begins after contemplating the impact of osteoporosis and osteoporotic fracture in stage two, becoming accustomed. Participants in stage three are looking at life through a new lens. Osteoporotic fracture has resulted in a realization of the need for a new life post-fracture involving modifications and treatment. Participant acceptance is highly motivated by the need to prevent future fracture and to return toward a new normal. One participant stated, "I'm hopeful that with medication I won't break anything else so that I can get back to being active." Another reported "I will take what is needed because just getting to this stage has taken forever." In reframing, participants undergo an embodied revelation and accept the necessary treatment and 


\section{REFRAMING}

modifications to prevent future fracture or are left longing for a pre-fracture state. Those participants unable move forward through reframing are at increased risk for subsequent fracture and the morbidity and mortality that follow.

Embodied revelation. The concept of embodied revelation was initially discovered by Vera Barton-Caro in 2013 while looking at the threat of sudden cardiac death for ICD candidates. The revelation she described was twofold. First occurring in the body based on feelings, beliefs, and values (Barton-Caro, 2013). Second embodied in the decision to accept or reject a treatment based on personal risk (Barton-Caro, 2013). The concept of embodied revelation had a good fit with the current study due to the similarities between study populations. In both studies participants held a diagnosis of a chronic condition and faced life altering decisions regarding treatment. Participants willing to accept treatment reported an awareness of osteoporosis by saying such things as "I know my bones are weak", "I am now aware of it" and "my life is slower and more cautious." Some even reported the initiation of treatment, "I am getting treatment to help prevent other broken bones." The decision to accept treatment and a new life with osteoporosis is quick in stage three for participants. Most have had sufficient time to experience life with fracture and are willing to do what they can to reduce the risk for future fracture. Such problems as pain, decreased mobility and a fear of falling were discussed by most participants' post-fracture. "It is a lot harder to get around because I am scared to fall. My hip hurts with the weather changes and I still have issues with steps." Another participant when describing the severity of her pain stated, "I just hope that I heal, and I don't have to go through this pain for the rest of my life." 


\section{REFRAMING}

\section{Theoretical Propositions}

The use of a hypothesis is common in research. It is defined as a "tentative assumption made in order to draw out and test logical or empirical consequences" (Merriam-Webster, 2021). Key to this definition is the ability of a hypothesis to be tested. Although this is the most common definition and use of a hypothesis in research, its use in grounded theory differs according to Glaser (1998). Glaser (1998) states that "a substantive theory is an integrated set of tentative hypotheses that account for much of the behavior seen in the substantive area" (p.3). It is the tentative hypotheses that reflect the theoretical relationships between or among concepts. Despite this definition by Glaser (1998) this connection amongst concepts is better stated/defined as a theoretical proposition. A proposition deals strictly with the connection between two concepts for which no laboratory test is available (Clay, 2018). The two major theoretical propositions for this study include:

1. The stage of resting in contentment has the properties of unsuspecting danger, underestimating risk, and looking the other way.

2. The stage of adjustment gradually leads into stage three, reframing.

\section{Summary}

This chapter has presented the new grounded theory of reframing: a grounded theory study of postmenopausal women following osteoporotic fracture. The theory which is grounded in participant interview data explains the process patients go through following osteoporotic fracture and a new diagnosis of osteoporosis. The stages, properties, and critical juncture of the theory were described. Two distinct groups emerged following osteoporotic fracture and the path taken by each was discussed. A summary of the theory, comparisons with existing theory and 


\section{REFRAMING}

literature, limitations of the study and implications for practice and future research will be discussed in chapter five.

\section{Chapter Five: Discussion}

This chapter presents discussion surrounding the new grounded theory of reframing: $a$ grounded theory study of postmenopausal women following osteoporotic fracture. The theory describes the reframing process that some women undergo following osteoporotic fracture and the result of refusing to accept a new diagnosis and way of life. Reframing, as used in the title of this dissertation, is defined by the Oxford English Dictionary (2021) as "to frame again or differently; to provide with a new frame." Previous knowledge of osteoporosis and risk for fracture prior to osteoporotic fracture was limited in all participants. Following fracture participants became aware of the relation of osteoporosis and their current osteoporotic fracture. For most, an enlightenment regarding personal risk resulted in an embodied revelation. This revelation involved an internal interpretation of thoughts and feelings about osteoporosis, its impact on life following fracture and the need to undergo modifications to reduce the risk for future complications. In this way, the revelation provided each participant with a new way to view life with osteoporosis following osteoporotic fracture. Those participants who did not undergo an embodied revelation continue to long for a pre-fracture life due to their inability to accept the new diagnosis, its relation to their current fracture and impact on future life. They stive for a previous life which may no longer be attainable. The investigator addresses the following in this final chapter: 1) a summary of the theory, 2) comparison of theory with extant 


\section{REFRAMING}

theoretical and research literature, 3) implications for clinical practice, 5) implications for nursing education, and 6) implications for nursing research.

\section{Summary of Reframing: A Grounded Theory Study of Postmenopausal Women Following Osteoporotic Fracture}

The theory of reframing: a grounded theory study of postmenopausal women following osteoporotic fracture consists of three stages and one critical juncture. The first stage of resting in contentment occurs prior to osteoporotic fracture. Participants in this stage reported high levels of independence and had varying degrees of pre-existing osteoporosis knowledge. Those participants without previous knowledge of osteoporosis were found to be unsuspecting of the danger of osteoporotic fracture. While other participants with pre-existing knowledge or even a prior diagnosis of osteoporosis were underestimating the risk and looking the other way by deprioritizing the risk for fracture by simply denying its existence despite diagnosis.

The stage of resting in contentment ends abruptly when a participant sustains an osteoporotic fracture. This fracture represents the beginning of the critical juncture, facing the threat. Following fracture participants are forced to face the diagnosis of osteoporosis and its impact on daily life. It is from this point that participants experience not only physical changes related to fracture but also the psychosocial changes required to recover. It is also from this point that participants must start to decide how they are going to handle the new diagnosis and the subsequent changes that will follow.

Following the critical juncture participants enter stage two, the stage of adjustment. During this stage participants are processing what has occurred and begin to decide how they will adapt to a life with osteoporosis. Participants are confronted with potential changes in levels of independence, pain related to fracture, fear about future fracture, and a post-fracture life. 


\section{REFRAMING}

Some participants come to the realization that they are no longer in control of what is happening to them and begin letting go. By letting go participants begin to show that they are approaching acceptance and the need to adapt to a new post-fracture life with modifications. Those participants unable to accept a new life with osteoporosis begin blame shifting. Blame shifting occurs when a participant, despite being diagnosed with osteoporosis, continues to place blame on anything other than the actual cause of the fracture. Diminishing significance is also seen in these participants and is a sub-property of blame shifting. By diminishing the significance osteoporosis has on their current health, participants are hopeful to return to a pre-fracture life without modifications.

The third stage of reframing begins after the impact of osteoporosis and osteoporotic fracture in stage two, becoming accustomed. Due to time spent with fracture in stage two, participants move quickly into either an embodied revelation or continue to long for a prefracture life. The ten participants undergoing an embodied revelation began to view life through a new lens and with a new perspective. They aimed at preventing future fracture through treatment and lifestyle modifications.

The two participants unable to accept the need for a new post-fracture life continued to focus on their pre-fracture life and their inability to attain their previous level of functioning immediately following fracture. This pre-occupation halted progress toward an embodied revelation and resulted in an inability to move forward or backward.

\section{Comparison of Reframing: A Grounded Theory of Study of Postmenopausal Women}

\section{Following Osteoporotic Fracture}

No studies were identified when a review of reframing and its use in patients with osteoporosis or osteoporotic fracture was completed. Further reviews looking into the use of 


\section{REFRAMING}

reframing in nursing resulted in limited applicable articles. The literature review presented in chapter two took place prior to the initiation of data collection or analysis of the present study. As recommended by Glaser (1998) an ongoing review of the literature took place throughout the constant comparative analysis and with each new emerging concept. Following emergence of the new grounded theory of reframing, connections with current theoretical literature were examined. These connections along with the current research on the use of reframing in health care help provide support for the new emerging theory. This section will present a comparison of the new grounded theory reframing: a grounded theory study of postmenopausal women following osteoporotic fracture with the extant literature and will be presented in the following related categories: 1) conceptual/theoretical literature and 2) empirical research literature including the following categories: a) reframing by healthcare providers as an aid in patient care, b) reframing and its use in patients facing stressful or new life altering health issues, c) reframing and its role in coping, and c) reframing as a way to improve nursing care and/or delivery.

\section{Conceptual and theoretical literature}

The new grounded theory, reframing: a grounded theory study of postmenopausal women following osteoporotic fracture will be evaluated for consistencies and inconsistencies with the writings of Alfred Adler, Aaron T. Beck, and Paul Watzlawick, symbolic interactionism, the health belief model, and the theory of embodied revelation by Vera Barton-Caro. The current study found that reframing was a natural process occurring in participants. Despite this finding the literature on reframing as a natural process is limited. Most of the literature in the following review focuses on reframing as a therapeutic tool.

Reframing. Existing literature examining the use of reframing in patients is primarily focused on patients with terminal, chronic, or psychiatric conditions. The use of reframing in 


\section{REFRAMING}

most studies was as a strategy to help patients cope with or understand a medical illness/diagnosis. This understanding not only gave the patient a more realistic idea of what was going on, but also aided in treatment decisions, and the setting of realistic goals. The other use of reframing identified in the review was as a mental process toward change. This use of reframing is like the one discussed in the current theory.

For years reframing has been discussed in the field of psychology as a concept and as part of successful psychotherapy. Such psychologists as Alfred Adler, Aaron T. Beck, and Paul Watzlawick have discussed the concept of reframing and its use in patients to promote change. A brief discussion of the use of reframing by each follows and includes a comparison with the current theory.

Writings of Alfred Adler. One of the earliest uses of reframing in psychology is by Alfred Adler an Austrian medical doctor, psychotherapist, and the founder of the school of individual psychology (“Alfred Adler," 2021). Adler "considered human beings as an individual whole, therefore he called his psychology "Individual Psychology" (Orgler, 1976). He is known for his work in personality development and was one of the first to emphasize the "importance of the social element in the readjustment process of the individual" ("Alfred Adler," 2021).

According to Adler (1972) "to reframe, then, means, to change the conceptual and/or emotional setting or viewpoint in relation to which a situation is experienced and to place it in another frame which fit the "facts" of the same concrete situation equally well or even better, and thereby changes its entire meaning" (p.235). Participants in the current study underwent an embodied revelation toward reframing in hopes to prevent future fractures and/or complications. They aimed at achieving a new normal which was built off their previous description of normal 


\section{REFRAMING}

life. Although a change in perspective took place, life as they saw it was not indefinitely changed it was just modified.

Writings of Aaron T. Beck. Aaron T. Beck also referred to as the "father of cognitive therapy and cognitive behavioral therapy" is an American psychiatrist and professor emeritus at the University of Pennsylvania (“Aaron T. Beck," 2021). His theories focused on the treatment of the clinically depressed and patients with various anxiety disorders (“Aaron T. Beck," 2021). Through his work with depressed patients, Beck developed the key ideas behind cognitive behavioral therapy (CBT). He found that depressed patients experienced streams of negative thoughts, which he referred to as "automatic thoughts" (Beck, 1997, p.277). These "automatic thoughts" which were usually interrelated and focused on negative ideas about oneself, the world, and the future became validated according to Beck (1997) due to the limited amount of time one spent reflecting on them (p.277). He suggested that through CBT patients can use such cognitive processes as introspection, insight, reality testing, and learning to master psychological problems and sharpen discriminations, correct misconceptions, and learn more adaptive attitudes (Beck, 1967, p. 318). It is through such problem-solving techniques that patients can correct “fallacious thinking” per Beck (1967).

The general use of CBT as described by Beck (1967) as a technique to reframe misconceptions or fallacious thinking partially supports the new theory of reframing: a grounded theory study of postmenopausal women following fracture. In the current study participants were found to undergo the process of reframing without interference from the researcher. Reframing was a naturally occurring process that was internally motivated from within the participant and by their need to return to a new post-fracture life aimed at preventing future fractures and/or complications. 


\section{REFRAMING}

The only consistency of CBT with the new theory of reframing involves Beck's (1997) discussion on distorted thinking and its relation to a person's behavior. According to Beck (1997) distorted thinking has a negative effect on a person's behavior. The two participants who were unable to accept the connection between osteoporosis and their current fracture experienced what Beck (1976) would describe as distorted thinking. Due to this pattern of negative thought the two participants placed themselves at increased risk for future fracture and/or complications due to their inability to undergo an embodied revelation toward reframing.

Writings of Paul Watzlawick. Paul Watzlawick was an Austrian-American family therapist, psychologist, communication theorist, and philosopher who focused on the fields of family therapy and general psychotherapy ("Paual Watzlawick," 2021). According to Watzlawick "people create their own suffering in the very act of trying to fix their emotional problems" ("Paul Watzlawick," 2021). Most of his research is focused on communication within family and he well known for his theory on communication, known as the Interactional View (“Paual Watzlawick," 2021).

Reframing according to Watzlawick (1974) operates on the level of metareality where change can take place even when the objective circumstances of a situation are beyond human control. He states that in the most abstract terms, "reframing means changing the emphasis from one class membership of an object to another, equally valid class membership, or, especially, introducing such a new class membership into the conceptualization of all concerned" (Watzlawick, 1974, p.97). Therefore, the process of reframing is "aimed at altering the opinions a person holds" but "does not require the situation itself to change" (Eisendrath, 1986, p.92). This finding is exceptionally valuable when looking at patients with chronic medical conditions or illness, such as osteoporosis, that are unlikely to change. 


\section{REFRAMING}

In keeping with the view of Watzlawick (1974) our experience of the world is based on the categorization of the "objects of our perception into classes" (p.97). Classes are formed by the physical properties of objects and are strengthened by the meaning and value they hold to us (Watzlawick, 1974). Once an object is conceptualized as a member of a given class, "its reality," it is difficult to see it as belonging to another class (Watzlawick, 1974, p.97). Through reframing a new alternative class membership is assigned, making it almost impossible for a former "reality" to be perceived (Watzlawick, 1974). This inability to easily revert to a previous "reality," is what makes reframing an effective technique for change per Watzlawick (1974).

The conceptual use of reframing as discussed by Watzlwick (1974) partially supports the new theory of reframing. In the current study reframing was described as a natural process internally completed by participants following fracture. The use of reframing by Watzlwick (1974) is as a psychological therapy or technique toward change. Participants in the current study described their pre-fracture life as "normal." This classification of life as "normal" is like the categorization of reality described by Watzlawick (1974). During "normal” life participants reported having independence both physically and socially and were free from the limitations of illness or diagnosis. It isn't until osteoporotic fracture that participants begin to see the need for a "new normal" or a "new reality." By reframing, some participants were able to take on a new view of "normal" and reclassify "reality."

The writings by Watzlawick also suggest that the inability of the two participants in the present research to undergo a new classification of normal may be due to what they value in their pre-fracture "normal" life. As stated above, classification of objects is strengthened by what one values and not just the physical properties of the object. Participants unable to accept a "new 


\section{REFRAMING}

normal" may have been unable to re-classify life with osteoporotic fracture due to their values and beliefs regarding "normal" life.

Symbolic interactionism. As previously discussed in chapter one of this dissertation, symbolic interactionism was chosen as the theoretical framework for the study prior to data collection and analysis. Although the founders of classic grounded theory do not subscribe to the use of a particular theoretical framework to underpin their work, connections between the social processes examined and the human interactions involved can be directly linked. According to Glaser (1998) at the most basic level, grounded theory assumptions regarding the social construction of reality and meaning are manmade. This finding is congruent with the assumptions of symbolic interactionism in that what is true and real is what the individual perceives to be real.

While classic grounded theory aims at explaining a social process, symbolic interactionism provides a framework to collect meaningful, contextual data to explain behavior (Charon, 1979). In classic grounded theory researchers collect and analyze data on the premise that common social processes will emerge from human behavior (Glaser, 1979). During the current grounded theory study behavioral patterns were analyzed and the new grounded theory of reframing emerged. This theory will be discussed based on the three premises of symbolic interactionism.

The first premise of symbolic interactionism is that human beings act toward things based on the meanings which these things have for them (Blumer, 1969). This assumption supports the findings of the new grounded theory. Participants made the decision to undergo an embodied revelation toward reframing and a new post-fracture life based on their understanding of their new diagnosis, its relation to their current fracture, and risk for future complications. Those 


\section{REFRAMING}

participants unable to accept or understand the relation of their current osteoporotic fracture and new diagnosis were unable to proceed toward the process of reframing.

According to symbolic interactionism meaning is derived from or arises from social interaction with one's fellows (Blumer, 1969). In the current study some participants described previous discussion about osteoporosis with healthcare providers and friends. Some even reported that based on statements from those providers or friends that they thought they were not at risk for osteoporosis or fracture. One participant reported her willingness toward a new postfracture life was highly motivated by her need to return home to her partner and dog. It was the ability to maintain those relationships that gave her life purpose and meaning. This supports the second premise of symbolic interactionism that meaning is derived or arises from social interaction. Based on this finding and the literature reviewed later in the chapter providers may play a pivotal role in helping patients reframe.

The third premise of symbolic interactionism deals with how individuals handle or deal with meaning. Blumer (1969) states that meaning is handled and modified through an interpretative process. Participants in the current study were diagnosed with osteoporosis based on the mechanism of their current fracture. They received limited information on their new diagnosis and had little to no interaction with the provider regarding this diagnosis immediately following fracture. This lack in interaction with the provider and other members of the healthcare team may have hindered the ability of some participants to find meaning. Participants in the current study persistently attributed meaning in life as coming from social interaction with others and the influence those interactions had on their choices. By assisting patients in the process of reframing providers will not only better inform patients but also provide the social interaction 


\section{REFRAMING}

necessary for a meaningful life. This finding supports the role of the healthcare provider in assisting in reframing.

Health belief model. The health belief model was chosen to compare with reframing: $a$ grounded theory study of postmenopausal women following osteoporotic fracture due to its wide use as a conceptual framework in nursing research and its ability to predict preventive behavior in patients. The Health Belief Model originated in the 1950's and grew out of a set of independent, applied research problems faced by the Public Health Service, which at that time was focused on disease prevention (Rosenstock, 1974). Originally designed to explain and predict responses to therapies by seriously ill patients, the model was initially used by three social psychologists to explain the behaviors of patients with tuberculosis who failed to engage in a free health screening program (Rosenstock, 1966). Perceived personal threat and expected effectiveness of treatment were found to be predictive of patient willingness toward treatment. The health belief model supports the new grounded theory in terms of the model's four basic concepts. A person will act upon 1) perceived susceptibility, 2) perceived severity, 3) perceived benefit, and 4) perceived barriers (Rosenstock, 1974). Perceived susceptibility is manifested in the critical juncture of facing the threat. Perceived severity speaks to the participants understanding of the seriousness of osteoporosis, its relation to their current osteoporotic fracture, and the risk for subsequent fractures. For most participants osteoporotic fracture also served as a "trigger factor" in leading participants to perceive the severity and its link with the new diagnosis and the need for a new post-fracture life. Perceived benefit refers to the belief in the ability of treatment and modifications to prevent future fractures and other complications related to the new diagnosis of osteoporosis. 


\section{REFRAMING}

The current study diverges from the fourth health belief model concept of perceived barriers. Perceived barriers refer to participant opinions regarding potential risks. Barriers to acting in the current study included the perceived loss of independence due to the needed treatment and modifications to prevent future fracture. Fear of potential treatments was not identified by participants in the current study as a barrier toward action. The fear of future fracture served as a motivating factor for most participants and led participants to strive for a new post-fracture life.

Although the health belief model may offer a greater understanding of the decisionmaking process toward health-related decisions and therapies, a decision-making process did not emerge as the main concern of participants. Despite this finding components of the current model may offer a greater understanding of the internal revelation that takes place from within participants, the factors that enable an embodied revelation, and the barriers that could lead to resistance toward change. It is from this revelation that participants begin reframing and move toward a "new normal."

Writings of Vera Barton-Caro. As previously stated, Glaser (1978) proposed that the findings of classic grounded theory serve as the groundwork for future investigations. Since classic grounded theory is based upon patterns of behavior that can be predicted and explained it allows for the data and concepts from other studies that fit to be interwoven into emerging theories. Like Glaser, Peirce wrote that there is a true answer or final conclusion to every question, toward which every person is constantly gravitating (Peirce, 1871). He proposed that the final opinion is independent of all arbitrary and individual thought, therefore everything which is thought to exist in the "final opinion" is real (Perice, 1871). In other words, every piece of scientific evidence adds to what was previously known and moves toward a complete picture 


\section{REFRAMING}

of truth and reality (Perice, 1871). The current study found that participants began reframing after experiencing a revelation which involved an internal realization of the impact of osteoporosis and the decision to accept treatment. This process as described by participants in the current study is the same as the process of embodied revelation discovered by Barton-Caro in 2013.

As previously discussed in chapter four the concept of embodied revelation was a good fit with the current study due to its similarities between study populations. Both studies focused on participants with chronic conditions facing life altering decisions regarding treatment to prevent future complications. In the study by Barton-Caro (2013) participants choose to accept or decline an implantable cardioverter defibrillator (ICD) following a revelation of personal risk and what that risk meant to the participant. The current study adds to the study by Barton-Caro (2013) by describing the process that occurs following the decision-making process toward treatment. Participants in the current study who underwent an embodied revelation began to view life differently and through a new lens through the process of reframing.

\section{Empirical literature}

In the current study participants underwent the process of reframing following an embodied revelation. This process was internal and was highly motivated by the need of participants to attain a new normal post-fracture life. Most of the current literature focuses on the process of reframing as a technique or intervention toward change or coping. The ability of participants in the current study to naturally undergo the process of reframing and its success in offering a new perspective on a new normal provides support for the use of reframing as an effective therapy. 


\section{REFRAMING}

In general, the extant literature supports the emerging theory of reframing and its use in patients facing stressful life altering diagnoses or treatments. The current use of reframing in the literature is as a technique for patients, healthcare providers or family members to cope with or better handle stressful health related issues and/or diagnoses. Despite the use of a variety of descriptive methods and several explanations of the process of reframing, the current literature fails to provide a detailed theoretical explanation of the concept. The grounded theory of reframing: a grounded theory study of postmenopausal women following osteoporotic fracture explains in conceptual terms what is going on in postmenopausal women following osteoporotic fracture when they are confronted with a new diagnosis, the effects of fracture, and the need for a new post-fracture life. A comparative review of the current empirical literature on reframing follows. The review will be broken down into the following categories based on the different uses of reframing in healthcare seen in the literature: 1) reframing by healthcare providers as an aid in patient care, 2) reframing as an intervention or technique, 3) reframing as a way for parents to cope or reframe risk and 4) reframing to improve nursing care and/or delivery.

Reframing by healthcare providers as an aid in patient care. The diagnosis of a new, terminal, or chronic health condition is a stressful time for patients. Much of how this information is processed and received by the patient is dependent on how the healthcare provider delivers the information. The literature surrounding the use of reframing in healthcare providers focuses not only on medical providers such as physicians and nurses but also on those extended members of the healthcare team such as patient advocates, clergy, and social workers. Both articles included in the review focus on the use of reframing as a process of offering detailed medication information on the current medication condition and its prognosis to help aid in 


\section{REFRAMING}

realistic goal setting. It is through this information patients and their family members have the necessary information needed to reframe and adapt to their new condition or illness.

The use of reframing may offer patients a better sense of control during a time of uncertainty. According to Currin-McCullock et al (2018), negative outcomes arise when patients have a limited understanding of prognosis. The authors also suggest that through the communication of disease information, prognosis, and anticipated disease progression medical providers hold a significant power in fostering or depleting hope (Currin-McCulloch et al., 2018). By reframing hope, healthcare providers can enable patients to better understand what is going on and aid in setting realistic goals (Currin-McCulloch et al., 2018). Currin-McCulloch et al. (2018) state that patients gain a "sense of certainty about their illness, control, and hope as they prepare for the future" (p. 804). These findings support the grounded theory of reframing: $a$ grounded theory study of postmenopausal women following osteoporotic fracture and may help explain why participants in the current study initially resisted or continued to resist the need for a new post-fracture life following fracture. Most participants reported little to no prior knowledge on osteoporosis, that coupled with an uncertain prognosis immediately following fracture may have led to the resistance toward a new normal. Some participants in the current study also described a loss of control following fracture. It was from this recognition that most participants were able to let go of their old life and move toward a new normal. Participants in the new grounded theory study were able to gain control over their new life by reframing. By reframing, participants began to view life through a new lens and gain a sense of control by making modifications to prevent future fractures.

Reframing and its use as a strategy to help resolve conflict amongst family members has also been studied. Hopeck and Harrison (2017) look at the use of reframing as a strategy for 


\section{REFRAMING}

nurses, patient advocates, clergy, and social workers to help resolve conflict between family members at the end of a patient's life. The use of a grounded theory method revealed that family conflict can be managed by reframing, refocusing, referring, reconciling, and reflecting. Through the process of reframing, medical terminology is translated in a patient directed fashion to better help with accessibility and understanding of information by family members (Hopeck \& Harrison, 2017). These findings further suggest the importance of the role of the healthcare provider in helping patients to reframe their perspectives of a new diagnosis or illness. They also suggest that the current theory has implications for nursing practice in that in may be useful in developing reframing strategies to better enable patients going through the process. Participants in the current study also reported being offered little to no information on osteoporosis by a healthcare provider prior to fracture. This lack in information on osteoporosis could have been what led to resistance or inability of some participants to adapt and undergo the process of reframing. This finding further suggests implications for nursing practice, which will be discussed further in the section on implications for nursing practice and education.

Through the use reframing terminology, healthcare providers provide patients with a new or more realistic perspective to aid in decision making regarding potentially life threatening health issues. In the study by Monaro et al. (2020) patients faced the possibility of amputation or death from chronic limb-threatening ischemia. Participants either choose to flee and hope for more time by not opting for amputation or confront the certainty of the "end" by making decisions toward amputation (Monaro, et al., 2020). The authors emphasized the importance of reframing terminology to better discuss and approach the topic of amputation and its progression toward the end of limb and life. Some participants initially against amputation once faced with the painful results of chronic limb-threatening ischemia changed their mind and opted for 


\section{REFRAMING}

amputation. Reframing of the conversation to discuss what amputation means in relation to end of life as discussed by Monaro et al. (2020) can help improve patient and family knowledge and decision making. Participants in the current study also faced not only physical pain but the psychosocial impact of osteoporotic fracture. Like the findings by Monaro et al. (2020) these changes led some participants to flee while promoting others toward an embodied revelation to help prevent future fracture.

Reframing as an intervention or technique. Four studies in the review looked at interventions or techniques which involved a component of reframing. The first by Rosenberg et al. (2018) looked at the use of a "Promoting Resilience in Stress Management" (PRISM) intervention to improve targeted coping skills in adolescents and young adults with cancer (p.1). The authors focused on the targeted coping skills of benefit finding, hopeful patterns of thought, and goal setting. Using exercises in stress management and mindfulness, cognitive reframing, and goal setting, participants, were able to make improvements in benefit finding and hopeful thinking. Although PRISM was associated with goal oriented hopeful patterns of thought, no specific changes in goal-setting skills were identified by the authors.

The use of reframing in the PRISM intervention was in the form of cognitive reframing during which participants were asked to re-identify their strengths and accomplishments. This recognition gave participants "a sense of successful determination in meeting past, present, and future goals" which the authors identified as part of the framework of hope (Rosenberg et al., 2018, p.5). Cognitive reframing as used by Rosenberg et al. (2018) differs from the use of reframing in the current study. Participants in the current study are reframing and viewing life through a new lens to help prevent future complications while participants in the study by Rosenberg et al. (2018) are reframing cognitions by drawing on past experiences to gain hope for 


\section{REFRAMING}

the future. The use of reframing by Rosenberg et al. (2018) is as a coping strategy to deal with a difficult or stressful situation, while the use of reframing in the current study is as a mental process toward change. The studies by Wolters et al. (2019) and Ranney et al. (2017) also looked at the use of an intervention or technique with a component of reframing to help participants cope or improve well-being.

Wolters et al. (2019) looked at the use of reframing as an intervention to reframe dysfunctional beliefs in childhood obsessive-compulsive disorder (OCD). Participants received sixteen weekly sessions of cognitive behavioral therapy consisting of exposure plus response prevention (ERP) and cognitive therapy (CT) (Wolters et al., 2019). OCD severity and dysfunctional beliefs were assessed pre-treatment, mid-treatment, post-treatment, and at a 16week follow-up. The authors found that OCD severity statistically predicted changes in dysfunctional beliefs within time intervals but not over time. Therefore, Wolters et al. (2019) were unable to determine if the decrease in dysfunctional beliefs was the actual effect of a decrease in OCD severity.

The use of reframing has also been used as a technique to improve stress levels and overall health. The study by Ranney et al. (2017) compared the effects of three online cognitive reappraisal trainings on well-being. The authors randomly assigned participants to learn positive reframing, self-distancing, or temporal distancing. Participants were instructed to use the techniques when encountering stresses during daily life. All three cognitive reappraisal training protocols were found to decrease negative emotional reactivity during visualization of a stressful event 2 weeks post training and showed a general increase in well-being from baseline when compared to the control group (Ranney et al., 2017). Positive reframing involved finding the 


\section{REFRAMING}

positive in a negative event, learning from the negative event, and determining how to better handle the negative event in the future (Ranney et al., 2017).

Reframing has also been used during motivational interviewing to acknowledge the views of another. Riegel et al. (2016) looked at the effectiveness of a motivational interviewing intervention and its techniques toward changes in self-care in adults with heart failure. The authors found that three techniques, including the one involving reframing and reflection, “stimulated openness to goal setting, positive self-talk, perceived ability to overcome barriers, and change talk" which were all positively linked to self-care (p.283). Reframing in this study involved the reframing of statements by the interviewer/researcher to acknowledge a participant's view on a particular issue (Riegel et al., 2016). This acknowledgement offered new meaning within the context of heart failure self-care and allowed participants to reflect on their perspective (Riegel et al, 2016).

The use of reframing by Riegel et al. (2016) is different than the use of reframing used by Rosenberg et al. (2018), Wolters et al. (2019), and Ranney et al. (2017) which looked at reframing as a technique for coping and altering dysfunctional beliefs. Reframing as used by Riegel et al. (2016) is as a mental process initiated by the interviewer/researcher to help participants provide new meaning to their self-care. This use of reframing is like the one seen in the present study but differs as participants only come to a new meaning of self-care after acknowledgment of the interviewer/researcher on their current views. Participants in the current study begin reframing after undergoing an embodied revelation which is self-induced following the trauma of fracture. The use of reframing by Riegel et al. (2016) offers support for the use of reframing as described by the current study and its use as part of an intervention to help participants view a situation with a new lens or to find a new meaning. 


\section{REFRAMING}

Reframing as a way for parents to cope or reframe risk. Review of the current literature on reframing brings about not only the use of reframing in patients and healthcare providers but also in family members, specifically parents. Two of the studies that looked at the use of reframing in parents saw it as a way to help parents personally cope with a difficult diagnosis or death of a child. In the study by Al-Kandari et al. (2017) the process of positive reframing was described as a naturally occurring process, whereas in the study by Albuquerque et al. (2017) reframing was a learned process or technique for coping with the feelings surrounding the death of a child. The findings of reframing as a naturally occurring process by Al-Kandari et al. (2017) provide support for the new theory of reframing. The study by Brussoni et al. (2018) examined a risk-reframing tool and its effects on mothers' tolerance for, and parenting practices associated with children's risky play. Although the use of reframing in all but one study differs from the use of reframing in the current study, they offer support for the use of reframing as a coping strategy or intervention. It also sheds light on the importance of positive coping following a new or chronic diagnosis for not only the patient but also for involved family members.

The study by Al-Kandari et al. (2017) looked at the use of reframing as a technique to help mothers of children suffering from autism spectrum disorder (ASD). In this study mothers with children with ASD's reported decreased ability to perform social duties and self-care (AlKandari et al., 2017). Participants were given a self-administered questionnaire and three common coping strategies were identified: religion, acceptance, and positive reframing. The use of positive religious coping helped mothers cope with stressful situations and were found to be associated positive psychological outcomes such as emotional well-being, acceptance, and optimism. 


\section{REFRAMING}

Albuquerque et al. (2017) “examined parents' perceptions of positive interpersonal coping processes that helped their relationship after the death of their child" (p.1817). The authors identified three main themes: search for meaning, communication with the partner, and care-in-relation. Within the search of meaning theme partners search for meaning in partners' behaviors and positive reframing of different timings in coping (Albuquerque et al., 2017). Through a positive reframing of different timings in coping partners were better able to deal with the death of a child due to their ability to support one another during difficult times. Also, during this time partners' reframed relationship difficulties as temporary and as a commitment (Albuquerque et al., 2017).

The following authors also proposed the use of a risk-reframing intervention to change parenting behavior in hopes to positively effect childhood development. Brussoni et al. (2018) report that risky play has been found to be associated with positive developmental, physical, and mental health outcomes but despite this information has eroded over the years due to parent fear about risk (Brussoni et al., 2018). The intervention consisted of a risk-reframing digital tool and a risk-reframing in-person workshop. Although the study provided information on the intervention and how the study would take place no actual testing of the intervention was completed. The study by Brussoni et al. (2018) looked at reframing as a mental process but focused specifically on risk-reframing. In the current study participants began to reframe to prevent complications and future fracture. If this intervention is able to effectively increase tolerance for risky play, adding a risk-framing component to an intervention may prove successful in helping participants cope with the adaptations and modifications needed in a new post-fracture life. 


\section{REFRAMING}

Reframing to improve nursing care and/or delivery. The last section of the empirical review addresses reframing and its use in nurses to reframe their own perspectives and how that change can improve nursing care. It offers a greater understanding of reframing and its usefulness and application in all members of the healthcare team. Nurses provide direct patient care and their ability to reframe can directly impact their ability to support a patient through the process of reframing following osteoporotic fracture.

Dobrina et al. (2020) conducted a qualitative descriptive study to look at nurses and their labeling of "difficult patients" in a hospice care setting. The authors sought to answer the following questions: 1) "When do nursing staff label a patient suffering from advanced cancer as "difficult" in a hospice care setting? 2) What are the problems that the nursing staff fact in dealing with them, and 3) What are the specific strategies that nursing staff adopt in their daily practice to overcome issues and improve their relationship with "difficult patients"?" (p.1). Three main themes: "feeling rejected", "feeling uncomfortable with the life story experienced by the patient," and "experiencing the limits of the profession" were identified and strategies to overcome the identified issues emerged (Dobrina et al. 2020, p. 1). One of those strategies included the positive reframing of emotional challenges. The authors state that through positive reframing nurses were able to return to their helpful role and avoid the risk of "raising a wall between themselves and the patients" (p.7).

The use of reframing has also been studied in nursing students. The study conducted by Sun et al. (2019) developed a theory to guide nursing students caring for patients with suicidal tendencies on their psychiatric clinical practicum. The core category that emerged was "changing of mindsets towards caring for suicidal patient's and promotion of suicidal care competencies" (Sun et al, 2019, p. 157). Students reported changing their mindsets through reframing. This 


\section{REFRAMING}

reframing not only offered the nursing students a new way of viewing their patient population but also provided confidence in their ability to care for and communicate with their patient. The use of reframing in this study provides support for the use of reframing as a mental process and provides evidence of the potential increase in confidence and competence reframing can offer.

Reframing has also been reported as an effective technique to overcome professional barriers toward new technology. The study by Debono et al. (2017) looked at identifying “barriers and targeted interventions to enhance nurses' appropriate use of Electronic Medication Management Systems" (EMMS) (p.1). Reframing was identified by the authors as a behavior change technique to help nurses overcome barriers in the social/professional role and identity domain. In this domain the degree to which a behavior aligns with, strengthens, or undermines a person's social or professional role and identity will influence to what degree a person implements it (Debono et al., 2017). This finding is like that of the current study. Participants in the current study were more likely to undergo an embodied revelation toward reframing if it aligned with their current view of life. Those who viewed the necessary modifications and treatments as burdensome tended to be more hesitant toward a new post-fracture life.

\section{Limitations of the Study}

A few limitations to this study have been recognized by the researcher. The first involves the small sample size of 12 participants. Data saturation was met rather quickly during the data collection process despite only two participants rejecting a new post-fracture life. Future research should focus on those women who choose not to go toward treatment and modifications immediately following fracture and how that choice increases their risk for subsequent fractures and complications. Additional studies may want to focus on those women unable to reframe 


\section{REFRAMING}

following osteoporotic fracture to gain a better understanding of their inability to move toward new post-fracture life with treatment and modifications.

In the current study, all but two participants were willing to reframe life after a fracture. This finding may be the results of purposive sampling. Recruitment occurred from one practice in one geographic location. Future studies should examine women from different geographic locations and practices to see if findings are similar. In the current study all but two participants underwent an embodied revelation toward reframing a new post-fracture life. Participants unable to accept the relationship of osteoporosis and their current fracture may have been less likely to participate in the study. Also, they may have had specific factors such as other pre-existing health issues, financial hardships, or other unknown personal issues that may have influenced their choices following fracture.

This researcher is also a clinician, and, in a few cases, participants were current patients of the researcher. Participants were given clear explanations of the researcher's role as both the researcher and clinician. Despite this disclosure, the possibility of bias must be acknowledged. The researcher separated patient care from research by setting up separate appointments for each. At times it was difficult to keep the appointments separate due to questions from participants regarding their current or future care or treatments. Additionally, the use of current or future patients by the researcher also has the potential to cause a Hawthorne-like effect bias. This form of bias involves the modification of responses by participants based on their knowledge that they are being studied (Gillespie, 1991). Although the researcher was unable to identify situations when this occurred, participants could have downplayed the negative aspects of their experience or overestimated their willingness toward a new post-fracture life. 


\section{REFRAMING}

Another limitation of the current study is the use of a very specific population. Participants in the current study resided within the same geographic region, were all females over the age of 65, and had all recently sustained an osteoporotic fracture. The specificity of the population criteria makes the transferability of the results limited. Future research should focus on a broader population to determine if the findings apply to a larger proportion of patients with osteoporosis.

\section{Implications for Research, Nursing Science, and Clinical Practice}

The new grounded theory of reframing: a grounded theory study of postmenopausal women following osteoporotic fracture has potential implications for nursing research, the discipline of nursing, nursing education and clinical practice. Potential implications for each of these areas will be addressed below along with a discussion on how the two major theoretical propositions can structure future research in nursing education and can be applied to clinical practice. The two major theoretical propositions for the current study are: 1) the stage of resting in contentment has the properties of unsuspecting danger, underestimating risk, and looking the other way and 2) the stage of adjustment gradually leads into stage three, reframing.

\section{Nursing research}

The findings of this study provide the framework for future research. As stated above a good, grounded theory lays the groundwork for future research (Glaser, 1978). This groundwork is composed of empirically grounded hypotheses, that serve to correct data and assure the truth of the investigator's interpretation (Glaser, 1978). These empirically grounded hypotheses, also referred to by Glaser (1998) as "tentative hypotheses", also allow for modification as more populations are studied and data gathered. It is from these hypotheses new data and findings emerge and an even deeper understanding of a phenomenon develops. 


\section{REFRAMING}

Review of the current study and literature surrounding the concept of reframing exposed gaps in knowledge regarding its use in women following osteoporotic fracture. Although many studies have investigated treatment preferences for osteoporosis, the values and beliefs of patients diagnosed with chronic illness, and the decision-making process toward treatment during chronic illness, none have mentioned the concept of reframing and its use as a naturally occurring coping strategy or cognitive process toward change. Future research should further investigate the role of reframing in the decision-making process following diagnosis of a chronic illness or life altering medical event. A greater understanding of this connection can better help researchers develop interventions specifically designed to aid in coping and adaptation following diagnosis.

The current study found that the main concern of participants following osteoporotic fracture was not the decision-making process toward treatment, but rather a longing to return to a time prior to osteoporosis and fracture during which participants reported higher levels of independence and freedom. Participants stressed the importance of autonomy, independence, and maintaining family and social roles following fracture. These findings were similar to the literature reviewed in chapter two which also mentioned the importance of independence and maintaining social roles. Despite these similarities, many women continue to remain untreated for osteoporosis following diagnosis or fracture. This finding may be due to the lack of current research, interventions and literature on the cognitive process following diagnosis or fracture prior to the actual need for decision-making. The current study found that participants were better able to adapt and make changes based on their new diagnosis and fracture only after reframing their new post-fracture life. Additional research into the cognitive process that occurs following fracture and the development of decision aids including reframing techniques may 


\section{REFRAMING}

help patients make the necessary treatment and lifestyle choices needed for a new post-fracture life. The theory should also be tested on other chronic illness populations since there is little empirical literature on reframing and the health threat experience. Also, future research should examine the use of reframing as a technique to better inform patients of the risks of osteoporosis prior to fracture and other chronic illnesses as a way to enhance preventative care.

\section{The discipline of nursing}

The new grounded theory of reframing: a grounded theory study of postmenopausal women following osteoporotic fracture contributes to the discipline of nursing as described by Newman, Sime, and Corcoran (1991) and Newman (2002). According to Newman et al. (1991) the focus of the discipline of nursing and/or mission of the profession is caring in the human health experience. As Newman (2002) states "caring in the human health experience is a unitary phenomenon, one of undivided wholeness and transformation" (p.8). It is this synthesis of the two concepts that encompasses what it means to be a nurse, not each concept separately. Reframing is a human health experience as described by the women experiencing osteoporotic fracture. The new theory that emerged was grounded in participant experiences and embraced the values, beliefs, and choices communicated with the researcher during the interview process.

Another key concept discussed by Newman (2002) that also emphasizes a unitary dynamic view of wholeness and transformative unfolding is health as expanding consciousness (HEC). One assumption of HEC is that life is a process of expanding consciousness, with consciousness being inclusively connected with the wholeness of the universe (Newman, 2002). As Newman (2002) suggests this premise is "what health is all about (p.8). Health is not simply the absence of disease as suggested by the medical model. By reframing as suggested in the current study participants are better able to "lift the problem out of the symptom" and gain a new 


\section{REFRAMING}

perspective to better handle life post-fracture (Clark, 1977, p.841). This view is congruent with the current focus of the discipline as defined by Newman et al. (1991).

\section{Nursing education}

Much of what was learned in the current study is focused on the unsuspecting and underestimating nature of participants toward a diagnosis of osteoporosis prior to fracture. This finding has significant implications for nursing education. The role of the nurse is that of a patient advocate and educator. These roles require the nurse to be properly educated on not only the diagnosis of osteoporosis but also the challenges that osteoporosis patients face prior to and following diagnosis and fracture. To ensure proper up-to-date information, courses should include lectures by an osteoporosis specialist. These lectures would focus on the pathophysiology of the disease process, the role of the nurse in caring for a patient with osteoporosis with and without osteoporotic fracture, and the importance of preventive care through screening to prevent future complications. Through increased knowledge nursing students can become empowered to advocate for their patients and preventative care. It can also provide them the needed resources to better inform the population, future employers, and colleagues on osteoporosis and its potential risks.

Along with introducing a more thorough curriculum into nursing programs, schools of nursing can also begin to educate students on the use of techniques such as reframing. A better understanding of the role of the nurse in reframing, its ability to help patients cope, and its use as an intervention in osteoporosis care can help students provide a more holistic approach to osteoporosis care. It can also serve as a building block for those students pursuing advanced degrees who will later be tasked with screening, diagnosing, and treating osteoporosis. 


\section{REFRAMING}

\section{Clinical practice}

The new grounded theory of reframing holds implications for clinical practice. This section will include the ramifications for both, nurses, and physicians since both are essential in providing comprehensive osteoporosis care which addresses the physical and psychosocial impact of the disease process and its potential complications. Most of the participants in the current study reported unsuspecting or underestimating the impact of osteoporosis and its complications. To help increase patient awareness, providers can initiate public health programs. These programs would focus on describing in a patient friendly way what osteoporosis is, what the diagnosis means, the potential risks, and available treatment options. These programs would increase patient knowledge and awareness of osteoporosis. They would also supply patients with the needed information to initiate a conversation with their providers about the need for osteoporosis screening and care.

Providers can also increase awareness of osteoporosis through public service announcements and support groups. Announcements and support groups would provide patients with real life experiences as described by women with osteoporosis and osteoporotic fracture. They would offer firsthand information on life after a fracture and ways to avoid suffering the same fate. They could also offer information on the available treatment options and patient experiences with those medications. By increasing patient awareness and education healthcare providers supply patients with the necessary tools to make informed decisions regarding their osteoporosis care.

Providers are also tasked with the need to raise the awareness of policy makers on osteoporosis. It is these policy makers who can increase the availability of osteoporosis screening programs and coverage for treatment. Since many patients with osteoporosis are over the age of 


\section{REFRAMING}

65 and have government issued insurance, the need to involve legislation to improve coverage is essential in providing quality care. As discussed in chapter one, the indirect and direct costs following osteoporotic fracture are significant. By increasing the availability of screening and treatment for those with government issued insurance, the government could potentially decrease its overall costs of osteoporosis. Although much of the discussion so far has focused on prevention of osteoporotic fracture through increased awareness, education, and preventative screening the results of the current study also show the importance of reframing following fracture to gain a new perspective on a new post-fracture life.

Both nurses and physicians need to be aware of the role reframing plays in the process toward a new post-fracture life. They need to be well versed in the techniques of reframing, the way they can help patients through the reframing process, and the consequences of not being able to reframe. Providers should also be aware of their own ability to reframe osteoporosis by better explaining the disease process and potential treatments. Although the participants in the current study described the process of reframing as one occurring naturally, the use of an intervention or decision aid with a reframing technique may better help patients unable to initiate the process on their own envision a "new" normal.

\section{Conclusion}

\section{Reframing: a grounded theory study of postmenopausal women following osteoporotic}

fracture represents a new substantive theory that explains what is going on following osteoporotic fracture in women aged 65 and older. Participants expressed the need to return to a new normal following osteoporotic fracture and this was achieved through the process of reframing. The new theory consists of three stages, two of which occur following the critical juncture during which fracture occurs. Following fracture participants either undergo an 


\section{REFRAMING}

embodied revelation toward reframing a "new" post-fracture life or continue to long for a prefracture life. Two participants expressed their inability to accept a new normal and were stuck in a holding pattern with increased risk for subsequent fracture and/or complications. The new theory adds to the current body of knowledge of osteoporosis and fills the gap on what is going on following osteoporotic fracture in women aged 65 and older. Given the use of classic grounded theory methodology the current study serves as the framework for ongoing study. The theory holds implications for research, the discipline of nursing, and clinical practice. 


\section{REFRAMING}

\section{References}

Aaron T. Beck. (2021, February 15). In Wikipedia.

https://en.wikipedia.org/wiki/Aaron_T._Beck\#cite_note-past_and_future-22.

Adler, A. (1972). The practice and theory of individual psychology. New York: Harcourt, Brace.

Al-Kandari, S., Alsalem, A., Abohaimed, S., Al-Orf, F., Al-Zoubi, M, Al-Sabah, R., \& Shah, N. (2017). Brief report: Social support and coping strategies of mothers of children suffering from ASD in Kuwait. J Austism Dev Disord, 47, 3311-3319.

Albuquerque, S., Ferreira, L.C., Narcisco, I., \& Pereira, M. (2017). Parents’ positive interpersonal coping after a child's death. Journal of Child and Family Studies, 26, $1817-1830$.

Alfred Adler. (2021, February 15). In Wikipedia. https://en.wikipedia.org/wiki/Alfred_Adler. Allen, D., Badro, V., Denyer-Willis, L., Macdonald, M.E., Pare, A., Hutchinson, T., Barre, P., Beauchemin, R., Bocti, H., Broadbent, A., \& Cohen, S.R. (2015). Fragmented care and whole-person illness: Decision-making for people with chronic end-stage kidney disease. Chronic Illness, 11(1), 44-55.

Anderson-Wurf, J., Harding, C., \& Seal, A. (2018). Increasing the knowledge, identification and treatment of osteoporosis through education and shared decision-making with residents living in a retirement village community. Australasian Journal of Ageing, 37(1), E17E22. 


\section{REFRAMING}

Baheiraei, A., Ritchie, J.E., Eisman, J.A., \& Nguyen, T.V. (2006). Exploring factors influencing osteoporosis prevention and control: A qualitative study of Iranian men and women in Australia. Maturitas, 54(1), 127-134.

Barton-Caro, V. (2013). Embodied revelation: The threat of sudden cardiac death for implantable cardioverter defibrillator candidates. Graduate Theses, Dissertations, and Problem Reports. 199. http://researchrepository.wvu.edu/etd/199.

Barton-Caro, V. (2015). Embodied revelation: A classic grounded theory of heart failure decision making surrounding primary prevention implantable cardioverter defibrillator therapy. Grounded Theory Review an International Journal, 2(1), 1-17.

Beck, A.T. (1967). Cognitive therapy and the emotional disorders. Penguin Group.

Beck, A.T. (1997). The past and future of cognitive therapy. The Journal of Psychotherapy Practice and Research, 6(4), 276-284.

Billington, E.O., Feasael, A.L., \& Kline, G.A. (2019). At odds about the odds: Women’s Choices to accept osteoporosis medications do not closely agree with physician-set Treatment thresholds. Journal of General Internal Medicine, 35(1), 276-282.

Blumer, H. (1969). Symbolic interactionism: perspective and method. Englewood Cliffs, NJ: Prentice-Hall.

Boudreau, D.M., Yu, O., Balasubramanian, A., Wirtz, H., Grauer, A., Crittenden, D.B., \& Scholes, D. (2017). A survey of women's awareness of and reasons for lack of postfracture osteoporotic care. Journal of the American Geriatrics Society, 65, 1829-1835.

Brussoni, M., Ishikawa, T., Han, C., Pike, I., Bundy, A., Faulkner, G., \& Masse, L.C. (2018). Go play outside! Effects of a risk-reframing tool on mothers' tolerance for, and parenting 


\section{REFRAMING}

practices associated with, children's risky play: Study protocol for a randomized controlled trial. Trials, 19(173), 1-9.

Cauley, J.A. (2013). Public health impact of osteoporosis. Journals of Gerontology, 68(10), 1243-1251.

Chang, H.A., Wallis, M., Tiralongo, E., \& Wang, H.L. (2012). Decision-making related to complementary and alternative medicine use by people with type 2 diabetes: A qualitative study. Journal of Clinical Nursing, 21, 3205-3215.

Charmaz, K. (1989). Discovering chronic illness: Using grounded theory. Social Science and Medicine, 30, 1161-1172.

Clark, C.C. (1977). Reframing. American Journal of Nursing, 1, 840-841.

Clay, C. (2021, February 16). Difference between Proposition \& Hypothesis. Sciencing.com. Retrieved from https://sciencing.com/difference-between-proposition-hypothesis-

\section{$\underline{12749814 . h t m l}$.}

Cornelissen, D., Boonen, A., Bours, S., Evers, S., Dirksen, C., \& Hilligsmann, M. (2019). Understanding patients preferences for osteoporosis treatment: The Impact of pateints' characteristics on subgroups and latent classes. Osteoporosis International, 31, 85-96.

Currin-McCulloch, J., Lippe, M., Acker, K., \& Jones, B. (2018). Communicating terminal prognosis: The provider's role in reframing hope. Palliative and Supportive Care, 16, 803-805.

Danila, M.I., Outman, R.C., Rahn, E.J., Mudano, A.S., Redden, D.T., Li, P., Allison, J.J., Anderson, F.A., Wyman, A., Greenspan, S.L., LaCroix, A.Z., Nieves, J.W., Silverman, S.L., Siris, E.S., Watts, N.B., Miller, M.J., Curtis, J.R., Warriner, A.H., Wright, N.C., \& Saag, K.G. (2018). Journal of Bone and Mineral Research, 33(5), 763-772. 


\section{REFRAMING}

Debono, D., Taylor, N., Lipworth, W., Greenfield, D., Travaglia, J., Black, D., \& Braithwaite, J. (2017). Applying the theoretical domains framework to identify barriers and targeted interventions to enhance nurses' use of electronic medication management systems in two Australian hospitals. Implementation Science, 12(42), 1-13.

Dempster, D.W. (2011). Osteoporosis and the burden of osteoporosis-related fractures. American Journal of Managed Care, 17(6), S164-S169.

Dobrina, R., Chialchia, S., \& Palese, A. (2020). "Difficult patients" in the advanced stages of cancer as experienced by nursing staff: A descriptive qualitative study. European Journal of Oncology Nursing, 46, 1-7.

Duvall, K. (2001). Advances in the prevention and management of osteoporosis. Special Series: Preventive Medicine, 23(13), 19-25.

Fisher, J.D., \& Fisher, W.A. (1992). Changing AIDS-risk behavior. Psychological Bulletin, 111(3), 455-474.

Forstein, D.A., Bernardini, C., Raymond, C.E., Harris, S.T., \& Singer, A. (2013). Before the breaking point: Reducing the risk of osteoporotic fracture. The Journal of the American Osteopathic Association, 113(2), S5-S24.

Glaser B. (1978). Theoretical sensitivity. Mill Valley, CA: Sociology Press.

Glaser, B. (1992). Basics of grounded theory analysis: Emergence vs forcing. Mill Valley, CA: Sociology Press.

Glaser, B.G. (1998). Doing grounded theory. Mill Valley, CA: Sociology Press.

Glaser, B.G. (2002). Conceptualization: On theory and theorizing using grounded theory. International Journal of Qualitative Methods, 1(2), 1-31.

Glaser, B., \& Strauss, A. (1967). The discovery of grounded theory. New York: Aldine 


\section{REFRAMING}

Publishing Company.

Gold, D.T. (1996). The clinical impact of vertebral fractures: Quality of life in women with osteoporosis. Bone, 18(3), S185-S189.

Gold, D.T., Lyles, K.W., Shipp, K.M., \& Drezner, M.K. (2001). Chapter 61-Osteoporosis and its nonskeletal consequences: The impact on treatment decisions. In Osteoporosis (Second Edition), Academic Press, 479-484.

Guba, E.G., \& Lincoln, Y.S. (1994). Competing paradigms in qualitative research. In N.K. Denzin \& Y.S. Lincoln (Eds.), Handbook of qualitative research (pp.105-117). Thousand Oaks, CA: Sage.

Hansen, C., Konradsen, H., Abrahamsen, B., \& Pedersen, B.D. (2014). Women's experiences of their osteoporosis diagnosis at the time of diagnosis and 6 months later: A phenomenological hermeneutic study. International Journal of Qualitative Studies on Health and Well-Being, 9, 1-10.

Harwood, L., \& Clark, A.M. (2014). Dialysis modality decision-making for older adults with chronic kidney disease. Journal of Clinical Nursing, 23, 3378-3390.

Hiligsmann, M., Dellaert, B.G., Dirksen, C.D., Watson, V., Bours, S., Goemaere, S., Reginster, J.Y., Roux, C., McGowan, B., Silke, C., Whelan, B., Diez-Perez, A., Torres, E., Papadakis, G., Rizzoli, R., Cooper, C., Pearson, G., \& Boonen, A. (2017). Patients' preferences for anti-osteoporosis drug treatment: A cross-European discrete choice experiment. Rheumatology, 56, 1167-1176.

Hopeck, P., \& Harrison, T.R. (2017). Reframing, refocusing, referring, reconciling, and reflecting: Exploring conflict resolution strategies in end-of-life situations. Health Communications, 32(2), 240-246. 


\section{REFRAMING}

Hussein, M.E., Hirst, S., Salyers, V., \& Osuji, J. (2014). Using grounded theory as a method of inquiry: Advantages and disadvantages. The Qualitative Report, 19(27), 1-15.

Hypothesis. (2021). In Merriam-Webster.com dictionary. Retrieved from https://www.merriam-webster.com/dictionary/hypothesis.

Jensen, A.L., Lomborg, K., Langdahl, B.L., \& Wind, G. (2016). Managing a bone healthy lifestyle after attending a multifaceted group education. Calcified Tissue International, 99(3), 272-281.

Jeray, K.J. (2015). Osteoporosis and fragility fractures. The Journal of Bone and Joint Surgery, 97-A(19), 1553-1554.

Johansson, H., Siggeirsdottir, K., Harvey, N.C., Oden, A., Gudnason, V., McCloskey, E., Sigurdsson, G., \& Kanis, J.A. (2017). Imminent risk of fracture after fracture. Osteoporosis International, 28(3), 775-780.

Jones, A.S.K., Fernandez, J., Grey, A., \& Petrie, K.J. (2017). The impact of 3-D models versus animations on perceptions of osteoporosis and treatment motivation: A randomized trial. Annals Behavioral Medicine, 51, 899-911.

Kerr, C., Bottomley, C., Shingler, S., Giangregoria, L., De Freitas, H.M., Patel, C., Randall, S., \& Gold, D.T. (2017). The importance of physical function to people with osteoporosis. Osteoporosis Int., 28, 1597-1607.

Kumano, H. (2005). Osteoporosis and stress. Clinical Calcium, 15(9), 1544-1547.

Lincoln, Y., \& Guba, E. (1985). Naturalistic inquiry. London: SAGE.

Liu, R., Chao, A., Wang, K.E., \& Wu, J. (2018). Incidence and risk factors of medical complications and direct medical costs after osteoporotic fracture among patients in China. Archives of Osteoporosis, 13(12), 1-11. 


\section{REFRAMING}

Lopez-Olivo, M.A., Ingleshwar, A., Volk, R.J., Jibaja-Weiss, M., Barbo, A., Saag, K., Leong, A., \& Suarez-Almazor, M.E. (2018). Development and pilot testing of multimedia patient education tools for patients with knee osteoarthritis, osteoporosis, and rheumatoid arthritis. Arthritis Care \& Research, 70(2), 213-220.

Lowey, S.E., Norton, S.A., Quinn, J.R., \& Quill, T.E. (2013). Living with advanced heart failure or COPD: Experiences and goals of individuals nearing the end of life. Research in Nursing \& Health, 36, 349-358.

Martin, V.B., \& Gynnild, A. (Eds.). (2011). Grounded theory-the philosophy, method, and work of Barney Glaser. Boca Raton, FL: Brown Walker Press.

Mittelmark, M.B., \& Bauer, G.F. (2017). The meanings of salutogenesis. The Handbook of Salutogenesis, 2,7-13. doi: 10.1007/978-3-319-04600-6_2.

Monaro, S., West, S., \& Gullick, J. (2020). Chronic limb-threatening ischaemia and reframing the meaning of "end". Journal of Clinical Nursing, 00, 1-14.

Morton, R.L., Snelling, P., Webster, A.C., Rose, J., Masterson, R., Johnson, D.W, \& Howard, K. Factors influencing patient choice of dialysis versus conservative care to treat end-stage kidney disease. Canadian Medical Association Journal, 184(5), E277-283.

Nathaniel, A. (2019). How classic grounded theorists teach the method. Grounded Theory Review, 18(1), 13-28.

Nielsen, D., Huniche, L., Brixen, K., Sahota, O., \& Masud, T. (2013). Scandinavian Journal of Caring Sciences, 27, 516-524.

Nielsen, D.S., Brixen, K., \& Huniche, L. (2011). Men's experiences of living with osteoporosis: Focus group interviews. American Journal of Men's Health, 5(2), 166-176.

Nuti, R., Caffarelli, C., Guglielmi, G., Gennari, L., \& Gonnelli, S. (2014). Undiagnosed vertebral 


\section{REFRAMING}

fractures influence quality of life in postmenopausal women with reduced ultrasound parameters. Clinical Orthopaedics and Related Research, 472, 2254-2261.

Olsen, C.F., \& Bergland, A. (2014). The effect of exercise and education on fear of falling in elderly women with osteoporosis and a history of vertebral fracture: Results of a randomized controlled trial. Osteoporosis International, 25, 2017-2025.

Orgler, H. (1976). Alfred Adler. International Journal of Social Psychiatry, 22(1), 67-68.

Paul Watzlawick. (2021, February 15). In Wikipedia

https://en.wikipedia.org/wiki/Paul_Watzlawick.

Pawson, R., \& Tilley, N. (1997). Realistic Evaluation. Sage Publications, London.

Peirce, C.S. (1871). Fraser's The Works of George Berkeley: A critical review by Charles Peirce. North American Review, 449-472.

Petty, N.J., Thomson, O.P., \& Stew, G. (2012). Ready for a paradigm shift? Part 2: Introducing qualitative research methodologies and methods. Manual Therapy, 17(5), 378-384.

Polit, D., \& Beck, T.B. (2010). Generalization in quantitative and qualitative research: Myths and strategies. International Journal of Nursing Studies, 47, 1451-1458.

Pfister, A.K., Sale, W.G., \& Shaukat, S. (2009). The economics of fragility fractures in West Virginia. West Virginia Medical Journal, 105, 10-13.

Qaseem, A., Forciea, M.A., McLean, R.M., \& Denberg, T.D. (2017). Treatment of low bone density or osteoporosis to prevent fractures in men and women: A clinical practice guideline update from the American College of Physicians. Annals of Internal Medicine $166,818-839$.

Ranney, R.M., Bruehlman-Senecal, E., \& Ayduk, O. (2017). Comparing the effects of three online cognitive reappraisal trainings on well-being. J Happiness Stud, 18, 1319-1338. 


\section{REFRAMING}

Reframing. (2021). In Oxford English.com dictionary. Retrieved from https://www-oedcom.wvu.idm.oclc.org/view/Entry/161064?redirectedFrom=reframing\#eid26157622.

Ricoeur, P. (1973). The hermeneutical function of distanciation. Philosophy Today, 17, 129-141.

Riegel, B., Dickson, V.V., \& Creber, R.M. (2016). Mechanisms of change in self-care in adults with heart failure receiving a tailored, motivational interviewing intervention. Patient Education and Counseling, 100(2017), 283-288.

Roberto, K.A., \& Reynolds, S.G. (2001). The meaning of osteoporosis in the lives of rural older women. Health Care for Women International, 22:599-611, 599-611.

Rosenstock, I.M. (1966). Why people use health services. Millbank Memorial Fund Quarterly, 44(3), 99-127.

Rosenstock, I.M. (1974). Historical origins of the health belief model. Health Education Monographs, 2(4), 328-335.

Salgo, P., Gill, C., Singer, A., \& Olerginski, T. (2019, June 6). An introduction of a new class of bone health episode 3: Economic burden of osteoporosis [Panel discussion video]. American Journal Managed Care. http://www.ajmc.com/view/treatment-of-bone-

\section{health? seriesVideo $=3$.}

Schwandt, T.A. (2007). The Sage dictionary of qualitative inquiry ( $3^{\text {rd }}$ ed.). Urbana, IL: Sage.

Shuler, F.D., \& Conjeski, J. (2011). Defining bone health and fracture risk in West Virginia: The world health organization FRAX assessment tool. West Virginia Medical Journal, 107, $12-17$.

Shuler, F.D., Scott, K., Wilson-Byrne, T., Morgan, L., \& Olajide, O.M. (2016). Improving rural bone health and minimizing fracture risk in West Virginia: Validation of the World Health Organization FRAX Assessment Tool as a phone survey for osteoporosis 


\section{REFRAMING}

detection. West Virginia Medical Journal, 112(3), 84-88.

Simmons, O. (2020). Experiencing Grounded Theory. Unpublished manuscript.

Smallwood, A.J., Schapira, M.M., Fedders, M., \& Neuner, J.M. (2017). A pilot randomized controlled trial of a decision aid with tailored fracture risk tool delivered via a patient portal. Osteoporosis International, 28, 567-576.

Stake, R. (1995). The art of case study research. Thousand Oakes CA: Sage.

Sun, F.K., Long, A., Chiang, C.Y., \& Chou, M.H. (2019). A theory to guide nursing students caring for patients with suicidal tendencies on psychiatric clinical practicum. Nurse Education in Practice, 38, 157-163.

Tufford, L., \& Newman, P. (2010). Bracketing in qualitative research. Qualitative Social Work, $0(0), 1-17$.

United States Census Bureau. (2019, September 10). Quick facts West Virginia. https://www.census.gov/quickfacts/fact/table/WV/PST045219.

Watzlawick, P. The gentle art of reframing. In Watzlawick, P., Weaknland, J., \& Fisch, R. (Eds.), Change-Principles of problem formation and problem resolution. New York: Norton, 1974.

Weycker, D., Li, X., Barron, R., Bornheimer, R., \& Chandler, D. (2016). Hospitalizations for osteoporosis-related fractures: Economic costs and clinical outcomes. Bone Reports, 5, 186-191.

Wilson, H.S., \& Hutchinson, S.A. (1996). Methodological mistakes in grounded theory. Nursing Research, 45, 122-124.

Wolters, L.H., Prins, P.J.M., Garst, G.J.A., Hogendoorn, S.M., Boer, F., Vervoort, L., \& De Hann, E. (2019). Mediating mechanisms in cognitive behavioral therapy for 


\section{REFRAMING}

childhood OCD: The role of dysfunctional beliefs. Child Psychiatry \& Human

Development, 50, 173-185.

Wozniak, L.A., Johnson, J.A., McAlister, F.A., Beaupre, L.A., Bellerose, D., Rowe, B.H., \& Majumdar, S.R. (2017). Understanding fragility fracture patients' decision-making process regarding bisphosphonate treatment. Osteoporosis International, 28, 219-229. 


\section{Appendix A}

Table 1

Literature Review: Living with Osteoporosis.

\begin{tabular}{|c|c|c|c|c|c|c|}
\hline Year & $\begin{array}{c}\text { Journal/ } \\
\text { author('s) }\end{array}$ & Title & $\begin{array}{l}\text { Research } \\
\text { question }\end{array}$ & Method & Participants & Findings \\
\hline 2001 & $\begin{array}{l}\text { Health Care } \\
\text { for Women } \\
\text { International } \\
\text { Roberto, } \\
\text { K.A. \& } \\
\text { Reynolds, } \\
\text { S.G. }\end{array}$ & $\begin{array}{l}\text { The meaning of } \\
\text { osteoporosis in the } \\
\text { lives of rural older } \\
\text { women }\end{array}$ & $\begin{array}{l}\text { What are the } \\
\text { functional and } \\
\text { psychosocial } \\
\text { consequences of } \\
\text { living with } \\
\text { osteoporosis? }\end{array}$ & $\begin{array}{l}\text { Qualitative } \\
\text { focus groups }\end{array}$ & $\begin{array}{l}21 \text { women } \\
\text { from } \\
\text { southwest } \\
\text { Virginia with } \\
\text { a diagnosis } \\
\text { of } \\
\text { osteoporosis }\end{array}$ & $\begin{array}{l}\text { Five major categories of } \\
\text { responses emerged: } \\
\text { identifying and diagnosing } \\
\text { osteoporosis, changes the } \\
\text { women made in their daily } \\
\text { activities, concerns and } \\
\text { challenges facing the women, } \\
\text { interventions used by the } \\
\text { women to manage their } \\
\text { osteoporosis, and advice from } \\
\text { other women with } \\
\text { osteoporosis. The importance } \\
\text { of maintaining one's } \\
\text { independence and autonomy } \\
\text { was reiterated throughout. }\end{array}$ \\
\hline 2006 & $\begin{array}{l}\text { Maturitas } \\
\text { Baheiraei, A. } \\
\text { et al. }\end{array}$ & $\begin{array}{l}\text { Exploring factors } \\
\text { influencing } \\
\text { osteoporosis } \\
\text { prevention and } \\
\text { control: A } \\
\text { qualitative study of } \\
\text { Iranian men and } \\
\text { women in } \\
\text { Australia }\end{array}$ & $\begin{array}{l}\text { What is the } \\
\text { influence of } \\
\text { understanding } \\
\text { osteoporosis risk } \\
\text { factors and } \\
\text { barriers on } \\
\text { osteoporosis } \\
\text { prevention and } \\
\text { control? }\end{array}$ & $\begin{array}{l}\text { Qualitative } \\
\text { open-ended } \\
\text { focus groups } \\
\text { semi-structured } \\
\text { interviews } \\
\text { opportunistic } \\
\text { group discussions }\end{array}$ & $\begin{array}{l}\text { Focus group } \\
\text { with } 22 \\
\text { Iranian } \\
\text { women and } 5 \\
\text { Iranian men. } \\
\text { In addition } \\
10 \text { Iranian } \\
\text { women were } \\
\text { involved in } \\
\text { semi- }\end{array}$ & $\begin{array}{l}\text { Textual analysis revealed four } \\
\text { major themes: understanding } \\
\text { of disease, perception of } \\
\text { causes, preventive behaviors, } \\
\text { and obstacles to preventive } \\
\text { actions. Misconceptions about } \\
\text { osteoporosis and its risk } \\
\text { factors adversely influence } \\
\text { osteoporosis prevention and } \\
\text { control. An unexpected } \\
\text { finding was the participants' }\end{array}$ \\
\hline
\end{tabular}




\begin{tabular}{|c|c|c|c|c|c|c|}
\hline & & & & & $\begin{array}{l}\text { structured } \\
\text { interviews. }\end{array}$ & $\begin{array}{l}\text { beliefs that emotional pain } \\
\text { may contribute to depletion of } \\
\text { bone density. }\end{array}$ \\
\hline 2011 & $\begin{array}{l}\text { American } \\
\text { Journal of } \\
\text { Men's Health } \\
\text { Nielsen, D.S. } \\
\text { et al. }\end{array}$ & $\begin{array}{l}\text { Men's experiences } \\
\text { of living with } \\
\text { osteoporosis: } \\
\text { Focus groups } \\
\text { interviews }\end{array}$ & $\begin{array}{l}\text { What are men's } \\
\text { experiences with } \\
\text { osteoporosis? }\end{array}$ & $\begin{array}{l}\text { Qualitative } \\
\text { focus groups } \\
\text { phenomenological }\end{array}$ & $\begin{array}{l}16 \text { men } \\
\text { diagnosed } \\
\text { with } \\
\text { osteoporosis }\end{array}$ & $\begin{array}{l}\text { Men have a broader range of } \\
\text { strategies for handling } \\
\text { osteoporosis than previously } \\
\text { thought Analysis resulted in } \\
\text { four main themes: the } \\
\text { importance of being active, } \\
\text { acting on a need for help, } \\
\text { social context of osteoporosis, } \\
\text { and relations with other } \\
\text { patients and professionals. }\end{array}$ \\
\hline 2013 & $\begin{array}{l}\text { Scandinavian } \\
\text { Journal of } \\
\text { Caring } \\
\text { Sciences } \\
\text { Nielsen, D. } \\
\text { et al. }\end{array}$ & $\begin{array}{l}\text { Handling } \\
\text { knowledge on } \\
\text { osteoporosis: A } \\
\text { qualitative study }\end{array}$ & $\begin{array}{l}\text { What is the } \\
\text { influence of } \\
\text { osteoporosis } \\
\text { information and } \\
\text { knowledge for } \\
\text { handling } \\
\text { osteoporosis in } \\
\text { everyday life? }\end{array}$ & $\begin{array}{l}\text { Semi-structured } \\
\text { individual } \\
\text { interviews } \\
\text { open and active } \\
\text { approach } \\
\text { participant } \\
\text { observation } \\
\text { phenomenological }\end{array}$ & $\begin{array}{l}14 \\
\text { participants } \\
\text { (10 women } \\
\text { and } 4 \text { men) } \\
\text { from two } \\
\text { English } \\
\text { university } \\
\text { hospitals } \\
\text { with } \\
\text { confirmed } \\
\text { osteoporosis } \\
\text { and } 12 \\
\text { participants } \\
\text { (10 women } \\
\text { and } 2 \text { men) } \\
\text { from a } \\
\text { Danish } \\
\text { University } \\
\text { Hospital with }\end{array}$ & $\begin{array}{l}\text { Three main themes emerged } \\
\text { from the condensed meaning } \\
\text { analysis: life conditions } \\
\text { influence the way in which } \\
\text { risk, pain and osteoporosis are } \\
\text { handled, everyday life is } \\
\text { influenced by the way in } \\
\text { which treatment is handled, } \\
\text { and patients' experiences and } \\
\text { relationships are related to } \\
\text { how information on } \\
\text { osteoporosis is handled. The } \\
\text { patients experiencing } \\
\text { emotional difficulty handling } \\
\text { osteoporosis were not those } \\
\text { suffering from severe } \\
\text { osteoporosis and fractures. } \\
\text { Approaches to living with } \\
\text { knowledge of future fracture } \\
\text { risk varied and was based on }\end{array}$ \\
\hline
\end{tabular}




\begin{tabular}{|c|c|c|c|c|c|c|}
\hline & & & & & $\begin{array}{l}\text { confirmed } \\
\text { osteoporosis }\end{array}$ & $\begin{array}{l}\text { the resourcefulness and } \\
\text { experiences of the patient. }\end{array}$ \\
\hline 2014 & $\begin{array}{l}\text { International } \\
\text { Journal of } \\
\text { Qualitative } \\
\text { Studies on } \\
\text { Health and } \\
\text { Well-Being } \\
\text { Hansen, C. et } \\
\text { al. }\end{array}$ & $\begin{array}{l}\text { Women's } \\
\text { experiences of } \\
\text { their osteoporosis } \\
\text { diagnosis at the } \\
\text { time of diagnosis } \\
\text { and } 6 \text { months later: } \\
\text { A } \\
\text { phenomenological } \\
\text { hermeneutic study }\end{array}$ & $\begin{array}{l}\text { What are the } \\
\text { experiences of } \\
\text { women who were } \\
\text { recently } \\
\text { diagnosed with } \\
\text { osteoporosis? }\end{array}$ & $\begin{array}{l}\text { Qualitative } \\
\text { phenomenological } \\
\text { in-depth interviews }\end{array}$ & $\begin{array}{l}15 \text { women } \\
\text { with } \\
\text { confirmed } \\
\text { osteoporosis } \\
\text { (T-score } \\
\text { below }-2.5) \text {, } \\
\text { age } 65+, \text { no } \\
\text { previous } \\
\text { osteoporotic } \\
\text { fracture, at } \\
\text { least one } \\
\text { osteoporosis } \\
\text { risk factor, } \\
\text { and } \\
\text { prescription } \\
\text { of anti- } \\
\text { osteoporotic } \\
\text { treatment. }\end{array}$ & $\begin{array}{l}\text { Three key themes emerged: } \\
\text { being diagnosed, being } \\
\text { prescribed medical treatment, } \\
\text { and being on the path of } \\
\text { learning to live with } \\
\text { osteoporosis. }\end{array}$ \\
\hline
\end{tabular}




\section{Appendix B}

Table 2

Literature Review: Decision-Making and Chronic Illness.

\begin{tabular}{|c|c|c|c|c|c|c|}
\hline Year & $\begin{array}{c}\text { Journal/ } \\
\text { author('s) }\end{array}$ & Title & $\begin{array}{l}\text { Research } \\
\text { question }\end{array}$ & Method & Participants & Findings \\
\hline 2012 & $\begin{array}{l}\text { Journal of } \\
\text { Clinical } \\
\text { Nursing } \\
\text { Chang, H.A. } \\
\text { et al. }\end{array}$ & $\begin{array}{l}\text { Decision-making } \\
\text { related to } \\
\text { complementary } \\
\text { and alternative } \\
\text { medicine use by } \\
\text { people with Type } \\
2 \text { diabetes: A } \\
\text { qualitative study }\end{array}$ & $\begin{array}{l}\text { What is the } \\
\text { decision-making } \\
\text { process related to } \\
\text { CAM } \\
\text { (complementary } \\
\text { and alternative } \\
\text { medicine) use, } \\
\text { reported by } \\
\text { people with type } \\
2 \text { diabetes using } \\
\text { CAM? }\end{array}$ & $\begin{array}{l}\text { An exploratory } \\
\text { study using a } \\
\text { naturalistic design }\end{array}$ & $\begin{array}{l}16 \\
\text { participants } \\
(6 \text { men and } \\
10 \text { women } \\
\text { ranging in } \\
\text { age from } 38 \text { - } \\
71) \text { were } \\
\text { purposively } \\
\text { selected from } \\
\text { diabetes } \\
\text { clinics at } \\
\text { three } \\
\text { hospitals } \\
\text { from } \\
\text { different } \\
\text { regions } \\
\text { within } \\
\text { Taiwan }\end{array}$ & $\begin{array}{l}4 \text { major categories emerged: } \\
\text { recognizing the need for using } \\
\text { CAM, assessing potential } \\
\text { CAM before use, matching } \\
\text { CAM use to personal } \\
\text { philosophy, and ongoing } \\
\text { evaluation of CAM. The } \\
\text { recognition of the need for use } \\
\text { included the need to be in } \\
\text { control, the need to improve } \\
\text { well-being, and the need for } \\
\text { spiritual comfort. Once they } \\
\text { recognized the need } \\
\text { participants required multiple } \\
\text { sources of data to make any } \\
\text { decisions. These decisions } \\
\text { were influenced by two main } \\
\text { subcategories: listening to the } \\
\text { opinion of others and } \\
\text { assessing products. CAM use } \\
\text { was found to be closely related } \\
\text { to personal philosophy and } \\
\text { three subcategories emerged: } \\
\text { belief or skepticism, proactive } \\
\text { involvement in self- } \\
\text { management and critical }\end{array}$ \\
\hline
\end{tabular}




\begin{tabular}{|c|c|c|c|c|c|c|}
\hline & & & & & & $\begin{array}{l}\text { assessment of information. } \\
\text { The pros and cons of CAM } \\
\text { use were evaluated using a } \\
\text { highly individualized process } \\
\text { and the decision to continue or } \\
\text { to cease was made } \\
\text { individually. The choice to } \\
\text { use CAM involved personal } \\
\text { perceptions of the outcomes } \\
\text { rather than opinions of health } \\
\text { professionals. Word-of-mouth } \\
\text { was a common primary source } \\
\text { of CAM information. }\end{array}$ \\
\hline 2012 & $\begin{array}{l}C M A J \\
\text { Morton, R.L. } \\
\text { et al. }\end{array}$ & $\begin{array}{l}\text { Factors } \\
\text { influencing } \\
\text { patient choice of } \\
\text { dialysis versus } \\
\text { conservative care } \\
\text { to treat end-stage } \\
\text { kidney disease }\end{array}$ & $\begin{array}{l}\text { What are the } \\
\text { most important } \\
\text { characteristics of } \\
\text { dialysis and the } \\
\text { trade-offs } \\
\text { patients are } \\
\text { willing to make } \\
\text { in choosing } \\
\text { dialysis instead of } \\
\text { conservative } \\
\text { care? }\end{array}$ & $\begin{array}{l}\text { Discrete choice } \\
\text { experiment. }\end{array}$ & $\begin{array}{l}105 \text { patients } \\
\text { with chronic } \\
\text { kidney } \\
\text { disease } \\
\text { (stages 3-5) } \\
\text { aged } 18 \text { and } \\
\text { older from } 8 \\
\text { Australian } \\
\text { metropolitan } \\
\text { and rural } \\
\text { renal clinics }\end{array}$ & $\begin{array}{l}\text { Factors most strongly } \\
\text { associated with patient } \\
\text { preference for dialysis over } \\
\text { conservative care were } \\
\text { increased life expectancy, the } \\
\text { opportunity to undergo } \\
\text { dialysis during the day or } \\
\text { evening, and the availability of } \\
\text { subsidized transport. Patients } \\
\text { approaching end-stage kidney } \\
\text { disease were willing to trade } \\
\text { considerable life expectancy to } \\
\text { reduce the burden and } \\
\text { restrictions of dialysis. }\end{array}$ \\
\hline 2013 & $\begin{array}{l}\text { Research in } \\
\text { Nursing \& } \\
\text { Health } \\
\text { Lowey, S.E. } \\
\text { et al. }\end{array}$ & $\begin{array}{l}\text { Living with } \\
\text { advanced heart } \\
\text { failure or COPD: } \\
\text { Experiences and } \\
\text { goals of } \\
\text { individuals }\end{array}$ & $\begin{array}{l}\text { Can you tell me } \\
\text { what it is like } \\
\text { living with } \\
\text { advanced heart } \\
\text { failure or COPD? } \\
\text { Have you thought }\end{array}$ & $\begin{array}{l}\text { Qualitative } \\
\text { descriptive } \\
\text { research design. }\end{array}$ & $\begin{array}{l}20 \\
\text { participants } \\
\text { ( } 9 \text { male and } \\
11 \text { female) } \\
\text { with } \\
\text { advanced }\end{array}$ & $\begin{array}{l}\text { Despite conditions considered } \\
\text { life-threatening by clinicians, } \\
\text { participants believed they still } \\
\text { had time. They hoped their } \\
\text { illness would remain stable, } \\
\text { despite specific experiences }\end{array}$ \\
\hline
\end{tabular}




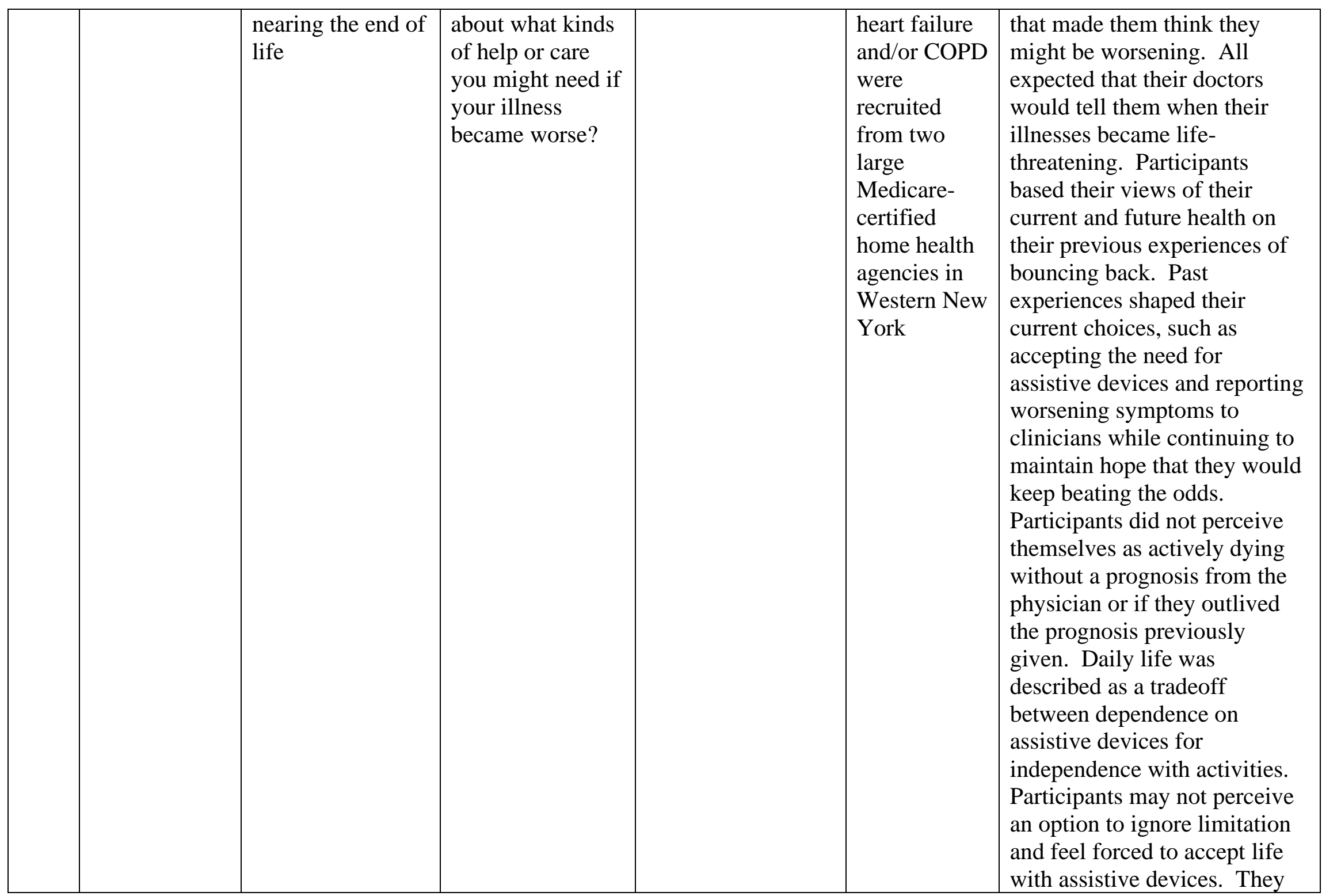




\begin{tabular}{|c|c|c|c|c|c|c|}
\hline & & & & & & $\begin{array}{l}\text { hold onto hope that future } \\
\text { deterioration can be avoided. }\end{array}$ \\
\hline 2014 & $\begin{array}{l}\text { Journal of } \\
\text { Clinical } \\
\text { Nursing } \\
\text { Harwood, L. } \\
\text { \& Clark, } \\
\text { A.M. }\end{array}$ & $\begin{array}{l}\text { Dialysis modality } \\
\text { decision-making } \\
\text { for older adults } \\
\text { with chronic } \\
\text { kidney disease }\end{array}$ & $\begin{array}{l}\text { What are the } \\
\text { personal and } \\
\text { structural barriers } \\
\text { and facilitators } \\
\text { for home-dialysis } \\
\text { decision-making } \\
\text { in older persons } \\
\text { with CKD? }\end{array}$ & $\begin{array}{l}\text { Qualitative } \\
\text { ethnography using } \\
\text { critical realism. }\end{array}$ & $\begin{array}{l}13 \text { people ( } 7 \\
\text { men and } 6 \\
\text { women, aged } \\
65-83 \text { ) who } \\
\text { received care } \\
\text { in a team } \\
\text { chronic } \\
\text { kidney } \\
\text { disease clinic } \\
\text { in Canada }\end{array}$ & $\begin{array}{l}\text { Four themes emerged: } \\
\text { precariousness with limited } \\
\text { choices and uncertainty, } \\
\text { personal factors, gender } \\
\text { differences, and the necessity } \\
\text { of support. Age imposes some } \\
\text { limitations on modality } \\
\text { options and transplantation. } \\
\text { Modality decisions were } \\
\text { influenced by health status, } \\
\text { gender, knowledge, values, } \\
\text { beliefs, past experiences, } \\
\text { preferences, lifestyle and } \\
\text { resources. Support from } \\
\text { family and healthcare } \\
\text { professionals was the largest } \\
\text { determinate to home-dialysis } \\
\text { selection. The social and } \\
\text { contextual factors associated } \\
\text { with age influenced home- } \\
\text { dialysis decision-making. } \\
\text { Adequate social support, } \\
\text { functional status and resources } \\
\text { enabled home-dialysis } \\
\text { selection. }\end{array}$ \\
\hline
\end{tabular}




\begin{tabular}{|c|c|c|c|c|c|c|}
\hline 2015 & $\begin{array}{l}\text { Chronic } \\
\text { Illness } \\
\text { Allen, D. et } \\
\text { al. }\end{array}$ & $\begin{array}{l}\text { Fragmented care } \\
\text { and whole-person } \\
\text { illness: Decision- } \\
\text { making for people } \\
\text { with chronic end- } \\
\text { stage kidney } \\
\text { disease }\end{array}$ & $\begin{array}{l}\text { How do patients } \\
\text { with } \\
\text { multimorbid, } \\
\text { chronic illness- } \\
\text { who receive care } \\
\text { in institutions } \\
\text { designed for } \\
\text { treatment of acute } \\
\text { illness-experience } \\
\text { and engage in } \\
\text { health-related } \\
\text { decisions? }\end{array}$ & $\begin{array}{l}\text { Ethnographic } \\
\text { study. }\end{array}$ & $\begin{array}{l}6 \\
\text { hemodialysis } \\
\text { patients and } \\
11 \text { health } \\
\text { professionals } \\
\text { involved in } \\
\text { their care at } \\
\text { an urban } \\
\text { Canadian } \\
\text { teaching } \\
\text { hospital }\end{array}$ & $\begin{array}{l}\text { Co-morbid ESRD patients; } \\
\text { decision-making is often } \\
\text { striking a balance between a } \\
\text { present known quality of life } \\
\text { and an uncertain future. } \\
\text { Decision-making is fluid } \\
\text { (ruminated on, revisited, } \\
\text { avoided) and cumulative } \\
\text { (referencing past experiences, } \\
\text { the result of several prior } \\
\text { decisions). Patients sought } \\
\text { decision-making support from } \\
\text { a constellation of significant } \\
\text { relationships, suggesting that } \\
\text { decision-making is more a } \\
\text { relationship centered activity } \\
\text { rather than an individual one. } \\
\text { Decision-making blended } \\
\text { together in the larger ongoing } \\
\text { project of integrating illness } \\
\text { into one's current and } \\
\text { anticipated or hoped-fore life. } \\
\text { Distribution of care according } \\
\text { to disease specialty works well } \\
\text { for short-term, acute-care } \\
\text { needs; but when faced with } \\
\text { long-term, multi-morbid } \\
\text { chronic illness this carefully } \\
\text { distributed care becomes } \\
\text { fragmented and inefficient. }\end{array}$ \\
\hline
\end{tabular}




\section{Appendix C}

Table 3

Literature Review: Decision-Making and Osteoporosis.

\begin{tabular}{|c|c|c|c|c|c|c|}
\hline Year & $\begin{array}{l}\text { Journal/ } \\
\text { author('s) }\end{array}$ & Title & $\begin{array}{c}\text { Objective/Research } \\
\text { Question }\end{array}$ & Method & Participants & Findings \\
\hline 2016 & $\begin{array}{l}\text { Calcified } \\
\text { Tissue } \\
\text { International } \\
\text { Jensin, A.L. et } \\
\text { al. }\end{array}$ & $\begin{array}{l}\text { Managing a bone } \\
\text { healthy lifestyle } \\
\text { after attending } \\
\text { multifaceted } \\
\text { group education }\end{array}$ & $\begin{array}{l}\text { Investigated if and } \\
\text { how patients } \\
\text { implemented } \\
\text { knowledge from } \\
\text { attending } \\
\text { multifaceted } \\
\text { osteoporosis group } \\
\text { education in their } \\
\text { daily lives. }\end{array}$ & $\begin{array}{l}\text { Interpretive } \\
\text { description } \\
\text { design using } \\
\text { ethnographic } \\
\text { field work }\end{array}$ & $\begin{array}{l}14 \text { women and } \\
3 \text { men } \\
\text { diagnosed with } \\
\text { osteoporosis } \\
\text { who attended } \\
\text { multifaceted } \\
\text { group } \\
\text { education at a } \\
\text { Danish } \\
\text { hospital }\end{array}$ & $\begin{array}{l}\text { Findings suggest that group } \\
\text { education can support and } \\
\text { influence patients' transfer of } \\
\text { preventive actions. It was also } \\
\text { found to increase attention and } \\
\text { reflection on osteoporosis } \\
\text { preventive actions and activities. } \\
\text { Participants who felt confident } \\
\text { or who were able to make the } \\
\text { preventive activity into a social } \\
\text { event demonstrated an increased } \\
\text { implementation of the preventive } \\
\text { activity. For some participants } \\
\text { attending group education was } \\
\text { not sufficient to overcome social } \\
\text { or physical concerns or to } \\
\text { eliminate uncertainty about } \\
\text { recommendations or a diagnosis } \\
\text { of osteoporosis. Findings suggest } \\
\text { a need for awareness of the role } \\
\text { social roles and physical ability } \\
\text { play in the implementation of } \\
\text { medical recommendations. }\end{array}$ \\
\hline 2017 & $\begin{array}{l}\text { Journal of the } \\
\text { American }\end{array}$ & $\begin{array}{l}\text { A survey of } \\
\text { women's } \\
\text { awareness of and }\end{array}$ & $\begin{array}{l}\text { To identify } \\
\text { women's beliefs } \\
\text { and other factors }\end{array}$ & $\begin{array}{l}\text { Observational } \\
\text { study design } \\
\text { (cross-sectional) }\end{array}$ & $\begin{array}{l}\text { Female Group } \\
\text { Health } \\
\text { Cooperative }\end{array}$ & $\begin{array}{l}\text { Women were at greater risk of } \\
\text { not undergoing OP-RX if they } \\
\text { did not think osteoporosis (OP) }\end{array}$ \\
\hline
\end{tabular}




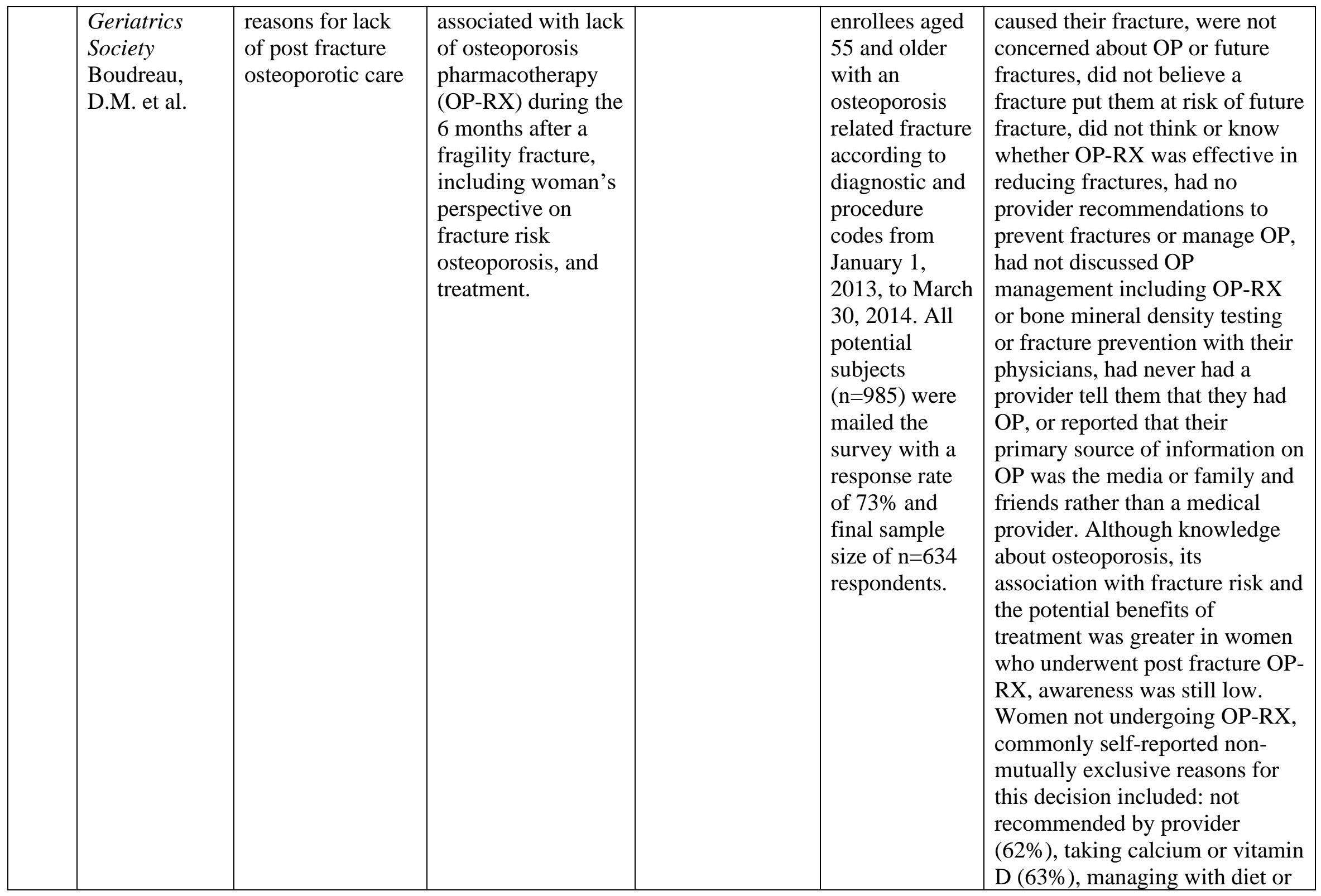




\begin{tabular}{|c|c|c|c|c|c|c|}
\hline & & & & & & $\begin{array}{l}\text { exercise (43\%), not having OP } \\
\text { or not being at high risk of } \\
\text { fracture }(33 \%) \text {, fear of side } \\
\text { effects }(22 \%) \text {, taking too many } \\
\text { other medications ( } 16 \%) \text {, } \\
\text { recommendation to stop }(10 \%) \text {, } \\
\text { and completion of a course }(9 \%) \text {. } \\
\text { Non responders to the } \\
\text { questionnaire ( } \mathrm{n}=232) \text { were } \\
\text { similar in age, but few had } \\
\text { undergone OP-RX before the } \\
\text { fracture (1.3\%) or during the } 6 \\
\text { months following fracture } \\
(6.9 \%) \text {. Distribution of fracture } \\
\text { site varied some but not } \\
\text { substantially from that of } \\
\text { responders. }\end{array}$ \\
\hline
\end{tabular}




\begin{tabular}{|c|c|c|c|c|c|c|}
\hline & & & & & & $\begin{array}{l}\text { significant differences for } 13 \text { out } \\
\text { of } 42 \text { attribute/level interactions. }\end{array}$ \\
\hline 2017 & $\begin{array}{l}\text { Osteoporosis } \\
\text { International } \\
\text { Smallwood, } \\
\text { A.J. et al. }\end{array}$ & $\begin{array}{l}\text { A pilot } \\
\text { randomized } \\
\text { controlled trial of } \\
\text { a decision aid } \\
\text { with tailored } \\
\text { fracture risk tool } \\
\text { delivered via a } \\
\text { patient portal }\end{array}$ & $\begin{array}{l}\text { To determine the } \\
\text { feasibility and } \\
\text { potential efficacy of } \\
\text { a patient portal- } \\
\text { based osteoporosis } \\
\text { decision aid (DA). }\end{array}$ & $\begin{array}{l}\text { Pilot randomized } \\
\text { controlled trial. }\end{array}$ & $\begin{array}{l}\text { Primary care } \\
\text { patients aged } \\
55 \text { and older } \\
\text { who were } \\
\text { enrolled in a } \\
\text { patient portal } \\
\text { and had a T- } \\
\text { score of less } \\
\text { than -1. Total } \\
\text { number of } \\
\text { subjects } \\
\text { meeting } \\
\text { criteria n=50 } \\
\text { with } \\
\text { randomization } \\
\text { and blinded } \\
\text { allocation to } \\
\text { either the } \\
\text { experimental } \\
\text { group which } \\
\text { received the } \\
\text { decision aid or } \\
\text { to the control } \\
\text { group which } \\
\text { was directed to } \\
\text { the National } \\
\text { Institute on } \\
\text { Aging } \\
\text { homepage. }\end{array}$ & $\begin{array}{l}\text { The DA was acceptable to } \\
\text { subjections, but } 17 \% \text { of the } \\
\text { patients in the decision aid arm } \\
\text { incorrectly entered their T-scores } \\
\text { into FRAX-based risk calculator. } \\
\text { Decisional conflict was lower } \\
\text { post-intervention for those who } \\
\text { were randomized to the decision } \\
\text { aid arm compared to controls } \\
\text { (17.8 vs } 47.1, \text { p<.001), and there } \\
\text { was a significant difference in } \\
\text { the percentage of patients who } \\
\text { made a treatment decision at } 3 \\
\text { months. No significant } \\
\text { differences were observed in } \\
\text { medication uptake. }\end{array}$ \\
\hline
\end{tabular}




\begin{tabular}{|c|c|c|c|c|c|c|}
\hline 2017 & $\begin{array}{l}\text { Osteoporosis } \\
\text { International } \\
\text { Wozniak, } \\
\text { L.A. et al. }\end{array}$ & $\begin{array}{l}\text { Understanding } \\
\text { fragility fracture } \\
\text { patients' decision- } \\
\text { making process } \\
\text { regarding } \\
\text { bisphosphonate } \\
\text { treatment }\end{array}$ & $\begin{array}{l}\text { To understand how } \\
\text { older patients with } \\
\text { new fractures } \\
\text { decided to persist } \\
\text { with or stop } \\
\text { osteoporosis (OP) } \\
\text { treatment over } 1 \\
\text { year }\end{array}$ & $\begin{array}{l}\text { Grounded } \\
\text { Theory Study }\end{array}$ & $\begin{array}{l}\text { Conducted } 21 \\
\text { interviews } \\
\text { with } 12 \\
\text { patients }\end{array}$ & $\begin{array}{l}\text { Three major themes emerged: 1) } \\
\text { patients perceived OP was not a } \\
\text { serious health condition and } \\
\text { considered its impact negligible } \\
\text { 2) persisters and stoppers } \\
\text { differed in weighting the risks } \\
\text { versus benefits of treatments, } \\
\text { with persisters perceiving less } \\
\text { risk and more benefit. Persisters } \\
\text { considered treatment as } \\
\text { "required" while stoppers } \\
\text { deemed treatment as "optional" } \\
\text { 3) patients could change } \\
\text { treatment status even 1-year } \\
\text { post-fracture because they re- } \\
\text { evaluated severity and impact of } \\
\text { OP vs risks and benefits of } \\
\text { treatments over time. Findings } \\
\text { suggest that healthcare providers } \\
\text { reinforce the severity, risks, and } \\
\text { arms related to untreated clinical } \\
\text { OP and the favorable benefit-to- } \\
\text { risk profile for OP treatments. }\end{array}$ \\
\hline 2017 & $\begin{array}{l}\text { Annals of } \\
\text { Behavioral } \\
\text { Medicine } \\
\text { Jones, A.S.K. } \\
\text { et al. }\end{array}$ & $\begin{array}{l}\text { The impact of 3- } \\
\text { D models versus } \\
\text { animations on } \\
\text { perceptions of } \\
\text { osteoporosis and } \\
\text { treatment } \\
\text { motivation: A } \\
\text { randomized trial }\end{array}$ & $\begin{array}{l}\text { To investigate } \\
\text { whether physical } \\
\text { models or virtual } \\
\text { animations had a } \\
\text { greater impact on } \\
\text { changing } \\
\text { perceptions of } \\
\text { osteoporosis and } \\
\text { treatment } \\
\text { motivation in an at }\end{array}$ & Randomized trial & $\begin{array}{l}128 \text { women } \\
\text { aged } 50 \text { and } \\
\text { over recruited } \\
\text { from email } \\
\text { advertisements } \\
\text { and flyers } \\
\text { placed around } \\
\text { the University } \\
\text { of Auckland } \\
\text { Research }\end{array}$ & $\begin{array}{l}\text { There were no significant } \\
\text { interaction effects, neither } \\
\text { medium had a greater impact on } \\
\text { beliefs over time. From baseline } \\
\text { to post-presentation, both } \\
\text { mediums increased consequence } \\
\text { beliefs, personal and treatment } \\
\text { control, understanding of } \\
\text { osteoporosis, motivations to take } \\
\text { treatment if needed and }\end{array}$ \\
\hline
\end{tabular}




\begin{tabular}{|c|c|c|c|c|c|c|}
\hline & & & $\begin{array}{l}\text { risk population of } \\
\text { older women }\end{array}$ & & $\begin{array}{l}\text { Clinic and } \\
\text { community } \\
\text { locations } \\
\text { (women's } \\
\text { gyms) }\end{array}$ & $\begin{array}{l}\text { medication necessity beliefs. } \\
\text { Timeline beliefs and medication } \\
\text { concerns decreased over time for } \\
\text { both groups. }\end{array}$ \\
\hline 2018 & $\begin{array}{l}\text { Journal of } \\
\text { Bone and } \\
\text { Mineral } \\
\text { Research } \\
\text { Danila, M.I. } \\
\text { et al. }\end{array}$ & $\begin{array}{l}\text { Evaluation of a } \\
\text { multimodal, } \\
\text { direct-to-patient } \\
\text { educational } \\
\text { intervention } \\
\text { targeting barriers } \\
\text { to osteoporosis } \\
\text { care: A } \\
\text { randomized } \\
\text { clinical trial }\end{array}$ & $\begin{array}{l}\text { A study to } \\
\text { determine if a } \\
\text { multimodal, } \\
\text { patient-centered, } \\
\text { tailored, video } \\
\text { based behavioral } \\
\text { intervention } \\
\text { improves the rate of } \\
\text { osteoporosis } \\
\text { treatment among a } \\
\text { high-risk } \\
\text { population who } \\
\text { previously reported } \\
\text { a fracture but } \\
\text { currently were not } \\
\text { using osteoporosis } \\
\text { therapies. The } \\
\text { primary study } \\
\text { outcome was self- } \\
\text { report of } \\
\text { osteoporosis } \\
\text { medication use at } 6 \\
\text { months. Other } \\
\text { outcomes included } \\
\text { calcium and } \\
\text { vitamin D } \\
\text { supplementation, } \\
\text { bone mineral }\end{array}$ & $\begin{array}{l}\text { Parallel, } \\
\text { controlled, } \\
\text { randomized } \\
\text { clinical trial. }\end{array}$ & $\begin{array}{l}2684 \text { women } \\
\text { with self- } \\
\text { reported } \\
\text { fracture history } \\
\text { after age } 45 \\
\text { years not using } \\
\text { osteoporosis } \\
\text { therapy from } \\
\text { US Global } \\
\text { Longitudinal } \\
\text { Study of } \\
\text { Osteoporosis } \\
\text { in Women } \\
\text { (GLOW) sites } \\
\text { were } \\
\text { randomized } \\
\text { 1:1 to receive a } \\
\text { multimodal, } \\
\text { tailored, } \\
\text { direct-to- } \\
\text { patient, video } \\
\text { intervention } \\
\text { versus usual } \\
\text { care. }\end{array}$ & $\begin{array}{l}\text { In intent-to-treat analyses, there } \\
\text { were no significant differences } \\
\text { between groups (intervention } \\
\text { versus control) in osteoporosis } \\
\text { medication use ( } 11.7 \% \text { versus } \\
11.4 \%, p=0.8) \text {, calcium } \\
\text { supplementation ( } 31.8 \% \text { versus } \\
32.6 \%, p=0.7), \text { vitamin D intake } \\
\text { (41.3\% versus } 41.9 \%, \text { p0.8), or } \\
\text { BMD testing (61.8\% versus } \\
57.1 \%, p=0.2) \text { In the } \\
\text { intervention group, fewer } \\
\text { women were in the } \\
\text { precontemplative stage of } \\
\text { behavior change, more women } \\
\text { reported seeing their primary } \\
\text { care provider, had concerns } \\
\text { regarding osteonecrosis of the } \\
\text { jaw, and difficulty in } \\
\text { taking/remembering to take } \\
\text { osteoporosis medications. } \\
\text { Differences were found in BMD } \\
\text { testing among the subgroup of } \\
\text { women with no prior } \\
\text { osteoporosis treatment, those } \\
\text { who provided contact } \\
\text { information, and those with no } \\
\text { past BMD testing. Women with }\end{array}$ \\
\hline
\end{tabular}




\begin{tabular}{|c|c|c|c|c|c|c|}
\hline & & & $\begin{array}{l}\text { density (BMD) } \\
\text { testing, readiness } \\
\text { for behavioral } \\
\text { change and barriers } \\
\text { to treatment. }\end{array}$ & & & $\begin{array}{l}\text { appreciable exposure to the } \\
\text { online intervention ( } \mathrm{n}=257) \text { were } \\
\text { more likely to start } \\
\text { nonbisphosphonates (OR=2.70; } \\
95 \% \text { CI } 1.26-5.79) \text { when } \\
\text { compared to the usual care } \\
\text { group. Although the intervention } \\
\text { did not increase the use of } \\
\text { osteoporosis therapy at } 6 \\
\text { months, it increased } \\
\text { nonbisphosphonate medication } \\
\text { use and BMD testing in select } \\
\text { subgroups, shifted participants' } \\
\text { readiness for behavior change, } \\
\text { and altered perceptions of barrier } \\
\text { to osteoporosis treatment. }\end{array}$ \\
\hline
\end{tabular}




\begin{tabular}{|c|c|c|c|c|c|c|}
\hline & & & & $\begin{array}{l}\text { fracture risk and } \\
\text { lifestyle factors. }\end{array}$ & & \\
\hline 2018 & $\begin{array}{l}\text { Arthritis Care } \\
\text { \& Research } \\
\text { Lopez-Olivo, } \\
\text { M.A. et al. }\end{array}$ & $\begin{array}{l}\text { Development and } \\
\text { pilot testing of } \\
\text { multimedia } \\
\text { patient education } \\
\text { tools for patients } \\
\text { with knee } \\
\text { osteoarthritis, } \\
\text { osteoporosis, and } \\
\text { rheumatoid } \\
\text { arthritis }\end{array}$ & $\begin{array}{l}\text { Improvement in } \\
\text { disease knowledge } \\
\text { was the primary } \\
\text { outcome with } \\
\text { decision conflict, } \\
\text { disease } \\
\text { management, and } \\
\text { acceptability as the } \\
\text { secondary } \\
\text { outcomes. }\end{array}$ & $\begin{array}{l}\text { Edutainment } \\
\text { model } \\
\text { incorporating } \\
\text { educational } \\
\text { patient story } \\
\text { lines }\end{array}$ & $\begin{array}{l}60 \text { patients, } 20 \\
\text { per disease, } \\
\text { were shown } \\
\text { the tool and } \\
\text { interviewed }\end{array}$ & $\begin{array}{l}\text { Statistically significant } \\
\text { differences in pre-to post- } \\
\text { intervention knowledge } \\
\text { questionnaire scores (OP: } \\
\mathrm{P}=0.01 \text { ). Most participants felt } \\
\text { they gained "clarity" on disease } \\
\text { duration, symptoms, and the } \\
\text { mechanism of onset of } \\
\text { medications. Most patients in all } \\
\text { disease groups found the length } \\
\text { and amount of information } \\
\text { presented to be "just right", and } \\
\text { the presentation to be } \\
\text { "balanced". In terms of } \\
\text { comprehension all participants } \\
\text { provided a favorable evaluation } \\
\text { of the video tool; all found the } \\
\text { video easy to use, the vocabulary } \\
\text { easy to understand, and the } \\
\text { materials to be well organized. }\end{array}$ \\
\hline 2019 & $\begin{array}{l}\text { Journal of } \\
\text { General } \\
\text { Internal } \\
\text { Medicine } \\
\text { Billington, } \\
\text { E.O. et al. }\end{array}$ & $\begin{array}{l}\text { At odds about the } \\
\text { odds: Women's } \\
\text { choices to accept } \\
\text { osteoporosis } \\
\text { medications do } \\
\text { not closely agree } \\
\text { with physician-set } \\
\text { treatment } \\
\text { thresholds }\end{array}$ & $\begin{array}{l}\text { Aimed to determine } \\
\text { whether patient } \\
\text { decisions to initiate } \\
\text { osteoporosis } \\
\text { medication agree } \\
\text { with guideline- } \\
\text { recommended } \\
\text { intervention } \\
\text { thresholds. }\end{array}$ & $\begin{array}{l}\text { Prospective } \\
\text { cohort study }\end{array}$ & $\begin{array}{l}85 \text { women } \\
\text { aged } 45 \text { and } \\
\text { older referred } \\
\text { for age- } \\
\text { associated } \\
\text { osteoporosis }\end{array}$ & $\begin{array}{l}\text { Among participants } 27 \% \\
\text { accepted treatment and } 27 \% \\
\text { remained undecided. There was } \\
\text { wide overlap in fracture risk } \\
\text { between treatment acceptors and } \\
\text { non-acceptors. Odds of } \\
\text { accepting treatment were higher } \\
\text { in women with prior fragility } \\
\text { fracture (50\% accepted) and with } \\
\text { hip fracture risk greater than and } \\
\text { equal to } 3 \% \text {, but not major }\end{array}$ \\
\hline
\end{tabular}




\begin{tabular}{|c|c|c|c|c|c|c|}
\hline & & & & & & $\begin{array}{l}\text { osteoporotic fracture risk greater } \\
\text { than and equal to } 20 \% \text {. }\end{array}$ \\
\hline 2020 & $\begin{array}{l}\text { Osteoporosis } \\
\text { International } \\
\text { Cornelissen, } \\
\text { D. et al. }\end{array}$ & $\begin{array}{l}\text { Understanding } \\
\text { patients' } \\
\text { preferences for } \\
\text { osteoporosis } \\
\text { treatment: The } \\
\text { impact of } \\
\text { patients' } \\
\text { characteristics on } \\
\text { subgroups and } \\
\text { latent classes }\end{array}$ & $\begin{array}{l}\text { To identify single } \\
\text { patient } \\
\text { characteristics that } \\
\text { influence } \\
\text { preferences for } \\
\text { anti-osteoporotic } \\
\text { drugs and to } \\
\text { explore existence of } \\
\text { profiles of patient } \\
\text { profiles of } \\
\text { preferences for } \\
\text { osteoporotic drugs } \\
\text { and to investigate } \\
\text { how patient } \\
\text { characteristics } \\
\text { influence treatment } \\
\text { profiles. }\end{array}$ & $\begin{array}{l}\text { Discrete choice } \\
\text { experiment }\end{array}$ & $\begin{array}{l}\text { Data of } 188 \\
\text { patients were } \\
\text { used. Patients } \\
\text { were mostly } \\
\text { female ( } 78 \% \text { ), } \\
\text { with an } \\
\text { average age of } \\
66 \text { years (SD } \\
11 \text {, range 23- } \\
88 \text { years). } \\
\text { Seventy } \\
\text { percent of the } \\
\text { patients had } \\
\text { osteoporosis, } \\
\text { and } 49 \% \text { used } \\
\text { currently anti- } \\
\text { osteoporosis } \\
\text { medication. } \\
\text { Thirty eight } \\
\text { percent of the } \\
\text { patients } \\
\text { suffered from } \\
\text { a previous } \\
\text { fracture and } \\
79 \% \text { suffered } \\
\text { from GI } \\
\text { problems. }\end{array}$ & $\begin{array}{l}\text { All treatment options were } \\
\text { important for patients' decision } \\
\text { regarding osteoporotic treatment. } \\
\text { Significant heterogeneity was } \\
\text { observed for most attributes. } \\
\text { Subgroup analyses revealed that } \\
\text { patients with a previous fracture } \\
\text { valued efficacy most, and } \\
\text { patients with a fear of needles or } \\
\text { aged } 65 \text { and older preferred } \\
\text { tablets. Elderly patients disliked } \\
\text { intravenous medication. Three } \\
\text { latent classes were identified, in } \\
\text { which 6-month subcutaneous } \\
\text { injection was preferred in two } \\
\text { classes ( } 86 \% \text { ), while oral tablets } \\
\text { were preferred in the third class } \\
\text { (14\%). No statistically } \\
\text { significant associations between } \\
\text { the profiles regarding socio- } \\
\text { demographic or clinical } \\
\text { characteristics could be found. }\end{array}$ \\
\hline
\end{tabular}




\section{Appendix D}

\section{Sample Characteristics}

\section{Sample Characteristics}
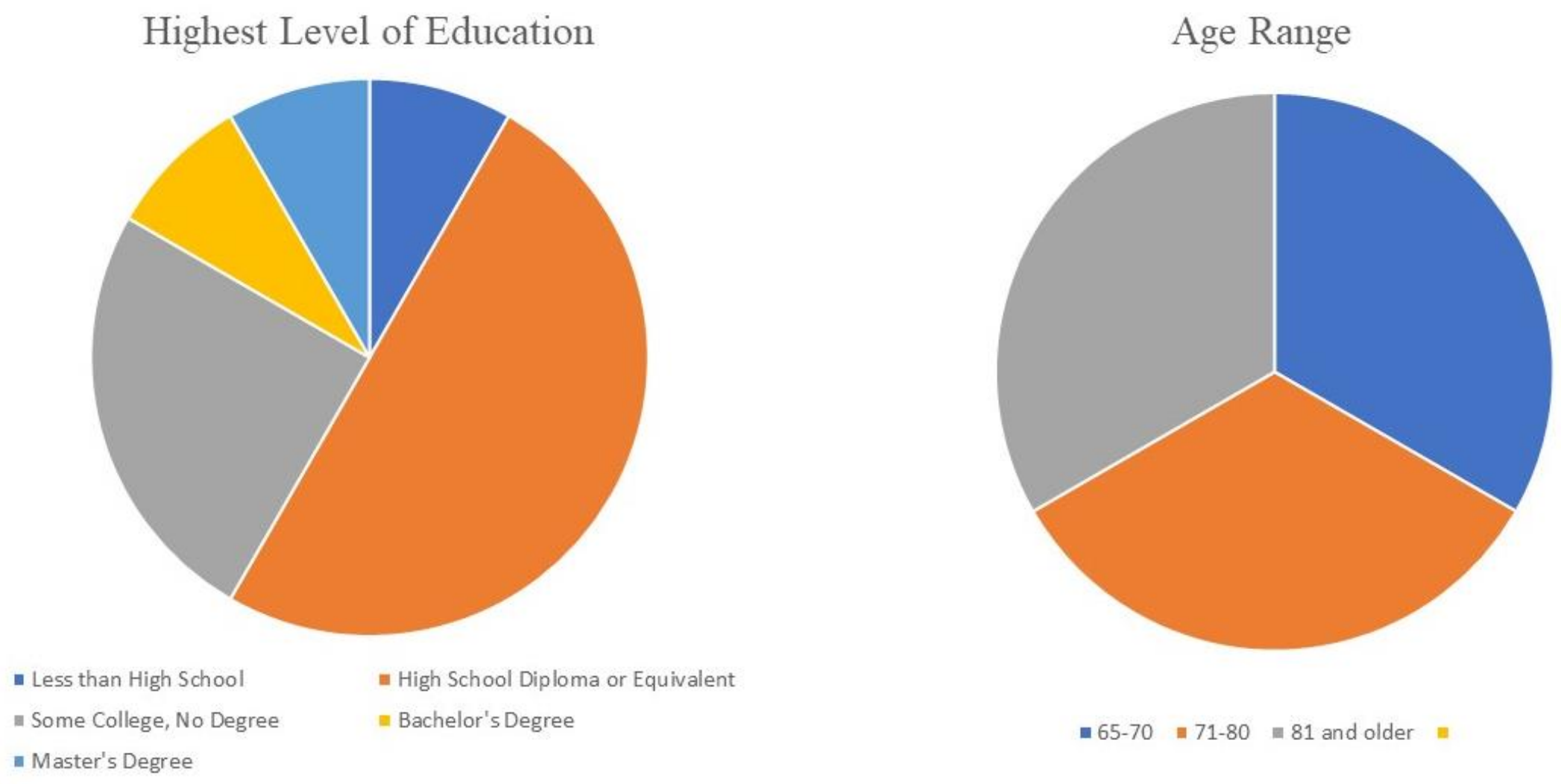


\section{Appendix E}

\section{Curriculum Vitae}

\section{Ashley D. Barber MSN, RN, FNP-BC}

Lecturer $50 \%$ with $100 \%$ Teaching

WVU School of Nursing

Adult Health

304-293-8058

wilsonash@hsc.wvu.edu

\section{Licensures and Certifications}

Registered Nurse in the State of West Virginia, license number 67271, valid 10/28/2005 to 10/31/2021.

ANCC Board Certified Family Nurse Practitioner, Certification number 2010007316, valid to 11/15/2025.

Certificate to prescribe in West Virginia, expires 6/30/2021.

Advanced Practice Certification through the WV Board of

Nursing valid to $6 / 30 / 21$

BLS certification $10 / 31 / 14$ to $10 / 2022$

\section{Professional Positions}

\section{Nurses Practitioner for the West Virginia University Department of Orthopaedics}

January 2011 to Current

\section{University Health Associates - Morgantown, WV}

- Diagnoses and treats patients with metabolic bone disease, rheumatoid arthritis, osteoarthritis and the gout.

- Interprets blood work and supplements as necessary.

- Evaluates bone density scan results and implements treatment.

- Provides patient education on medications.

- Instructs patients on proper injection techniques for medications.

- Obtains authorization for specialty medications and infusions.

- Gathers and records data for Own the Bone, a web-based quality improvement initiative.

- Prescribes medications to treat osteoporosis, vitamin D deficiency, rheumatoid arthritis, osteoarthritis and the gout.

- Provides patient advice over the phone.

- Served as a mentor for a nurse practitioner student from the University of Cincinnati.

\section{Part Time Lecturer}

\section{August 2010 to Current}

\section{West Virginia University School of Nursing - Morgantown, WV}

- Lecturer for medical surgical clinical students.

- Monitored and assisted students during clinical skills in a laboratory and hospital setting.

- Led pre and post-conferences discussing current patient care and evidence based practice.

- Assisted and observed during hands on demonstration of skills needed to care for medical surgical patients.

- Provided assistance during documentation of assessments and patient care.

- Evaluated and assigned grades based on observation of student performance during patient care and assigned pre-planning paperwork.

\section{Graduate Teaching Assistant}

May 2008 to May 2010

\section{West Virginia University School of Nursing - Morgantown, WV}

- Provided help and support to students and faculty.

- Monitored and assisted students caring for medical surgical patients.

- Led educational pre and post-conferences discussing current clinical guidelines.

- Educated pre-nursing students on the evolution and theory of nursing. 
- Graded paperwork assessing for accuracy and in-depth thought.

\section{Registered Nurse/Charge Nurse 5 North PACU}

June 2008 to May 2016

West Virginia University Hospitals - Morgantown, WV

- Cared for adult and pediatric patients' post-operatively implementing all physician orders.

- Provided quality nursing care to all patients.

- Performed continual evaluations of patient safety, comfort and privacy.

- Provided pain management through various medications and non-pharmacologic options.

- Participated in conscious sedation and bedside procedures.

- Obtained verbal report from the operating room and assigned patients according to staffing and level of care needed.

\section{Travel Registered Nurse at Johns Hopkins Hospital in the Neuro Critical Care Unit}

April 2008 to June 2008

Preferred HealthCare - Florida

- Cared for critically ill patients with intra-ventricular catheters and bolts.

- Provided HHH and modified HHH therapy to patients.

- Cared for patients who receive TPA.

- Performed neuro assessments hourly along with cranial and spinal nerve exams.

- Cared for patients requiring mechanical ventilation.

- Monitored and provided care for patients in vasospasm and herniation.

\section{Travel Nurse at University of Maryland Medical Center in the Surgical Intensive Care Unit}

October 2007 to April 2008

\section{Preferred HealthCare - Florida}

- Cared for post-operative patients that received liver, kidney or lung transplants.

- Assisted in bedside procedures to place arterial lines, central lines, G-tubes and tracheotomies.

- Assisted with the insertion of Swann Ganz catheters.

- Analyzed Swann Ganz waveforms and values and titrated drips accordingly.

- Analyzed cardiac enzymes and abnormal lab values and provided replacement as needed.

- Assisted in running several code situations with colleagues.

\section{Travel Nurse at Lancaster General Hospital in the Neuro/Trauma Critical Care Unit}

April 2007 to September 2007

\section{Preferred HealthCare - Florida}

- Provided care to acutely ill trauma patients.

- Assisted in bedside procedures to place arterial lines, central lines and intra-ventricular catheter placement.

- Provided care to patients placed in a barbiturate induced coma.

- Titrated vasoactive drips to maintain hemodynamic stability.

- Cared for patients on drips for sedation and paralysis.

- Weaned lumbar drains and intra-ventricular catheters.

\section{Registered Nurse in the Medical and Surgical Intensive Care Units}

September 2005 to June 2008

West Virginia University Hospitals - Morgantown, WV

- Cared for hemodynamically unstable patients.

- Provided care to post-operative critically ill patients.

- Served as a mentor for a WVU School of Nursing leadership student.

- Stabilized trauma patients prior to the operating room.

- Administered various types of blood products.

- Assisted in bedside procedures and provided conscious sedation.

- Monitored patients on mechanical ventilation receiving drips for sedation.

- Used the sedation agitation scale to monitor sedation status of mechanically ventilated patients. 


\section{Education}

West Virginia University 2015 to current

Morgantown, WV, USA

Nursing

PhD in Nursing anticipated

- Focused on osteoporosis in rural West Virginia.

West Virginia University 2010

Morgantown, WV, USA

Nursing

Masters of Science in Nursing

- ANCC Board Certified Family Nurse Practitioner.

- Performed the program in the accelerated part-time track.

- Clinical hours were obtained in several Morgantown locations including: Health Right, West Virginia University Hospitals Pre-admission Unit, West Virginia University Urgent Care and Cheat Lake Physician's Office Center.

\section{West Virginia University 2005}

Morgantown, WV, USA

Nursing

Bachelor of Science in Nursing

- Graduated Magna Cum Laude.

- Was on the Dean's list and President's list on several different occasions.

\section{East Fairmont High School 2001}

Fairmont, WV, USA

High School Diploma

- Graduated with high honors.

- Member of the Science Honorary.

\section{Professional Memberships}

- I am currently part of the American Orthopedic Association, Own the Bone project.

Professional Development Activity Attended
- Annual Meeting
American College of Rheumatology
San Diego, California
Oct. 2013

\section{Teaching}

- NSG 312

- $\quad$ NSG 312

- $\quad$ NSG 312

- NSG 312

- NSG 312

- $\quad$ NSG 312

- $\quad$ NSG 312

- $\quad$ NSG 312

- $\quad$ NSG 312

- NSG 312

- $\quad$ NSG 312

- NSG 312

- $\quad$ NSG 311

- $\quad$ NSG 211

- $\quad$ NSG 212

- $\quad$ NSG 460
Adult Health 2

Adult Health 2

Adult Health 2

Adult Health 2

Adult Health 2

Adult Health 2

Adult Health 2

Adult Health 2

Adult Health 2

Adult Health 2

Adult Health 2

Adult Health 2

Adult Health 1

Health Assessment

Foundations of Nursing Theory

Care of the Critically Summer 2014
Fall 2021

Spring 2021

Fall 2020

Spring 2020

Fall 2019

Spring 2019

Fall 2018

Spring 2018

Fall 2017

Spring 2017

Fall 2016

Spring 2016

Fall 2015

Spring 2015

Spring 2015
20-24 Clinical Instructor

20-24 Clinical Instructor

8-10 Clinical Instructor

8-10 Clinical Instructor

8-10 Clinical Instructor

8-10 Clinical Instructor

8-10 Clinical Instructor

8-10 Clinical Instructor

8-10 Clinical Instructor

8-10 Clinical Instructor

8-10 Clinical Instructor

8-10 Clinical Instructor

8-10 Clinical Instructor

8 Clinical Instructor

8 Clinical Instructor

16-20 Clinical Instructor 
REFRAMING

Ill Patient

- $\quad$ NSG 312

Adult Health 2

Fall 2013 to Fall 2014

$8-10$

Clinical Instructor

Research

Publication

Genetic variations in GPSM3 associated with protection from rheumatoid arthritis affect its transcript abundance.

Osteoporosis and health-related quality of life among older women.

Presentations

Health-Related Quality of Life among Older

Women

Service
Accepted by Genes and Immunity Journal.

Published by Journal of Nursing Practice

Case Western Reserve University
A study to establish GPSM3 as a novel biomarker and or drug discovery target for inflammatory arthritides.

No group differences in HRQoL by osteoporosis status suggests the need for additional research to flush out nuances in QOL changes.

Abstract presentation in March.

None 